\title{
Circulating purification of cutting fluid: an overview
}

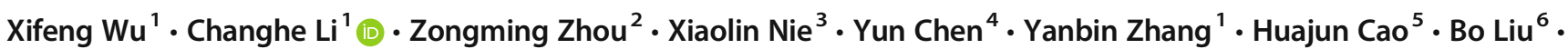 \\ Naiqing Zhang ${ }^{7} \cdot$ Zafar Said $^{8}$. Sujan Debnath ${ }^{9} \cdot$ Muhammad Jamil $^{10} \cdot$ Hafiz Muhammad Ali $^{11}$. Shubham Sharma ${ }^{12}$
}

Received: 23 May 2021 / Accepted: 8 August 2021 / Published online: 26 August 2021

(C) The Author(s), under exclusive licence to Springer-Verlag London Ltd., part of Springer Nature 2021

\begin{abstract}
Cutting fluid has cooling and lubricating properties and is an important part of the field of metal machining. Owing to harmful additives, base oils with poor biodegradability, defects in processing methods, and unreasonable emissions of waste cutting fluids, cutting fluids have serious pollution problems, which pose challenges to global carbon emissions laws and regulations. However, the current research on cutting fluid and its circulating purification technique lacks systematic review papers to provide scientific technical guidance for actual production. In this study, the key scientific issues in the research achievements of ecofriendly cutting fluid and waste fluid treatment are clarified. First, the preparation and mechanism of organic additives are summarized, and the influence of the physical and chemical properties of vegetable base oils on lubricating properties is analyzed. Then, the process characteristics of cutting fluid reduction supply methods are systematically evaluated. Second, the treatment of oil mist and miscellaneous oil, the removal mechanism and approach of microorganisms, and the design principles of integrated recycling equipment are outlined. The conclusion is concluded that the synergistic effect of organic additives, biodegradable vegetable base oils and recycling purification effectively reduces the environmental pollution of cutting fluids. Finally, in view of the limitations of the cutting fluid and its circulating purification technique, the prospects of amino acid additive development, self-adapting jet parameter supply system, matching mechanism between processing conditions and cutting fluid are put forward, which provides the basis and support for the engineering application and development of cutting fluid and its circulating purification.
\end{abstract}

Keywords Cutting fluid; · Circulating purification; · Additive; · Base oil; · Minimum quantity lubrication; · Mechanism

Changhe Li

sy_lichanghe@163.com

Xifeng Wu

wuxifeng_yx@163.com

Zongming Zhou

15610520185@163.com

Xiaolin Nie

niex1@njkerun.com

Yun Chen

qienxian@163.com

Yanbin Zhang

zhangyanbin1_qdlg@163.com

Huajun Cao

hjcao@cqu.edu.cn
Bo Liu

mryhyf@126.com

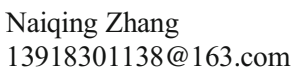

Zafar Said

zsaid@sharjah.ac.ae

Sujan Debnath

d.sujan@curtin.edu.my

Muhammad Jamil

engr.jamil@nuaa.edu.cn

Hafiz Muhammad Ali

h.m.ali@qmul.ac.uk

Shubham Sharma

shubham543sharma@gmail.com

Extended author information available on the last page of the article 


\section{Introduction}

In the field of machinery manufacturing, metal processing is an extremely important basic industry. Cutting fluid is an indispensable part in metal processing. Selecting a suitable cutting fluid can play a good role in lubrication, cooling, cleaning and rust prevention $[1,2]$, to improve tool service performance, ensure processing quality and precision, and improve productivity [3]. While the use of cutting fluid brings great convenience to the metal processing industry, it also threatens ecological environment and human health [4]. A substantial amount of waste cutting fluids is discharged into the natural environment because the traditional cutting fluids contain a large amount of nonbiodegradable mineral oil and additives that are harmful to the environment and organisms, and most metal processing companies have poor supervision over the treatment of waste cutting fluids. These factors cause environmental pollution. In addition, most of the cutting fluid supply method is pouring, but the pouring processing method has a low utilization rate of the cutting fluid and is prone to producing oil mist [5], which not only causes a waste of resources but also endangers the health of workers. Finally, the existence of microorganisms is the main factor of the service life of cutting fluids [6].

According to the causes of cutting fluid pollution, researchers should vigorously develop organic additives that are less harmful to organisms and the environment [7], and explore vegetable base oils with excellent biodegradability [8]. On the basis of ensuring the comprehensive performance of cutting fluids, a new formula of eco-friendly cutting fluid must be explored. In addition, the low utilization rate of cutting fluid caused by traditional processing methods, the easy generation of oil mist, and the unreasonable emissions of cutting fluid by enterprises are the reasons for the pollution of cutting fluid. Accordingly, researchers should explore green machining methods based on the idea of reducing the amount of cutting fluid or abandoning cutting fluid, and using green, nonpolluting cooling medium instead of cutting fluid $[9,10]$. Regarding the disposal of cutting waste fluid, on the one hand, the researchers must consider the removal of pollutants from the cutting waste fluid discharged into the natural environment to minimize its environmental and biological hazards; on the other hand, they should consider recycling cutting waste fluid with simple composition and reusing it recycling through purification technology to achieve the maximum economic benefits. The specific process is shown in Fig. 1.

According to the requirements of related laws and regulations such as carbon emissions, reducing the environmental pollution of cutting fluids and achieving cleaner production is an inevitable future trend in the field of the mechanical manufacturing. To achieve the goals of harmlessness, energy saving emission reduction, and rational allocation of resources, first, the chemical preparation and action mechanism of rust inhibitors, bactericides, and extreme pressure additives must be outlined. Then, the influence of the physical and chemical properties of the vegetable base oil on the lubricating performance should be systematically analyzed. Second, the process characteristics of cutting fluid reduction technology should be evaluated. Finally, the mechanism and approach of cutting fluid circulating purification technique must be
Fig. 1 Problems and solutions of cutting fluid
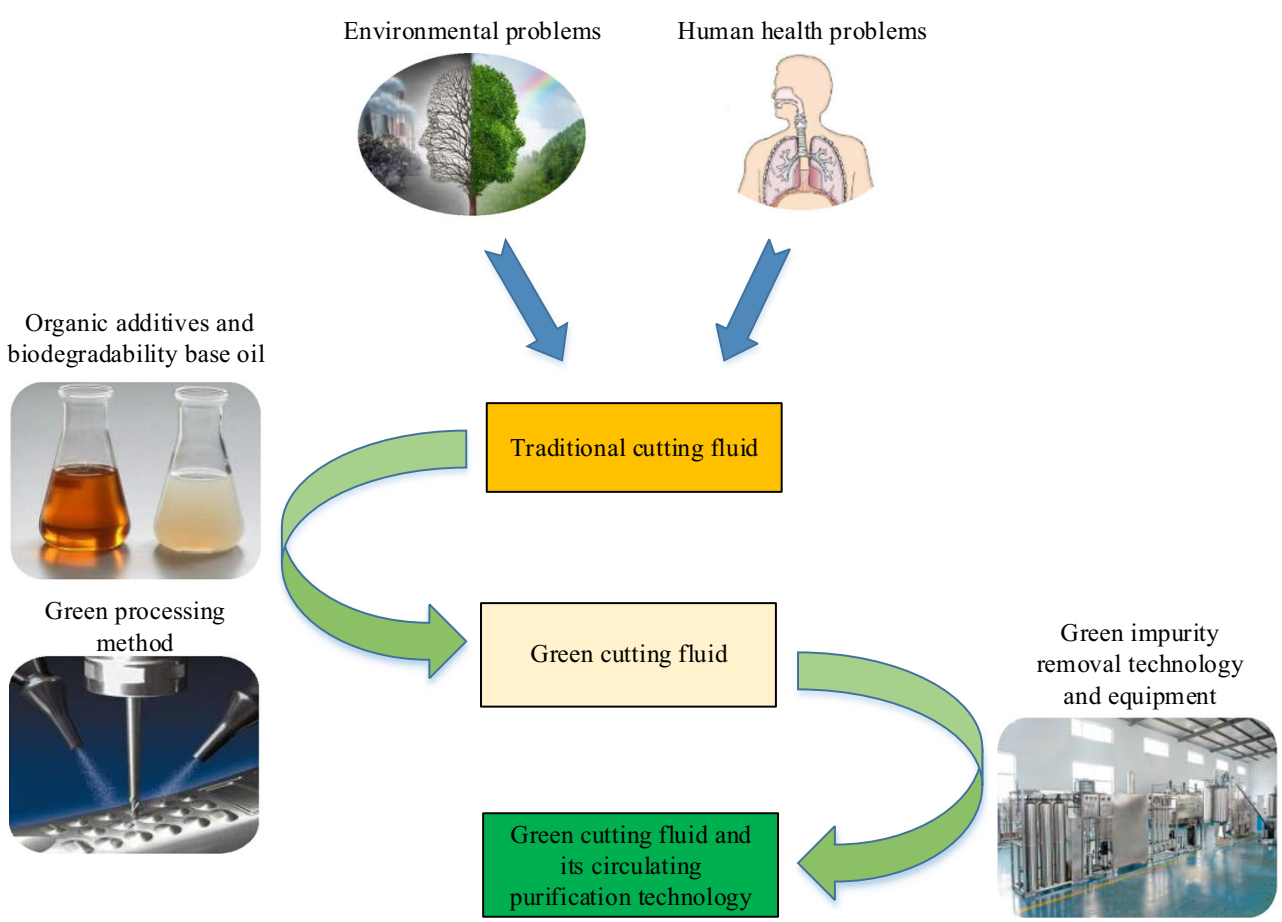
reviewed. In recent years, the development of eco-friendly cutting fluids and its circulating purification techniques based on biological sciences and sustainable engineering principles has become a major research focus in the manufacturing industry.

\section{Development of cutting fluid and its existing problems}

\subsection{Development of cutting fluid}

The earliest cutting fluid was not the oil or oil water mixture as we know it, but water was used as the cooling fluid in metal processing. Later, simple water-based solutions such as soapy water lime water and animal and vegetable oils such as linseed oil were used. People slowly discovered that these simplecomposition cutting fluids could not meet the cooling and lubricating effect required in metal processing. After people extracted a large amount of lubricating oil from crude oil, oilbased cutting fluids developed in a real sense. With the improvement of metal processing precision, the requirements for cooling and lubrication have become more stringent, and the cooling performance of oil-based cutting fluids can no longer fully meet the needs of high-speed cutting. People start to looking at the excellent cooling performance of water again because the specific heat capacity of water is larger than that of oil, and the cooling performance is better. However, due to insufficient lubrication and antirust properties of water, people used various additives such as lubricants and rust inhibitors additive to meet the lubrication and antirust properties required in metal processing.

\subsection{Classification of cutting fluid}

The current cutting fluid has a relatively mature application system in the field of metal processing and has become a multicategory product. Cutting fluids are mainly divided into oil-based cutting fluids and water-based cutting fluids. The main types are shown in Table 1.

Oil-based cutting fluid is made by mixing base oil with tribological additives and auxiliary additives, and does not need to be diluted with water when used. The base oil of oilbased cutting fluid is divided into mineral oil and synthetic oil. Mineral oil is a mixture of liquid hydrocarbons obtained from the refining of fossil fuels such as petroleum. According to the source of its raw material oil, it can be divided into two types: paraffin based and naphthenic based. Synthetic oil mainly includes synthetic hydrocarbons and synthetic esters. Among them, mineral oil-based cutting fluid has the characteristics of excellent lubrication and antirust properties, and is most used. Water-based cutting fluids are divided into emulsion type, semisynthetic type and synthetic type. Emulsified cutting fluid is an oil-in-water emulsion obtained by mixing base oil (mineral oil) with water containing emulsifiers. The content of mineral oil is greater than $60 \%$, showing milky white. Synthetic cutting fluid takes inorganic salt and organic amine as the main body and adds various additives such as preservatives or defoamers to dissolve in water to form a transparent or slightly colored aqueous solution. Semisynthetic cutting fluid is a combination of oil-in-water emulsion and synthetic fluid, which has the characteristics of emulsified cutting fluid and synthetic cutting fluid. Its service life is four to six times longer than that of emulsified cutting fluid. The mineral oil content is $5 \%$ en dash $40 \%$, showing translucent.

Compared with oil-based cutting fluids, water-based cutting fluids use additives such as lubricants, rust inhibitors, and antioxidants, which makes the water-based cutting fluid not only maintain the lubrication and antirust performance of the oil-based cutting fluid but also have a stronger heat dissipation capacity. Among water-based cutting fluids, semisynthetic cutting fluids have gradually become the best choice in the metal processing industry due to their excellent comprehensive performance. The powerful machinery manufacturing countries have gone through the development of emulsified cutting fluids to synthetic cutting fluids and then to semisynthetic cutting fluids.

\subsection{Mechanism of cutting fluid}

In metal processing, frictional heat will be generated between the tool, chip and workpiece, which is extremely detrimental to the service life of the tool and the surface quality of the workpiece. If the chips generated during cutting are not removed in time, machining quality will be affected. In addition, the antirust problem of the processed workpiece must be maintained during long-term placement. A cutting fluid with excellent performance needs to have lubrication, cooling, cleaning, antirust and other effects to solve these problems [11].

\section{(1) Lubrication effect}

In metal processing, friction will be generated in the tool chip and tool workpiece. After adding cutting fluid, a lubricating film will be produced between the two friction pairs to reduce friction and wear. Owing to the high temperature and high pressure characteristics of the cutting process, forming a fluid lubrication state is difficult, and the lubricating film formed is often a boundary lubricating film [12]. The lubricating film can effectively reduce the cutting force and the wear of the tool, thereby increasing the life of the tool and improving the quality of the workpiece.

(2) Cooling effect 


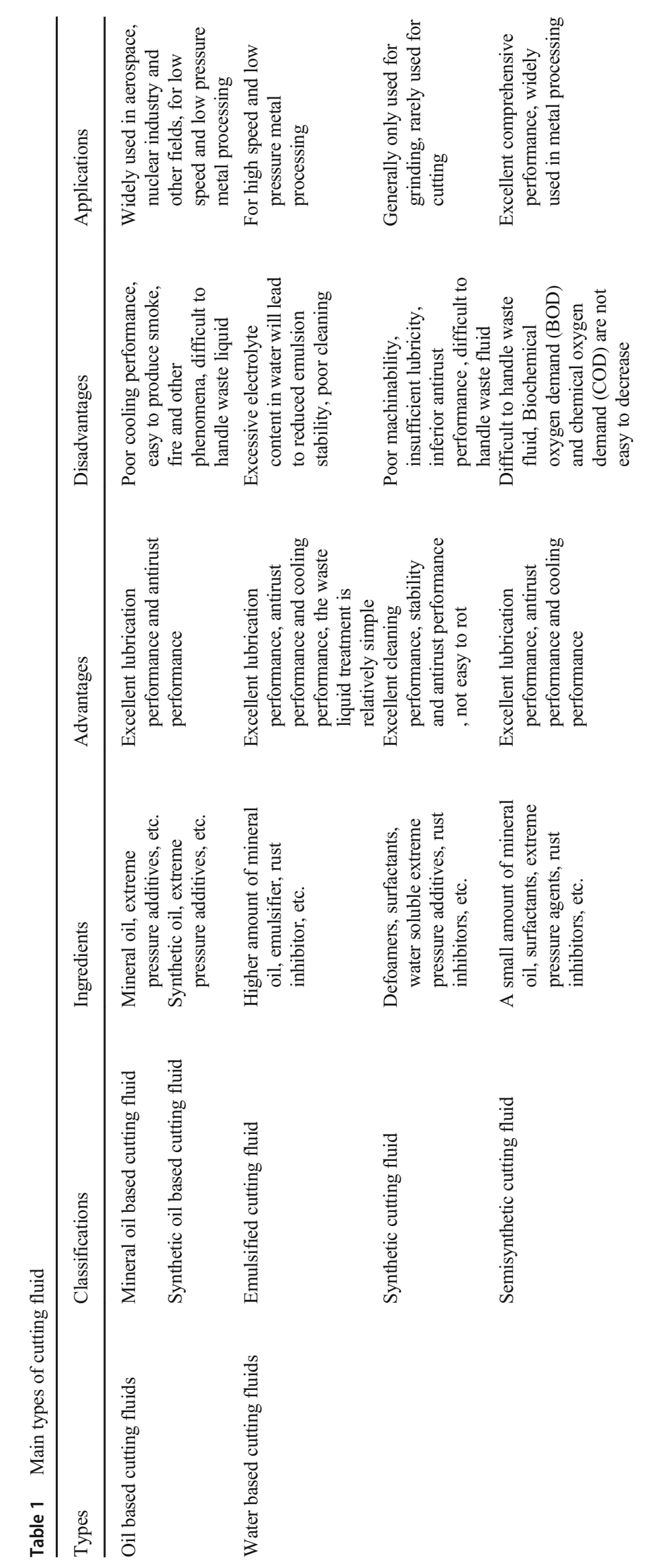


Owing to the shearing effect of the tool and the workpiece and the friction between the tool and the chips, hightemperature phenomena are generated in the cutting area, and the cutting heat is the most unfavorable for cutting, easily causing damage to the surface of the workpiece. To avoid this phenomenon, the cooling effect of the cutting fluid is required. When the cutting fluid enters the cutting area, a part of the heat will be taken away by the cutting fluid through convection heat transfer, and the vaporization of the cutting fluid can take away part of the heat [13]. The traditional pouring supply method maximizes the cooling effect by spraying a large amount of cutting fluid but it consumes more cutting fluid. The minimum quantity lubrication (MQL) supply method can speed up the vaporization speed of the cutting fluid and reduce the consumption of the cutting fluid while ensuring the cooling effect.

\section{(3) Cleaning effect}

Many small chips are generated during metal processing. If the chips are left in the cutting area for a long time, accelerating the tool wear and scratch the workpiece is easy; hence, it needs to be processed in time. After adding the cutting fluid, the cutting fluid can wash away the small chips and clean the cutting area when the cutting fluid flows through the cutting area [14]. The cleaning effect and cooling effect of the cutting fluid are inseparable. The cutting fluid will reduce the temperature of the chips while playing the cleaning effect to prevent the flying chips from causing burns to the operators.

\section{(4) Antirust effect}

During the storage time after processing, the workpiece is likely to react with air media, resulting in rust or corrosion. To avoid this phenomenon, the cutting fluid is required to have antirust and anticorrosion effects. The cutting fluid forms a physical adsorption film or a chemical reaction film on the surface of the workpiece to delay the rust of the workpiece. In addition, the antirust effect of the cutting fluid is not only manifested on the workpiece but also has a maintenance effect on the machine tool and the cutting tool.

\subsection{Problem of cutting fluid}

\subsubsection{Chemical composition}

The current metal processing industry is developing in the direction of faster processing efficiency and more complicated processing conditions. The cooling and lubricating effect of general cutting fluids cannot meet the requirements of the metal processing industry. For this reason, researchers opt to add various additives in cutting fluids. For example, under high-speed, heavy-load conditions, extreme pressure additives can provide the cutting fluid the effect of reducing wear and pressure to meet these needs $[15,16]$. In addition, the cutting fluid contains the necessary elements for the survival of microorganisms, which easily breed bacteria and microorganisms. A bactericide must be added to inhibit the growth of microorganisms in the cutting fluid [17].

The use of additives determines the performance of the cutting fluid and provides the cutting fluid a sense of the times. However, the use of several additives can cause serious water pollution problems. For example, the sodium phosphate in rust inhibitors can lead to eutrophication of water, which in turn triggers red tides; antioxidants have poor biodegradability and are prone to long-term pollution of water sources. The water pollution level and biodegradation rate of commonly used additives are shown in Table 2 . In addition, several substances in additives can cause serious harm to workers. as shown in Table 3.

In addition, the base oil of cutting fluid is divided into mineral oil, synthetic oil and vegetable oil. Synthetic hydrocarbons in synthetic oils have poor biodegradability, similar to mineral oils. When this type of cutting fluid is discharged into the natural environment, it will stay in the water and soil for a long time, causing adverse effects on the environment. The US Environmental Protection Agency pointed out that more than $10 \mathrm{ppm}$ of oil in water will kill marine plants, and $300 \mathrm{ppm}$ of oil will kill freshwater fish. Synthetic cutting fluids based on inorganic salts and organic amines are alkaline, which can cause symptoms such as dryness and degreasing of human skin. The biodegradability of common base oils is shown in Table 4. The use of toxic additives and base oils with poor biodegradability is the key to the pollution problem of cutting fluids.

Table 2 Water pollution level and biodegradation rate of commonly used additives

\begin{tabular}{lllll}
\hline Additives & Chemical materials & $\begin{array}{l}\text { Biodegradation } \\
\text { rates\% }\end{array}$ & $\begin{array}{l}\text { Water pollution } \\
\text { levels }\end{array}$ & $\begin{array}{l}\text { Testing } \\
\text { methods }\end{array}$ \\
\hline Rust inhibitor & Ashless Sulfonate & 50 & 1 & CECL-33-T82 \\
& Tolytriazole & 70 & 1 & OECD302B \\
Extreme pressure additives & Calcium Dialkylbenzene Sulfonate & 60 & 1 & CECL-33-T82 \\
Antioxidants & Alkyl Diphenylamin & 9 & 1 & OCED301D \\
\hline
\end{tabular}


Table 3 Toxic substances in additives and their harm mechanism

\begin{tabular}{|c|c|c|c|c|}
\hline Additives & $\begin{array}{l}\text { Chemical } \\
\text { materials }\end{array}$ & $\begin{array}{l}\text { Molecular } \\
\text { formulas }\end{array}$ & Structural formulas & Hazard mechanisms \\
\hline \multirow[t]{2}{*}{$\begin{array}{c}\text { Rust } \\
\text { inhibitor }\end{array}$} & $\begin{array}{l}\text { Sodium } \\
\text { Nitrite/Al } \\
\text { coholami } \\
\text { ne }\end{array}$ & $\begin{array}{c}\mathrm{NaNO}_{2} \\
\mathrm{C}_{5} \mathrm{H}_{13} \mathrm{NO}_{2}\end{array}$ & Alcoholamine: & $\begin{array}{l}\text { Sodium nitrite and amines can form } \\
\text { nitrosamines. In acidic and high } \\
\text { temperature environments, } \\
\text { nitrosamines can form diazonium } \\
\text { salts. This substance can produce } \\
\text { carbocations and react with biological } \\
\text { nucleophiles (such as DNA or } \\
\text { enzymes) in cells, leading to cell } \\
\text { cancer or cell apoptosis. }\end{array}$ \\
\hline & $\begin{array}{l}\text { P-tert-but } \\
\text { yl } \\
\text { benzoic } \\
\text { acid }\end{array}$ & $\begin{array}{c}\left(\mathrm{CH}_{3}\right)_{3} \mathrm{CC}_{6} \\
\mathrm{H}_{4} \mathrm{CO}_{2} \mathrm{H}\end{array}$ & & $\begin{array}{l}\text { It will irritate the respiratory tract, } \\
\text { skin, eyes, and be harmful to internal } \\
\text { organs such as liver and kidney of } \\
\text { animals. }\end{array}$ \\
\hline & $\begin{array}{c}\text { Glutarald } \\
\text { ehyde }\end{array}$ & $\mathrm{C}_{5} \mathrm{H}_{8} \mathrm{O}_{2}$ & & $\begin{array}{l}\text { Glutaraldehyde is through its two } \\
\text { aldehyde groups combined with } \\
\text { organic molecules such as proteins in } \\
\text { tissue cells, destroying the molecular } \\
\text { structure of tissue cells, causing them } \\
\text { to lose their biological activity and }\end{array}$ \\
\hline & & & & causing body damage [18]. \\
\hline & $\begin{array}{c}\text { 4-chloro- } \\
\text { 3-methyl } \\
\text { phenol }\end{array}$ & $\mathrm{C}_{7} \mathrm{H}_{7} \mathrm{ClO}$ & & $\begin{array}{l}\text { The biodegradability is poor, and it } \\
\text { has great harm to aquatic organisms. } \\
\text { It is decomposed by heat to liberate } \\
\text { chlorine, which has a strong irritating } \\
\text { effect on eyes, skin and mucous } \\
\text { membranes. }\end{array}$ \\
\hline
\end{tabular}
membranes.

Ketohydr oxyethylh exahydro s-triazine
Slowly release harmful gas formaldehyde in cutting fluid [19].
Extreme pressure additives
Short-cha

$$
\text { in }
$$
chlorinate

d paraffin
$\mathrm{C}_{9} \mathrm{H}_{21} \mathrm{~N}_{3} \mathrm{O}_{3}$<smiles>OCCN1CN(CCO)CN(CCO)C1</smiles>

Short-chain chlorinated paraffins can cause liver hypertrophy in rodents and peroxisome proliferation in liver cells. Studies have shown that short-chain chlorinated paraffin doses can increase the incidence of murine adenomas and cancers of the liver, thyroid and kidney [20].

$\begin{array}{ccc}\text { Dialkyl } & \text { Zinc dialkyl } \\ \text { dithio } & \text { dithiophosp } \\ \text { hates } & \text { (ZDDP) } & \end{array}$

Contains sulfur which is harmful to organisms [21]. 


\subsubsection{Physical action}

In addition to the pollution caused by the chemical composition of the cutting fluid, the way the cutting fluid is used will also pollute the human body and the environment. In many high-speed machining, oil-based cutting fluid easily forms oil mist, and water-based cutting fluid easily generates aerosol. The bacteria and microorganisms in the cutting fluid enter the workers respiratory system along with the oil mist or aerosol, causing people to suffer from diseases such as lung disease and eczema. In addition, these minute cutting fluid molecules emit pungent odors and stay in the air, causing pollution to the working environment. Bukowski [22] found that workers who have been working in metal processing for a long time are prone to allergic pneumonia, bronchitis, and asthma, and their respiratory diseases are most likely caused by microorganisms in water-based cutting fluids. Picciotto et al. [23] found that suspended particles of oil-based cutting fluids are related to death from ischemic heart disease. Therefore, the defects of processing methods are sources of cutting fluid pollution.

The amount of cutting fluid used in metal processing is substantial, and metal processing is inseparable from cutting fluid at present. To reduce the hazards of cutting fluids, developed countries have formulated many relevant legal standards, such as the regulations of the US labor safety and security national institutions: The limit is $3 \mathrm{mg} / \mathrm{m}^{3}$ for cutting fluids that do not contain polyaromatic hydrocarbons and $0.5 \mathrm{mg} /$ $\mathrm{m}^{3}$ for cutting fluids that contain polyaromatic hydrocarbons. In addition, the British Health and Safety Executive recommends that the droplet contents of oil-based cutting fluid and water-based cutting fluid are 3 and $1 \mathrm{mg} / \mathrm{m}^{3}$, respectively [24]. Although these established standards have alleviated the problem of cutting fluid pollution to a certain extent, manufacturers have increased production costs to comply with them, which is not conducive to the development of the metal processing industry. For this reason, how to solve the problem of cutting fluid pollution effectively has become a key issue in the field

Table 4 Biodegradability of common base oils

\begin{tabular}{ll}
\hline Base oils & Biodegradation rates\% \\
\hline Polyester & $80 \sim 100$ \\
Dibasic acid diester & $60 \sim 100$ \\
Polyol ester & $60 \sim 100$ \\
Phthalate diester & $60 \sim 70$ \\
Polyolefin & $\leq 20$ \\
Polyisobutylene & $\leq 30$ \\
Polypropylene glycol & $\leq 10$ \\
Alkylbenzene & $\leq 10$ \\
Mineral oil & $20 \sim 60$ \\
Vegetable oil & $70 \sim 00$ \\
\hline
\end{tabular}

of metal processing. Researchers are looking for solutions to problems.

\section{Research on eco-friendly cutting fluid and green machining method}

On the one hand, the pollution of cutting fluid comes from the its chemical composition. On the other hand, the pollution of cutting fluid comes from the processing methods that require cutting fluid. To comply with the concept of green development, combined with the causes of cutting fluid pollution, the development of eco-friendly cutting fluids and green processing methods has become a key issue in the field of metal processing. This section reviews the current research progress of eco-friendly cutting fluids and green machining methods.

\subsection{Research progress of eco-friendly cutting fluid}

The pollution problems of traditional cutting fluids mainly come from base oils with poor biodegradability and additives that are harmful to organisms and the environment. According to the source of the pollution problem, researchers have developed some eco-friendly cutting fluids with good biodegradability and low harm to organisms and the environment. Bhaumik et al. [25] used nano minimum glycerin with good biodegradation and low biological hazard as a substitute for traditional cutting fluid. Sultan et al. [26] reviewed the effect of vegetable oil-based cutting fluid with good biodegradability on the surface integrity of the workpiece during drilling. To outline the research progress of eco-friendly cutting fluids better, according to the pollution components of traditional cutting fluids, explanations will be made by summarizing several commonly used eco-friendly additives and base oils with good biodegradability.

\subsubsection{Rust inhibitor}

In the field of metal processing, the corrosion of workpieces and machine tools often causes great economic losses to the enterprise. Adding rust inhibitors to the cutting fluid is an effective way to solve the problem. Many rust inhibitors are commonly used in cutting fluids, which are mainly divided into two categories: inorganic and organic. Inorganic rust inhibitors include inorganic salts such as sodium nitrite and molybdate, and their mechanism of action is mainly to form an insoluble passivation film on the metal surface to prevent the metal from rusting. The advantages of inorganic rust inhibitors are good rust prevention performance and excellent economic efficiency. However, most of their inorganic rust inhibitors cause great pollution to the environment and are easily toxic to organisms. Organic rust inhibitors are composed of hydrophilic polar groups and lipophilic nonpolar 
Fig. 2 Synthesis process of rust inhibitor: a Dodecenyl succinic acid diethanolamide rust inhibitor. b Dodecenyl succinic acid diethanolamide

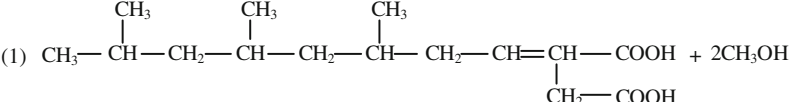

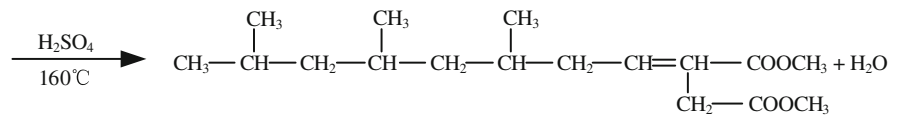

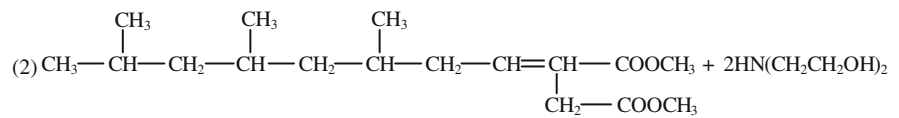

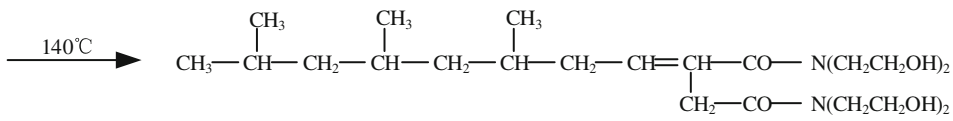

(a)

(1)
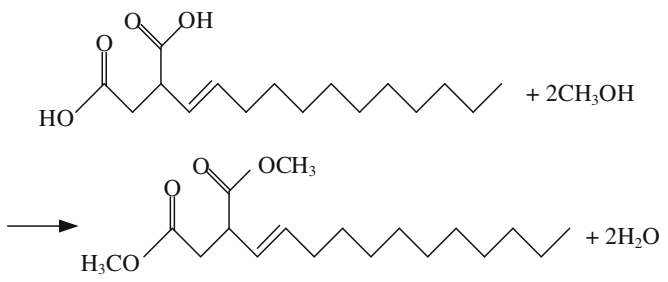

(2)
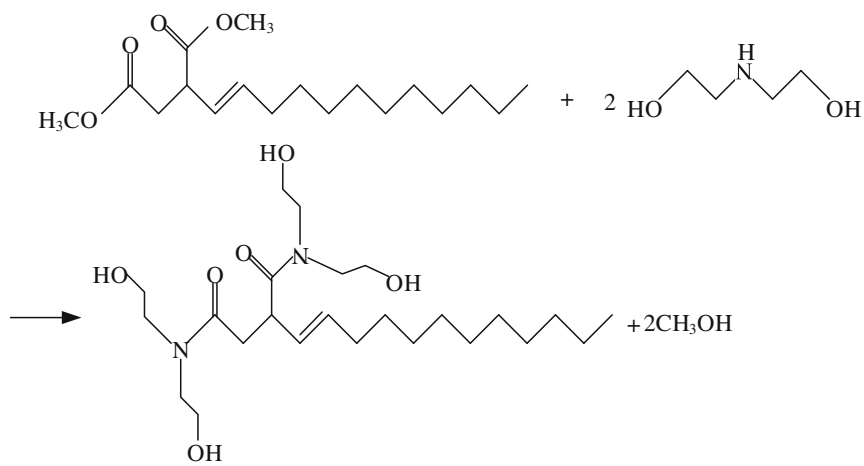

(b)

hydrocarbon groups, mainly including alcamines, carboxylic acids, amides, and boric acid ester. The mechanism of action is to make the polar end of the rust inhibitor adsorb on the metal surface through electrostatic adsorption and chemical adsorption. The nonpolar ends are randomly oriented and arranged on the side away from the metal surface, thereby

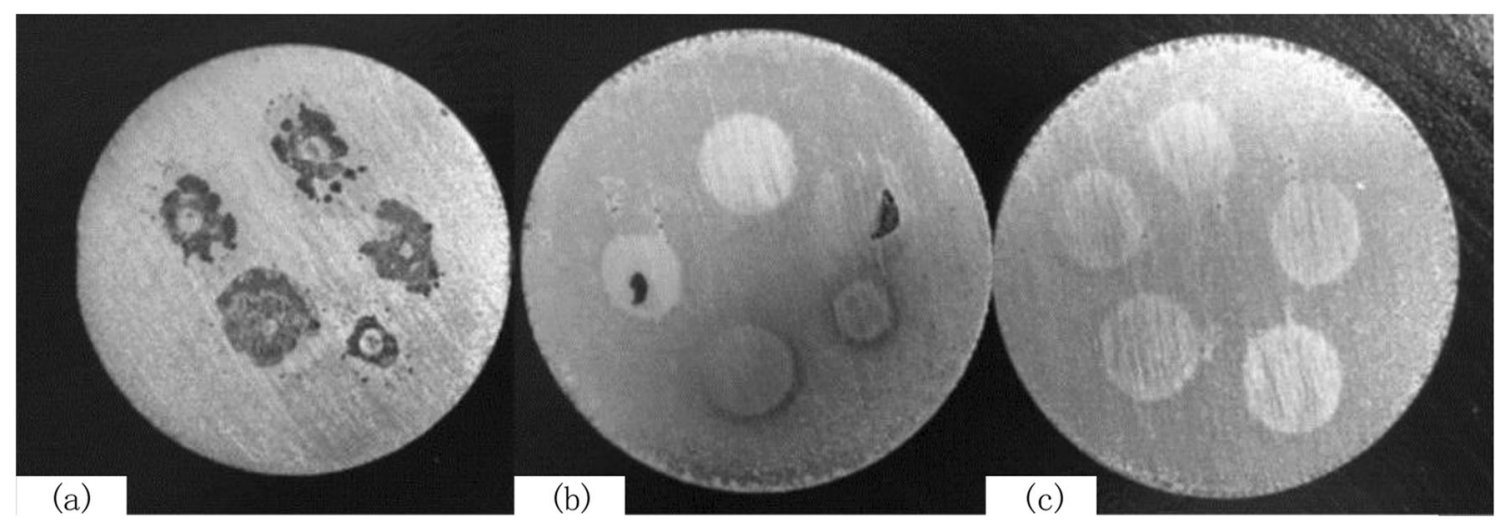

Fig. 3 Results of single-chip antirust experiment with different contents of T746-X: a Did not contain T746-X. b Contains T746-X with a mass concentration of $1.25 \mathrm{~g} / \mathrm{L}$. c Contains $7746-\mathrm{X}$ with a mass concentration of $3.75 \mathrm{~g} / \mathrm{L}$ 
forming a nonpolar hydrophobic film on the metal surface. Organic rust inhibitors can not only guarantee rust performance but have minimal harm to organisms and the environment. The research and development of organic rust inhibitors is an important part of the research on eco-friendly rust inhibitors.

Researchers have studied organic rust inhibitors. Amide organic rust inhibitors have the advantages of excellent environmental protection performance and good antirust performance, which has become the main direction of research on eco-friendly rust inhibitors. Zhou et al. [27] synthesized a dodecenyl succinic acid diethanolamide rust inhibitor with improved water solubility and antirust effect. The synthesis is shown in Fig. 2(a). The polar group of the antirust inhibitor had a greater affinity for metal and can form a directional adsorption layer on the metal surface. Researchers carried out single-chip antirust experiments of cast iron with solution concentrations of $1 \%, 3 \%, 5 \%$, and $7 \%$, and the antirust performance met the GB/T6144-85 standard. Gan et al. [28] synthesized a water-soluble rust inhibitor dodecenyl succinic acid diethanolamide T746-X. The synthesis is shown in Fig. 2(b), The results of the single-chip antirust experiment are shown in Fig. 3. Five rust spots were observed on the chip of the semisynthetic cutting fluid that did not contain T746-X rust inhibitor. Two rust spots appeared on the chip containing the semisynthetic cutting fluid of T746-X with a mass concentration of $1.25 \mathrm{~g} / \mathrm{L}$. When the mass concentration of T746-X reached $3.75 \mathrm{~g} / \mathrm{L}$, the chip had no rust spots. In addition, the indicators of this antirust additive were in line with the industry standard of JB/T7453-2013.

In addition to amide rust inhibitors, boric acid ester rust inhibitors are environmentally friendly. Liu et al. [29] explored the compounding of boric acid ester rust inhibitors and other water-soluble rust inhibitors, and believed that selecting a suitable water-soluble rust inhibitor compound can make boric acid ester rust inhibitors have excellent antirust performance, microbial stability, and environmental protection performance. Wang et al. [30] synthesized triethanolamine borate with excellent antirust properties with boric acid and triethanolamine. He used 20 steel and 45 steel to soak in an aqueous solution containing $2.5 \%$ triethanolamine borate for 30 days, and no rust was observed on the surface of the specimen. Yang et al. [31] used hydroxymethylated Benzotriazole (BTA) and oleic acid polyacrylamide boric acid ester to synthesize an eco-friendly vitrogen organic boric acid ester antirust additive. Experiments showed that when the concentration of the solution was $0.25 \%$, the performance was good, and it can still maintain good rust resistance under higher temperature and longer working time. Several foreign patents have also conducted research on eco-friendly rust inhibitors. The chemical composition of the rust inhibitor is shown in Table 5. These rust inhibitors also have excellent antirust and environmental protection performance.

\subsubsection{Bactericide}

The cutting fluid has the conditions for the growth of microorganisms and bacteria, and easily spoils and deteriorates. At present, the most popular and effective way to control the growth of microorganisms in cutting fluids is to add bactericides. Common bactericides include phenolic compounds, bromine and chlorine compounds, and formaldehydereleasing compounds. However, these traditional bactericides have poor stability and bactericidal performance. For this reason, how to enhance the bactericidal performance and stability of bactericides is one of the key research directions in the current research on eco-friendly bactericides.

Researchers have developed efficient, stable eco-friendly bactericides based on the existing problems of bactericides. Zhang et al. [34] synthesized 4,5-dichloro-2-propyl4isothiazolin-3-ketone, an isothiazolinone bactericide with excellent bactericidal properties. The synthesis is shown in Fig. 4(a). The bactericidal performance was determined through the sterilization test. When the drug amount reached $60 \mathrm{mg} / \mathrm{L}$, the sterilization rate was close to $100 \%$. Ezzat et al.

Table 5 Chemical composition of rust inhibitor

$\begin{array}{ccc}\text { Patent numbers } & \text { Chemical components } \\ \text { EP05710526A [32] Hydroxylamine compound } & \mathrm{N} \text {-acyl amino acid }\end{array}$


Fig. 4 Synthesis of bactericides: a 4,5-dichloro-2-propyl-

4isothiazolin-3-ketone. b Ethane-

1,2-diyl diformate. $\mathbf{c}$ New organic

guanidine bactericide through

condensation reaction, $\mathrm{n}=1-20$,

$\mathrm{R}=\mathrm{CH} 3(\mathrm{CH} 2) \mathrm{m}$, and $\mathrm{m}=3-15$

(1)

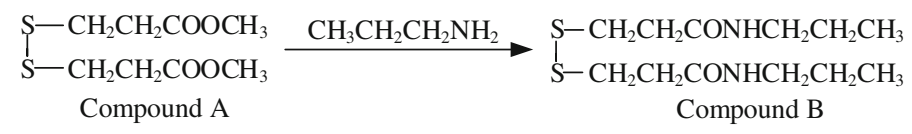

(2)

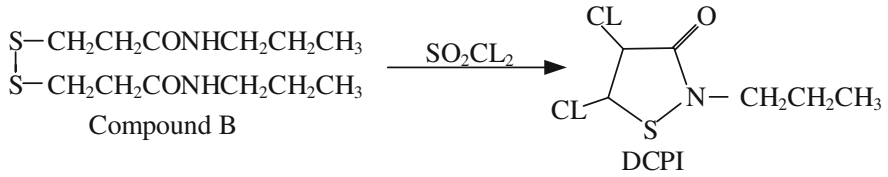

(a)

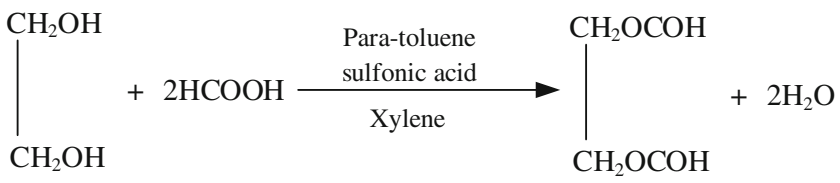

(b)

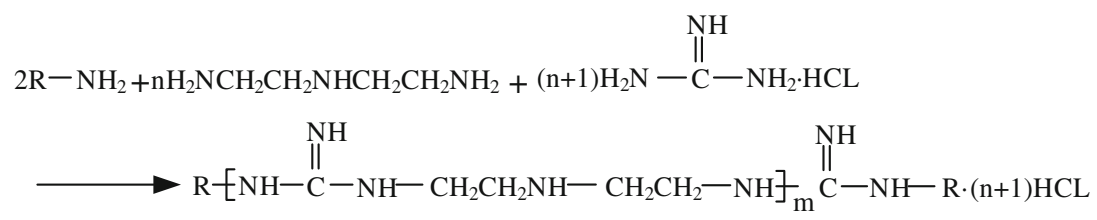

(c)

[35] used the glycols(s) and formic acid as raw materials, paratoluene sulfonic acid as catalyst, and xylene as an azeotropic solvent to produce ethane-1,2-diyl diformate, after esterification, the best product with antibacterial effects. The synthesis is shown in Fig. 4(b). Wang [36] used guanidine hydrochloride, diethylenetriamine, long-chain organic amines and other amine-containing monomers as raw materials to synthesize a new organic guanidine bactericide through condensation reaction. The synthesis is shown in Fig. 4(c). When the dosage of the organic guanidine bactericide GA was $30 \mathrm{mg} \cdot \mathrm{L}^{-1}$, the killing rate of blank heterotrophic bacteria, reducing bacteria and iron bacteria were all greater than $99 \%$. Several foreign

Table 6 Chemical composition of bactericides

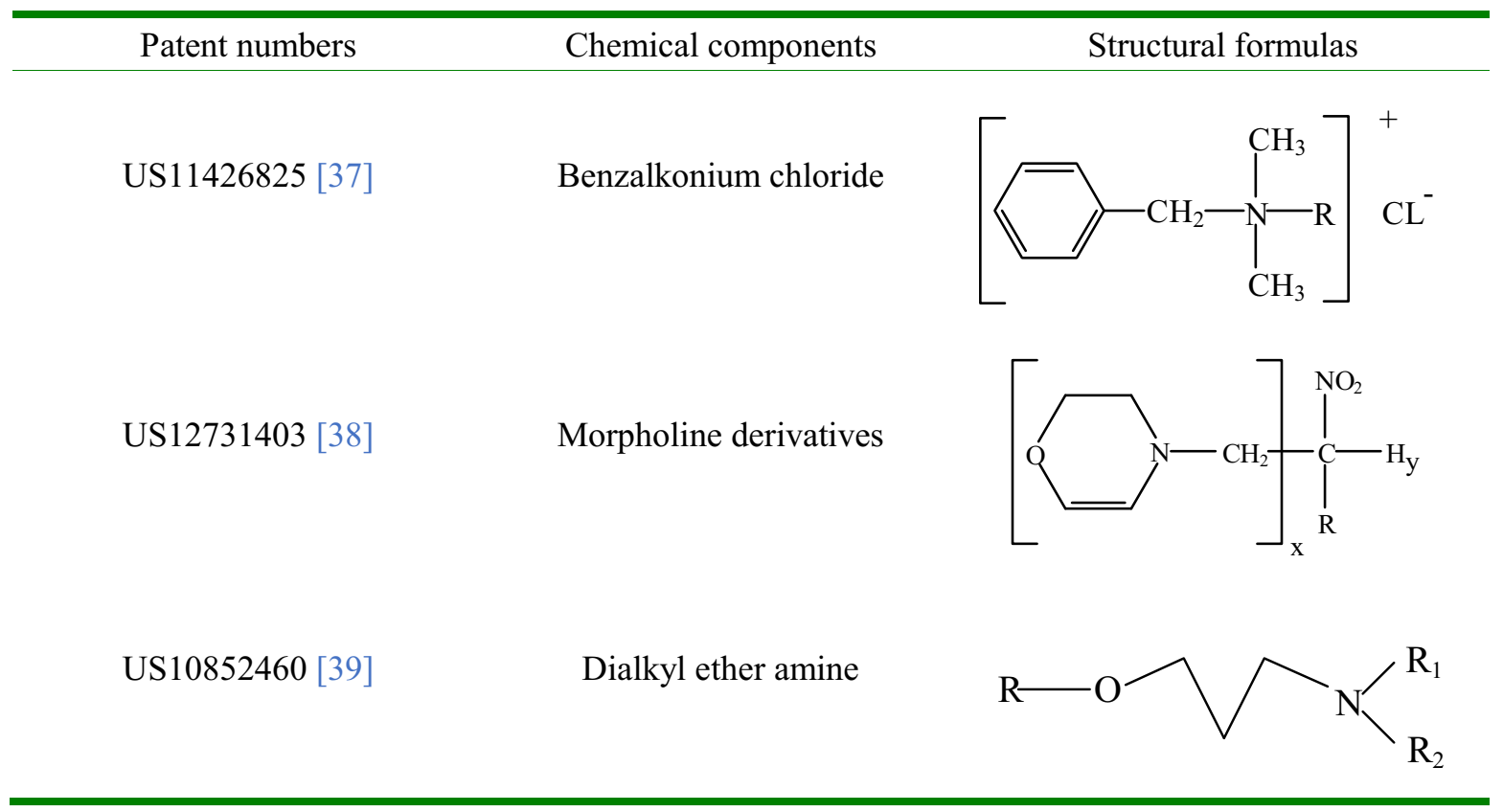


Fig. 5 Synthesis of extreme pressure additive: a Dodecanoic acid diethanolamide borate. $\mathbf{b}$ Alcohol amine borate antiwear additive
(1)

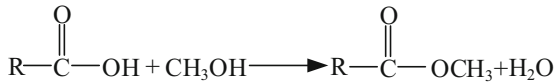

(2)

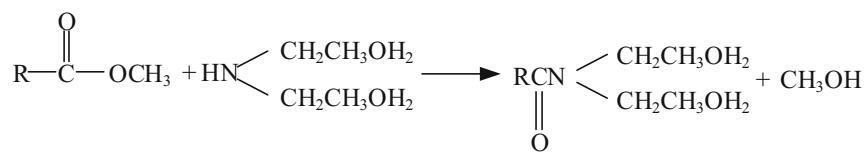

(3)

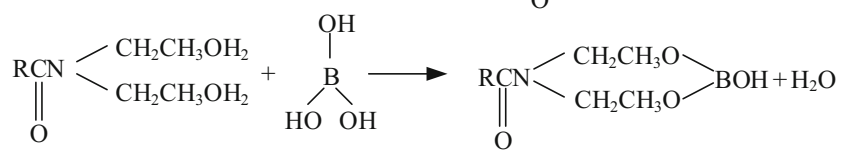

(1)

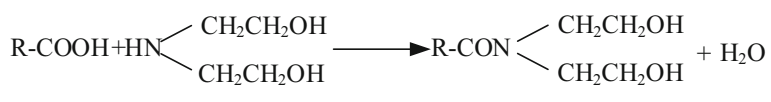

(2)

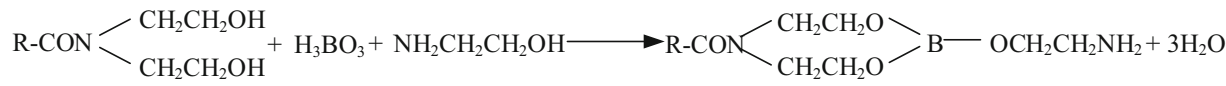

patents also conducted research on eco-friendly bactericides. The chemical composition of the bactericides is shown in Table 6. These eco-friendly bactericides have better low temperature stability and higher sterilization efficiency.

\subsubsection{Extreme pressure additives}

Extreme pressure additives are an important additive in cutting fluid. The extreme pressure additives form an extreme pressure lubricating film on the surface of the workpiece so that the cutting fluid can be used under extreme harsh conditions such as high temperature and high pressure, which broadens the scope of application of the cutting fluid. This behavior has an irreplaceable effect on the cooling and lubrication of processing methods such as cutting and forming of difficult-to-process materials. According to the film forming mechanism, extreme pressure agents can be divided into two types: One is capable of direct chemical reaction with the metal surface to form a reactive film, such as sulfur or chlorine-containing compounds, metal sulfides, and metal chlorides. The other forms films by thermal degradation during processing, such as phosphate disulfide and phosphoruscontaining organic compounds. However, these extreme pressure additives have poor biodegradability, and several extreme pressure agents are carcinogens, which do not meet the requirements of green development. Finding extreme pressure additives with good biodegradability and low biological hazards is a key issue in the field of metal processing.

With the research and development of green extreme pressure additives, researchers have found that boric acid ester extreme pressure additives are expected to become ecofriendly additives. Yuan et al. [40] used dodecanoic acid, diethanolamine and boric acid as raw materials to prepare dodecanoic acid diethanolamide borate by esterification and condensation reactions. The synthesis is shown in Fig. 5(a). The researchers added $11.3 \%$ dodecanoic acid diethanolamide borate into the semisynthetic cutting fluid. The prepared cutting fluid had good extreme pressure and wear resistance, and

Table 7 Chemical components of extreme pressure additives

\begin{tabular}{cccc}
\hline Patent numbers & Chemical components & Structural formulas \\
\hline US10219919 [42] & $\begin{array}{c}\text { Polyester partially esterified } \\
\text { acid and polyol ester }\end{array}$ & Alkyl fatty acid polyacrylam & ide
\end{tabular}


its friction factor can be as low as 0.056 . In addition, the semisynthetic metal cutting fluid was formulated with dodecanoic acid diethanolamide boric acid ester, and its all its indicators met the GB/T6144-2010 standard. Meng et al. [41] used ricinoleic acid, boron, and diethanolamine as raw materials, and prepared an alcohol amine borate antiwear additive using the azeotropic principle. The synthesis is shown in Fig. 5(b). He used a four-ball friction tester to investigate the tribological performance of alcohol amine boric acid ester antiwear additives. The results showed that when the additive dosage was $200 \mu \mathrm{g} \cdot \mathrm{g}^{-1}$, the antiwear effect of the base oil was better. The minimum wear scar diameter was $419 \mu \mathrm{m}$.

Foreign patents have also invented several eco-friendly extreme pressure additives. Among them, polyesters, rosin acid and its derivatives have become important eco-friendly extreme pressure additives that replace chlorinated the paraffin. The chemical composition is shown in Table 7.

The research on eco-friendly additives is not limited to the above three additives. For example, to enhance the cooling and cleaning performance of the water-based synthetic cutting fluid, a surfactant that can reduce the surface tension of the cutting fluid needs to be added to the cutting fluid [44]. To solve the foam problem of cutting fluid, defoamers must be added. These additives are mostly inorganic additives, which require green research and development. To follow the concept of sustainable development, researchers must continue to develop new eco-friendly additives to improve the performance of the cutting fluid continuously, making the cutting fluid more environmentally while maintaining excellent performance.

\subsubsection{Base oil}

Vegetable oil has gradually become the choice of green cutting fluid base oil due to its natural advantages such as good biodegradability, high yield, nontoxicity, and sufficient resources [45]. Using vegetable oil as the base oil of the cutting fluid can make the processing technology more eco-friendly while enhancing the antiwear and lubricating performance of the processing area. The main component of vegetable oil is triglyceride formed by the combination of fatty acid and glycerin. Different vegetable oils have different types and contents of fatty acids, which will affect their physical and chemical performance. The fatty acid can react with the metal surface to form a monolayer or multilayer fatty acid soap adsorption film, which has antiwear and antiwear effects; when the vegetable oil molecules are arranged vertically, tightly and evenly on the surface of the metal, a single-molecule boundary layer lubricating film with excellent lubricating performance is formed on the surface of the metal [46]. Fatty acids are divided

Table 8 Fatty acid content of several common vegetable oils and molecular structure of fatty acids

\begin{tabular}{|c|c|c|c|c|c|c|c|}
\hline \multirow{2}{*}{$\begin{array}{l}\text { Fatty acid } \\
\text { categories }\end{array}$} & \multirow{2}{*}{$\begin{array}{l}\text { Molecular } \\
\text { formulas }\end{array}$} & \multirow[b]{2}{*}{ Structural formulas } & \multicolumn{5}{|c|}{ Fatty acid content of vegetable oil (\%) } \\
\hline & & & $\begin{array}{c}\text { Soybean } \\
\text { oil }\end{array}$ & $\begin{array}{c}\text { Rapeseed } \\
\text { oil }\end{array}$ & $\begin{array}{c}\text { castor } \\
\text { oil }\end{array}$ & $\begin{array}{c}\text { Corn } \\
\text { oil }\end{array}$ & $\begin{array}{c}\text { Peanut } \\
\text { oil }\end{array}$ \\
\hline Oleic acid & $\begin{array}{c}\mathrm{C}_{17} \mathrm{H}_{33} \mathrm{CO} \\
\mathrm{OH}\end{array}$ & & $22-31$ & $40-60$ & $3-9$ & $26-40$ & $53-71$ \\
\hline $\begin{array}{c}\text { Linoleic } \\
\text { acid }\end{array}$ & $\begin{array}{c}\mathrm{C}_{17} \mathrm{H}_{31} \mathrm{CO} \\
\mathrm{OH}\end{array}$ & & $49-55$ & $11-23$ & $2.0-3.5$ & $40-55$ & $13-27$ \\
\hline $\begin{array}{l}\text { Linolenic } \\
\text { acid }\end{array}$ & $\begin{array}{c}\mathrm{C}_{17} \mathrm{H}_{29} \mathrm{CO} \\
\mathrm{OH}\end{array}$ & & $6-11$ & $5-13$ & - & $1-2$ & - \\
\hline $\begin{array}{l}\text { Palmitic } \\
\text { acid }\end{array}$ & $\begin{array}{c}\mathrm{C}_{17} \mathrm{H}_{31} \mathrm{CO} \\
\mathrm{OH}\end{array}$ & & $7-10$ & $1.5-6$ & - & $9-19$ & $6-9$ \\
\hline $\begin{array}{l}\text { Stearic } \\
\text { acid }\end{array}$ & $\begin{array}{c}\mathrm{C}_{17} \mathrm{H}_{35} \mathrm{CO} \\
\mathrm{OH}\end{array}$ & & $3-5$ & $0.5-3$ & - & $1-3$ & $3-6$ \\
\hline
\end{tabular}


into saturated fatty acids and unsaturated fatty acids. The fatty acid content of common vegetable oils and the molecular structure of fatty acids are shown in Table 8. Oleic acid, linoleic acid, and linolenic acid are unsaturated fatty acids, whereas stearic acid and palmitic acid are saturated fatty acids. For fatty acids, the lubricity of saturated fatty acids is better than that of unsaturated fatty acids [47].

Based on the physical and chemical properties of vegetable oils, researchers have developed vegetable oil-based ecofriendly fluids with excellent lubricating properties. Among them, soybean oil has the most fatty acid content and has become the research focus of eco-friendly fluid base oil. Lodhi et al. [48] used soybean oil as the base oil of the cutting fluid and tested it with a four-ball tester. The results showed that under a load above $1600 \mathrm{~N}$, vegetable oil-based cutting fluids can still maintain a lower friction coefficient than traditional cutting fluids. Guo [49] studied the lubrication mechanism of castor oil mixed with other vegetable oils (soybean oil, corn oil, and palm oil) as a base oil for MQL grinding, and they found that mixed base oil had a better lubricating effect than castor oil. Moreover, the soybean oil/castor oil mixed base oil had the best lubrication effect, and the tangential force and normal force were reduced by $27.03 \%$ and $23.15 \%$, respectively. In addition, most of the friction interface was based on boundary lubrication in part processing. However, under boundary lubrication conditions, adding nanoparticles to vegetable oils can substantially improve their lubricating properties [50]. Li et al. [51] added graphene nanoparticles to vegetable oil-based cutting fluids to enhance their cooling and lubricating properties. Under the conditions of graphene nanoparticle mass fraction of $0.1 \%$, cutting fluid flow rate of 60 $\mathrm{mL} / \mathrm{h}$, and gas pressure of $0.6 \mathrm{MPa}$, the optimal milling surface roughness was $0.406 \mu \mathrm{m}$. According to the grinding processing conditions of vegetable oil as the base oil of nano fluid minimum quantity lubrication (NMQL), Zhang [52] studied the law of influence of different vegetable oil molecular structures and nano fluid physical properties on the film formation mechanism and antiwear performance of the grinding area. The vegetable oil nanofluid was developed by using $\mathrm{MoS}_{2}$ nanoparticles with a particle size of $50 \mathrm{~nm}$ mixed with vegetable oil to study its lubricating properties. Studies have shown that vegetable oil nanofluids can obtain a lower microscopic friction coefficient than pure vegetable oil as a micro lubricating grinding fluid, and vegetable oil nanofluids have better lubricating properties. The size relationship between micro friction coefficients of different vegetable oil-based MQL is shown in Fig. 6.

Organic additives and biodegradable vegetable base oils are the main components of eco-friendly cutting fluids. First, the polar groups of amide and boric acid organic rust inhibitors have a greater affinity for metals and can be firmly adsorbed on the metal surface to form a directional adsorption layer, and the antirust performance of organic additives is further improved by the chemical modification of diethanolamine and dodecenyl succinic acid. Then, the esterification reaction of ethylene glycol and formic acid, and the condensation reaction of guanidine hydrochloride, diethylenetriamine and other amine group-containing monomers can obtain additives with excellent bactericidal properties. Second, the dodecanoic acid diethanolamide borate obtained by the esterification condensation reaction of fatty acid and methanol, and the azeotropic principle synthetic alcohol amine borate all have good extreme pressure performance. Finally, due to the excellent physical and chemical properties of saturated fatty acids, vegetable oils have become the primary choice for cutting fluid base oils. Among them, the high fatty acid content of soybean oil has become the focus of
Fig. 6 Microscopic friction coefficients under different grinding conditions

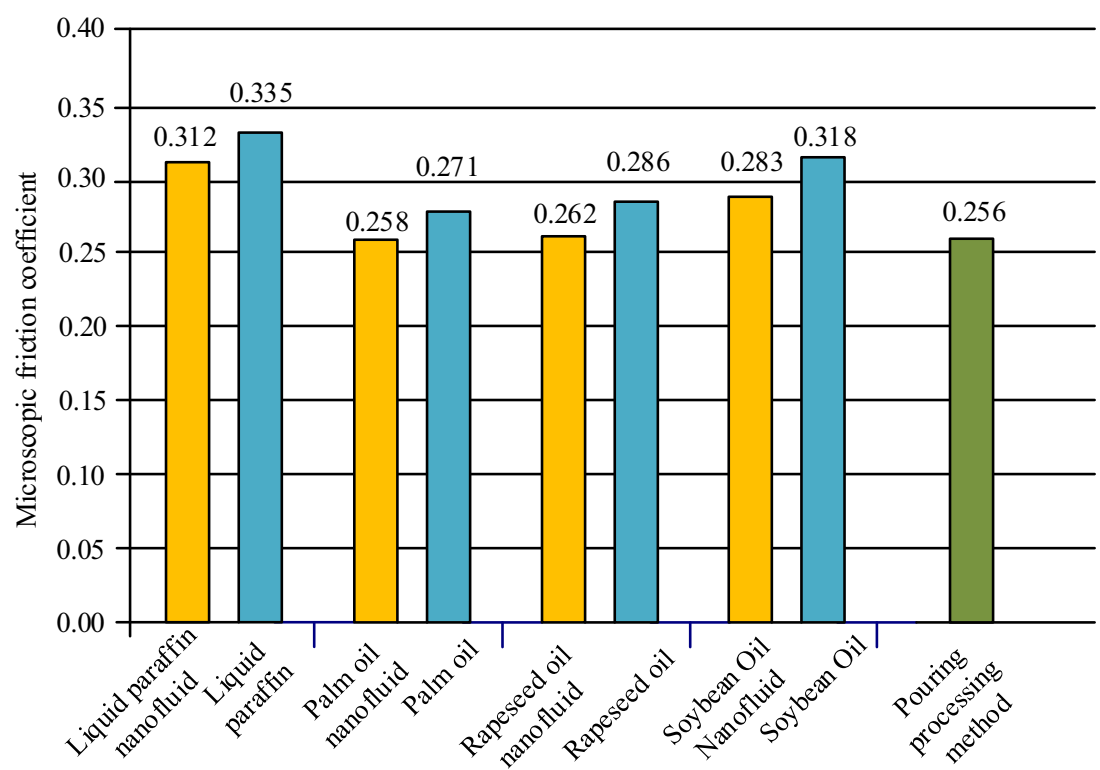




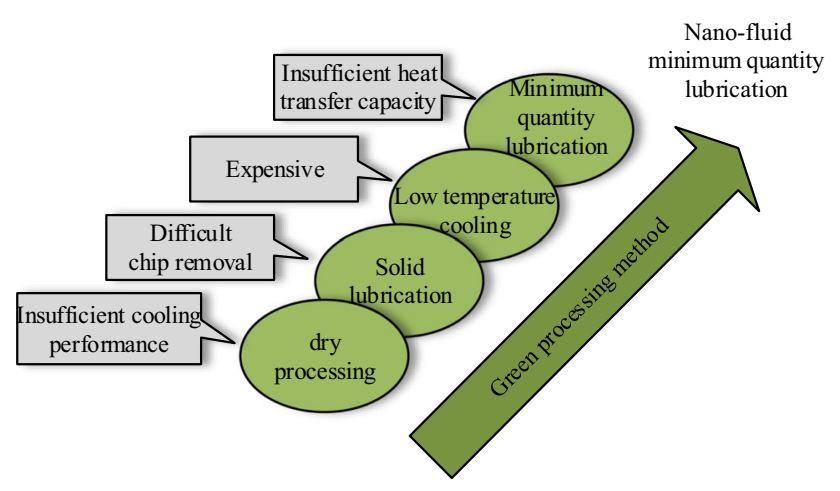

Fig. 7 Development of green processing methods

research. In addition, nanoparticles can further improve the lubricating properties of vegetable oils.

\subsection{Research progress of green processing methods}

For traditional cutting fluids, in addition to the pollution caused by harmful additives and poor biodegradable base oils to organisms and the environment, pouring processing methods are sources of pollution. Moreover, the pouring processing method has disadvantages such as high usage and processing costs. Owing to these problems, this method no longer meets the concept of green, sustainable development, and has even become a technical bottleneck for the highquality processing of emerging materials such as medical ceramics [53-55]. For this reason, how to find a green metal processing method has become the goal of related researchers. The main hazard of pouring processing is the use of a large amount of cutting fluid that is harmful to people and the environment. How to reduce the amount of cutting fluid or abandon the cutting fluid and use pollution-free green cooling medium to replace the cutting fluid has become the idea of exploring green processing methods. Based on these ideas, related researchers have made many attempts [56-59] and proposed various green processing methods. The development of green processing methods is shown in Fig. 7.

\subsubsection{Dry processing}

As a green processing technology, dry processing was first applied to the automotive industry. Initially, Professor F. Klocke from the Aachen University of Technology in Germany presented a keynote report on dry processing technology and said that dry processing technology has brought new prospects for green processing technology [60]. Dry processing is a machining method that uses high-quality cutting tools without using cutting fluid to ensure high efficiency, high machining quality and cutting reliability. It does not use a large amount of cutting fluid for auxiliary processing; thus no harmful problems will be caused by the cutting fluid. It is a green eco-friendly machining method without cutting fluid. At present, dry processing has become one of the green processing methods for processing steel, aluminum, and titanium alloys and other materials [61-63].

Dry processing reduces environmental pollution, avoids harm to the health of operators, and reduces processing costs. However, due to the lack of the cooling and lubricating effect of the cutting fluid, if the surface quality of the workpiece obtained by dry processing is equivalent to the surface quality of the workpiece obtained by the processing method using cutting fluid, the tool must have higher toughness, hardness, and wear resistance. In addition, because the heat transfer performance of the air and chips is far less than that of the cutting fluid, the generation of a large amount of frictional heat causes the temperature of the workpiece to rise, which seriously reduces the service life of the tool and the processing quality of the workpiece. Tawakoli et al. [64] used ultrasonicassisted dry processing, and Paul et al. [65] used lowtemperature liquid nitrogen to assist dry processing; both improved the problem of easy burns on the surface of the workpiece, but the conditions required were excessively harsh for dry processing. While researchers are exploring dry processing, they also urgently need to develop eco-friendly, lowconsumption and clean metal processing methods.

\subsubsection{Solid lubrication}

Under boundary lubrication conditions, the most effective way to reduce friction is not the cutting fluid but the selection of the appropriate solid lubricant. For this reason, solid lubrication processing methods have been proposed. The solid lubrication processing method is that the solid medium is added as a lubricant to the processing area. Compared with dry processing, solid lubrication processing effectively optimizes the tribological characteristics of the tool/workpiece interface, improves the lubrication performance and reduces the frictional heat output during the machining process. Solid lubrication processing has been researched in turning and grinding processing. Hu et al. [66] combined laser surface texture and $\mathrm{MoS}_{2}$ solid lubricant to prepare a composite lubricating structure on the surface of $45 \#$ steel and studied its friction and wear performance under dry friction conditions. Agarwal et al. [67] used graphite and molybdenum disulfide as solid lubricants to assist grinding, and the results showed that the process performance of solid lubricant-assisted grinding was greatly improved.

Compared with dry machining, solid lubrication machining has greatly improved in terms of reducing tool wear and friction heat. However, solid lubrication usually stores the lubricant by changing the shape of the tool and the surface micro texture, which makes the stability of the tool poor. In addition, the problem of chip removal in solid lubrication processing methods needs to be solved urgently. 


\subsubsection{Cryogenic cooling method}

Cryogenic cooling is a method that uses chemically stable liquid nitrogen, low-temperature $\mathrm{CO}_{2}$, and other cooling media instead of cutting fluid to be sprayed into the processing area for metal processing. Low-temperature gas and lowtemperature liquid have a stronger cooling capacity than high-pressure gas and water vapor $[68,69]$. In addition, lowtemperature gas or low-temperature liquid is sprayed for cooling and lubrication, which expands the effective area of heat transfer in the processing area, realizes efficient convective heat transfer, and plays an important role in reducing the temperature of the processing area [70-72]. Researchers conducted research on cryogenic cooling lubrication. Kaynak et al. [73] carried out a comparative experiment between dry turning and liquid nitrogen cooling turning Ni-Ti nickel-titanium memory alloy, and found that the depth of the influence layer produced by ultra-low temperature machining was twice that of dry cutting, which improved the surface hardness of the workpiece. Liu et al. [74] used a mixture of water vapor and $\mathrm{CO}_{2}$ gas and a mixture of water vapor and $\mathrm{O}_{2}$ as coolants and lubricants to improve the friction/heat conditions in the turning, and found that the direct use of water vapor and gas mixture can extend tool life.

Although the heat transfer performance of the lowtemperature cooling lubrication method is better than that of

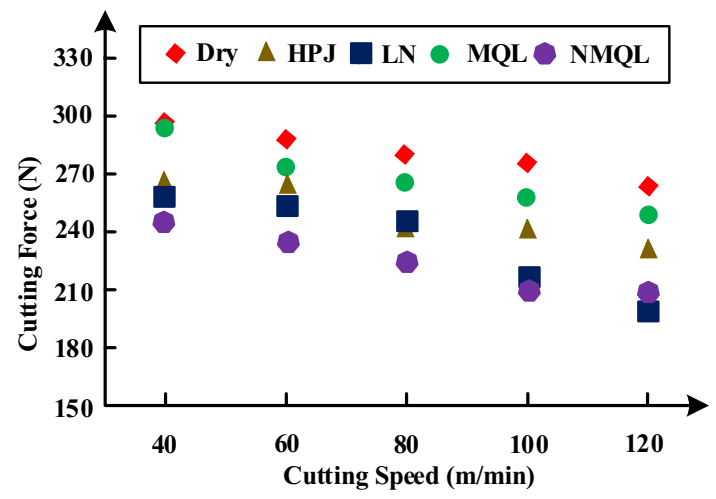

(a)

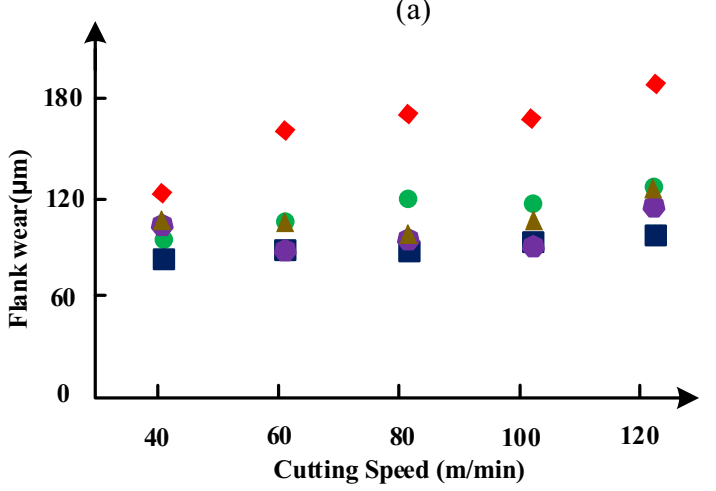

(c) the dry processing method, the low-temperature cooling medium is expensive, and the application of low-temperature cooling technology in some metal processing is still immature, especially for the application in the grinding of difficult-tomachine materials. Researchers need to investigate the antifriction and antiwear mechanism, material removal mechanism and process system optimization further. In addition, when the concentration of inert gases such as nitrogen and $\mathrm{CO}_{2}$ in the air is very high, a hidden danger of staff suffocation exists. These problems are technical bottlenecks that need to be solved urgently in low-temperature cooling and lubrication methods.

\subsubsection{MQL and NMQL}

MQL refers to mixing a small amount of lubricating liquid in high-pressure gas to form a gas-liquid two-phase flow, which enters the processing area after atomization [75]. The highpressure gas can take away the heat generated in the processing area and play a cooling role. In addition, the lubricating liquid droplets enter the processing area along with the highpressure gas and will adhere to the surface of the workpiece to form a film, which can reduce the friction between the tool and the workpiece and between the chips and the workpiece, and has the functions of anti-wear, antifriction and effective lubrication. In addition, the high-pressure gas can remove the
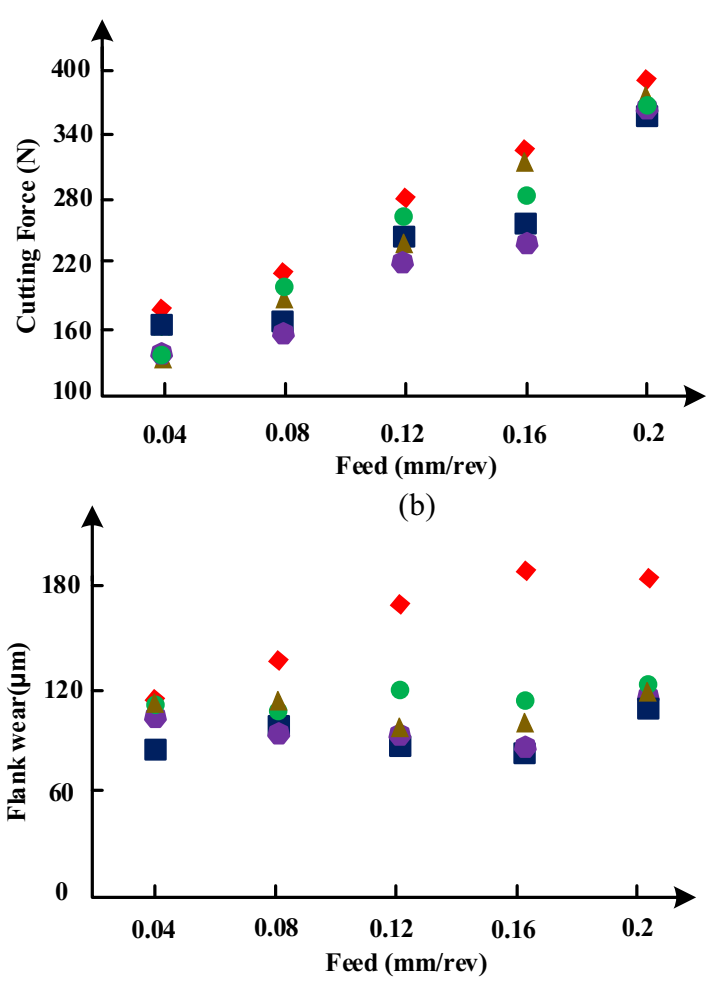

(d)

Fig. 8 Contrast of different lubrication conditions: a The variation of cutting force with cutting speed. $\mathbf{b}$ The variation of cutting force with cutting feed rate. $\mathbf{c}$ The variation of flank wear with cutting speed. $\mathbf{d}$ The variation of flank wear with feed rate 


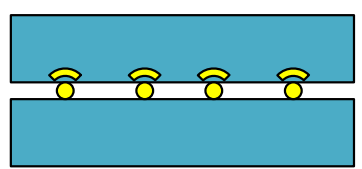

(a)

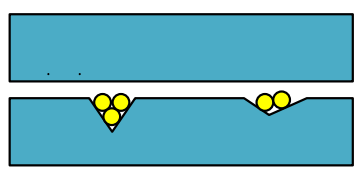

(c)

O Nanoparticles

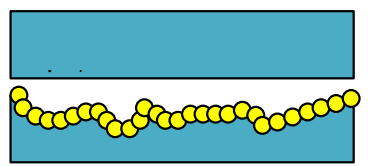

(b)

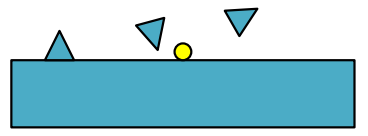

(d)

Metal workpiece
Fig. 9 Nanoparticles enhance the mechanism of lubrication [87]: a Rolling effect. b Protective film effect. c Reparative effect. d Polishing effect

chips, which can prevent the chips from damaging the surface of the workpiece.

MQL can greatly reduce the amount of cutting fluid used. Research has found that the traditional pouring cooling and lubricating method has a grinding fluid flow rate of $60 \mathrm{~L} / \mathrm{h}$ per wheel width while the MQL is reduced to $30-100 \mathrm{ml} / \mathrm{h}$ [76], which is only one thousandth of the pouring processing. For the processing performance of MQL, researchers have carried out relevant research, Wang et al. [77] conducted a test evaluation on the lubrication performance of the wheel/workpiece interface during the MQL grinding of different types of vegetable oils. The experimental results showed that castor oil had the best lubricating performance and the best surface quality of the workpiece in the vegetable oil grinding fluid. Castor oil had a friction coefficient and specific grinding energy of 0.30 and $73.47 \mathrm{~J} / \mathrm{mm}^{3}$, respectively, which decreased by $50.1 \%$ and $49.4 \%$, respectively, compared with flood grinding. Therefore, MQL can greatly improve the working environment and reduce the pollution of the natural environment to ensure the surface quality of the processed workpiece [78]. This method is one of the methods in line with green processing. However, in several processing conditions that require higher heat transfer capacity, the cooling performance of MQL seems slightly difficult. This technology should be further studied.

NMQL is a new method of high-efficiency, low-consumption, clean and low-carbon precision machining aimed at the bottleneck problem of MQL applications [79-81] NMQL is a processing method in which a certain proportion of nano scale particles is added to a minimum quantity lubricating fluid to be fully mixed to prepare a nano-fluid, which further atomized by compressed gas, and transported to the processing area through a nozzle [82]. Studies have found that nanoparticles can remarkably improve the thermal conductivity, permeability, and antiwear properties of cutting fluids [83-85]. For example, in the turning of Inconel 718 superalloy, as shown in Fig. 8, the cutting force of the 0.1 vol\% $\mathrm{Al}_{2} \mathrm{O}_{3} \mathrm{NMQL}$ condition was generally lower than that of the high-pressure jet, low temperature, and minimum lubrication conditions [86]. At present, four effects have been proposed to reveal the mechanism of interaction among nanoparticles in solids, as shown in Fig. 9. Therefore, NMQL can improve the surface quality of the workpiece due to the presence of nanoparticles [88]. Park et al. [89] found that graphite nanoplatelets can improve tool wear and considerably enhance processing performance. The results showed that the tool wear of MQL and low-temperature MQL was severe, the maximum side wears were 0.45 and $0.47 \mathrm{~mm}$, respectively, whereas the tool side wear of NMQL was $0.22 \mathrm{~mm}$. Zhang et al. [90] compared the grinding performance of dry grinding, pouring grinding, $\mathrm{MQL}$ grinding and NMQL grinding. They found that the grinding performance of NMQL was better. Compared with dry grinding, the grinding temperature was reduced by $150{ }^{\circ} \mathrm{C}$. Compared with dry grinding and MQL grinding, the grinding force was reduced by more than $15 \%$. In addition, the researchers used the combination of ultrasonic vibration, lowtemperature cooling and NMQL to enhance the cooling and lubrication performance of the technology [91-93].

NMQL is expected to become a green sustainable processing method that is resource saving, eco-friendly, and highly energy efficient [94-96]. Compared with dry cutting and solid lubrication, MQL and NMQL can effectively reduce the cutting temperature. Moreover, it can increase the viscosity of lubricating oil and the thickness of the oil film can keep the tool/workpiece interface completely separated. The carrying capacity is improved. Compared with low-temperature cooling, MQL and NMQL have excellent lubrication performance and economy. Compared with MQL, nano particles can substantially improve the thermal conductivity, permeability, and antiwear properties of the lubricating fluid, and the thermal-mechanical level of NMQL decreases faster. This advantage can not only slow down the wear of the tool but also help the workpiece to obtain the desired surface quality.

\section{Green circulating purification technology of cutting fluid}

To follow the concept of green and sustainable development, in addition to modifying additives, using nonhazardous additives, using vegetable oils with good biodegradability as base oils, and developing new green processing methods, the treatment of waste cutting fluid should be considered. Although the biodegradability of the current eco-friendly cutting fluid has been improved and the use of harmful additives has been reduced, the cutting fluid still contains factors that are harmful to organisms and the environment. For example, cutting fluid contains carbon, hydrogen, and oxygen elements necessary for the survival of harmful bacteria. The growth of harmful 
Fig. 10 Generation mechanism of oil mist

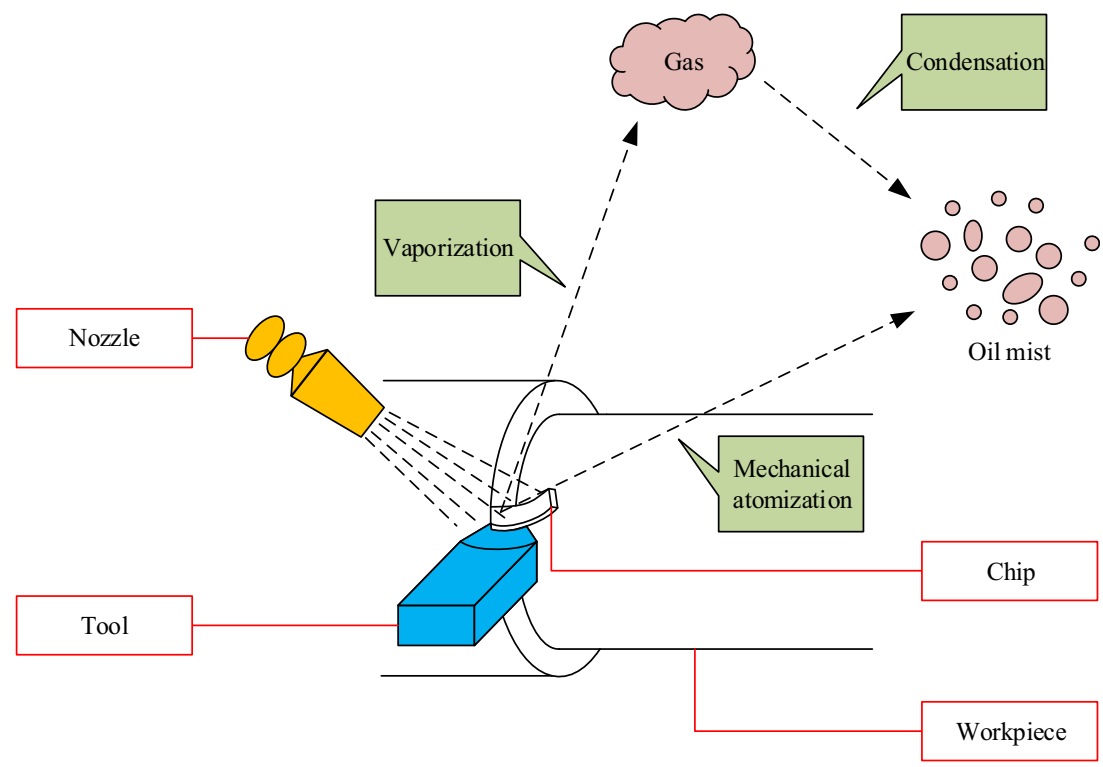

bacteria is inevitable, and the unreasonable discharge of the waste cutting liquid will inevitably lead to pollution problems. To this end, on the one hand, the removal of pollutants from waste cutting fluid discharged into the natural environment must be considered to minimize the harm of waste cutting fluid to the environment and biological; on the other hand, the recycling of the waste cutting fluid with simple components through the recycling purification technology must be considered such that the cutting fluid can achieve maximum economic benefits.

\subsection{Removal mechanism and ways of waste cutting fluid}

Waste cutting fluid can discharged into the natural environment in two main ways. The first is to discharge into the air through oil mist. Owing to the limitation of the processing method, the cutting fluid needs to be sprayed on the processing area of the tool/workpiece, which inevitably causes the

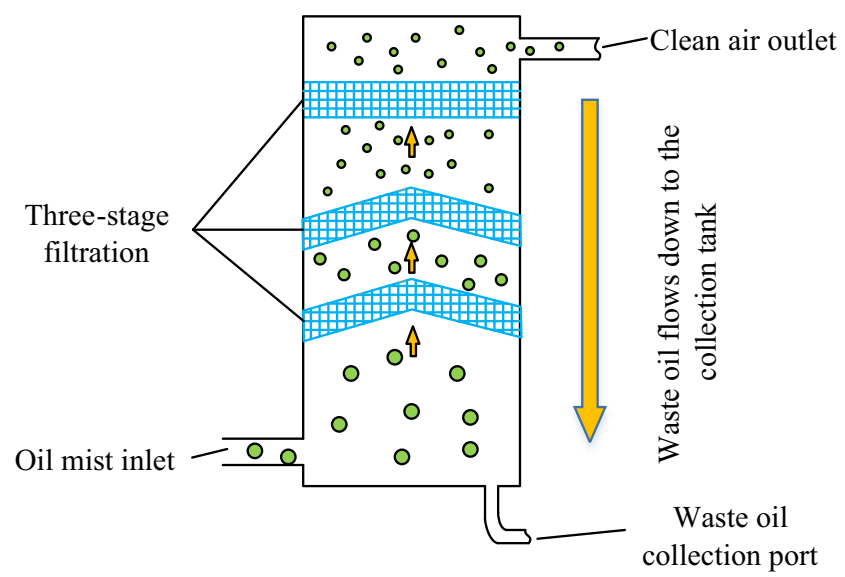

Fig. 11 Purification equipment and its filtering principle droplets to splash on the surface of the tool and the workpiece, causing mechanical atomization. In addition, the cutting fluid is vaporized due to the cutting heat and then condenses to generate oil mist to cause vaporization and condensation. The oil mist generation mechanism is shown in Fig. 10. Oil mist will be inhaled by workers and cause long-term harm to the body. The second is that the waste cutting fluid is discharged into the natural environment after a simple treatment through the recycling device. For this reason, a green, efficient waste cutting fluid treatment method must be found according to the cutting fluid discharge path.

\subsubsection{Air pollutants}

Mechanical mist reduction method and chemical mist reduction method are effective methods to reduce the concentration of cutting fluid oil mist. The mechanical mist reduction method mainly uses external equipment to reduce the concentration of oil mist or reduce the spread of oil mist by affecting air flow. This method includes exhaust fan, oil mist trap, and oil mist filter. The mechanical mist reduction method is simple to implement has remarkable effects, and is widely used in metal processing. Jiang et al. [97] used a centralized oil mist collection and treatment system to purify oil mist in the mechanical processing workshop. After purification, the concentration of cutting fluid oil mist in the entire workshop was controlled below $0.5 \mathrm{mg} / \mathrm{m}^{3}$, and the concentration of total suspended particulates dropped up to $24 \%$. The purification equipment and its filtering principle are shown in Fig. 11.

Many devices for mechanical mist reduction have been invented. These invented devices can effectively separate, recover and reuse oil mist particles in the air, making the air in the processing space cleaner. which is beneficial to the health 
Table 9 Patent equipment composition and effects

\begin{tabular}{|c|c|}
\hline Patent numbers & Composition and effects \\
\hline $\begin{array}{l}\text { CN201711400817.8 } \\
\quad[98]\end{array}$ & $\begin{array}{l}\text { Composition: Shell, telescopic pipe, air outlet pipe, wind bunker pipe and air duct. A mesh filter, a centrifugal impeller, a } \\
\text { primary filter, a secondary filter and a tertiary filter are arranged in the air duct. An auxiliary exhaust fan is installed in the air } \\
\text { outlet pipe. } \\
\text { Effect: Primary filtration is carried out through a mesh filter to adsorb large particles in the surrounding environment, and then } \\
\text { harmful substances are adsorbed and filtered through a multi-stage activated carbon filter. }\end{array}$ \\
\hline $\begin{array}{l}\text { CN201720285550.1 } \\
\quad[99]\end{array}$ & $\begin{array}{l}\text { Composition: Box body, front box body, middle box body and rear box body; the front box body is equipped with a front filter } \\
\text { device, the front filter device includes a frame, an inertial collision plate and a filling cotton. There is a centrifugal impeller in } \\
\text { the middle box. A motor board, a motor and a rear filter are arranged in the back box. } \\
\text { Effect: The oil mist filter is equipped with two filtering devices, and an inertial collision plate is installed in the front filter device } \\
\text { at the air inlet, which can block large particles in the air, prevent the filter from clogging, and make the oil mist filter more } \\
\text { effective. High filtration efficiency. }\end{array}$ \\
\hline $\begin{array}{l}\text { CN201721027059.5 } \\
\quad[100]\end{array}$ & $\begin{array}{l}\text { Composition: Hollow flat plate, cylindrical vertical plate. The cylindrical vertical plate is provided with a relatively } \\
\text { high-pressure oil mist inlet and a low-pressure oil mist inlet, and the hollow flat plate is provided with a hollow cylinder and a } \\
\text { hollow cyclone cylinder. } \\
\text { Effect: The oil mist medium enters the spinning chamber to generate a large centrifugal force, which can effectively separate } \\
\text { particles and oil larger than } 10 \mu \mathrm{m} \text { in the oil mist medium, and achieve a good primary spinning effect }\end{array}$ \\
\hline $\begin{array}{l}\text { CN201910100369.2 } \\
\quad[101]\end{array}$ & $\begin{array}{l}\text { Composition: Wind separation mechanism: including pipes and fans. There is a cone-shaped filter screen mechanism in the } \\
\text { pipeline. Filtration recovery mechanism: connected to the pipeline, including the box body, filtering mechanism and recovery } \\
\text { mechanism. } \\
\text { Effect: It can effectively separate, recover and reuse oil mist particles in the air, make the air in the processing space cleaner and } \\
\text { fresher, and be more beneficial to the health of workers, avoiding equipment contamination with oil, and prolonging the } \\
\text { service life of the equipment. }\end{array}$ \\
\hline
\end{tabular}

of workers. Patented equipment composition and effects are shown in the Table 9.

The mechanical mist reduction method has the advantages of simple implementation and evident effect. However, the installation and maintenance costs of the equipment used in the mechanical mist reduction method are very high, and the equipment is very large and hinders the operation of the staff. The chemical mist reduction method uses base oils with low evaporation loss to reduce the concentration of oil mist or adding antimisting additives to the cutting fluid. The evaporation loss of common base oils is shown in Fig. 12. Polyol esters and vegetable oils have lower evaporation losses. Therefore, they are the first choice as base oil for low oil mist, low hazard, and eco-friendly cutting fluid. According to previous reports, the German Binol $\mathrm{AB}$ has developed a

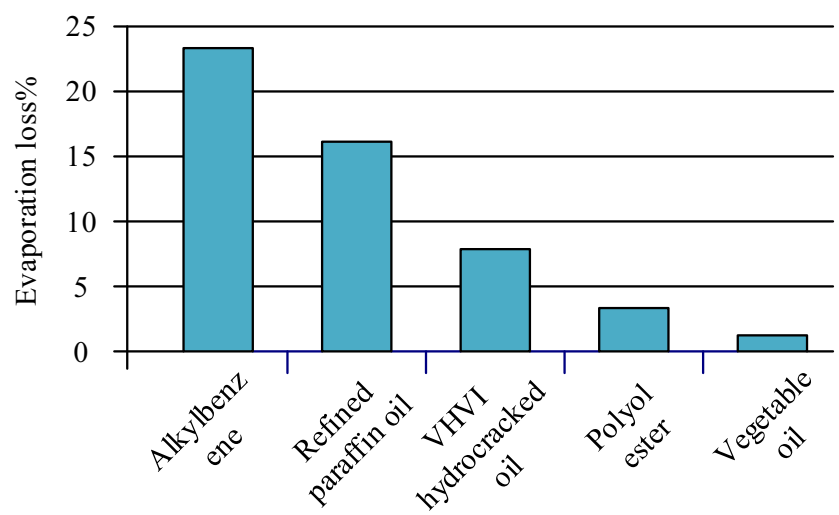

Fig. 12 Evaporation loss of common base oils vegetable oil-based cutting fluid, which can reduce the oil mist concentration by $90 \%$ compared with mineral oil-based cutting fluid. In addition, the greater the viscosity is, the greater the cohesion between molecules, and the less likely it is to be dispersed into fine particles. At $25^{\circ} \mathrm{C}$, the effect of viscosity on the concentration of cutting fluid oil mist is shown in Fig. 13. Therefore, changing the viscosity of the base oil is also one of the effective ways to reduce air pollution [102].

Antimisting additives are usually high-molecular polymers. These polymers can form large, heavy oil droplets with oil such that they are not easily carried by air, which achieves the purpose of reducing oil mist. Antimisting additives include oil-based cutting fluid antimisting additives and water-based cutting fluid antimisting additives. The

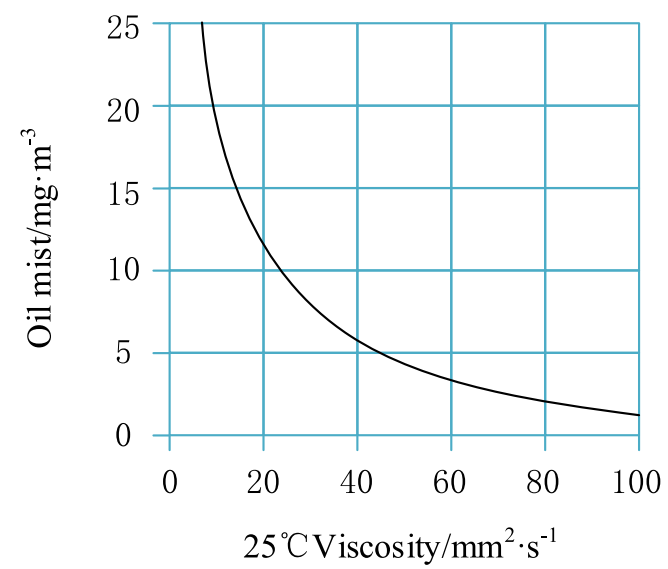

Fig. 13 Effect of viscosity on the concentration of cutting fluid oil mist 
Table 10 Characteristics of air pollutant removal methods

\begin{tabular}{|c|c|c|c|c|}
\hline Methods & Measures & Environmental performance & Timeliness & Economic performance \\
\hline Mechanical mist reduction method & Exhaust fan, oil mist trap, oil mist filter, etc. & Good & Poor & Poor \\
\hline \multirow[t]{2}{*}{ Chemical mist reduction method } & Low evaporative base oil & Good & Good & Marginal \\
\hline & Organic anti-misting additive & Excellent & Excellent & Marginal \\
\hline
\end{tabular}

main components are organic polymers such as polymethacrylate and polyethylene oxide. The antimisting additive solves the oil mist from the perspective of microscopic molecules. Compared with the mechanical mist reduction method, it has the advantage of fast aging. In addition, compared with selecting base oils with low evaporative properties, antimisting additives have a wider application range. Therefore, antimisting additives is a green way to reduce the concentration of cutting fluid oil mist.

The characteristics of air pollutant removal methods are shown in Table 10. From the perspective of environmental protection, health, and safety, the best way to reduce the concentration of cutting fluid oil mist is the chemical mist reduction method. Among them, the organic antimisting additive, which has become the best choice, has the advantages of environmental protection and quick response, Antimisting additives have been widely used abroad.

\subsubsection{Waste cutting fluid treatment technology}

The waste cutting fluid contains a large amount of base oil, metal chips, and organic matter, and its COD, total organic carbon (TOC), and oil concentration are all high [103]. If the waste cutting fluid is not treated and discharged into the natural environment, it will cause serious harm to the natural environment. After the waste cutting fluid flows into the river because the density of the base oil is less than that of water, it will form an oil film on the water surface, which will cause the water body to become hypoxic and threaten the growth of aquatic organisms. In addition, after the waste cutting fluid penetrates into the soil, it will flow to the groundwater layer and pollute the groundwater source. Furthermore, harmful additives and small cutting chips in the waste cutting fluid will be stored in the human body through the food chain, which will cause potential harm. Therefore, how to dispose of waste cutting fluid effectively has become an urgent problem in the field of metal processing.

The waste cutting fluid forms a very stable oil-water structure due to the presence of surfactants. Therefore, the key to the treatment of waste cutting fluid is whether it can demulsify to achieve oil-water separation. The oil in the waste cutting fluid is mainly divided into dissolved oil $(<5 \mu \mathrm{m})$, emulsified oil $(<20 \mu \mathrm{m})$, dispersed oil $(20-150 \mu \mathrm{m})$ and floated oil ( $>150$ $\mu \mathrm{m})$ according to the size of the oil particle diameter [104]. According to the principle of oil-water separation, it can be divided into physical chemical method and biological methods.

\section{(1) Physical method}

\section{a. Gravity separation method}

The gravity separation method is a typical primary treatment method, which mainly uses the density difference between oil and water and the incompatibility of oil and water to separate oil droplets, suspended solids and water in static or flowing states. The oil droplets dispersed in the water slowly rise and layer under the action of buoyancy. The floating speed of the oil droplets depends on the size of the oil droplets, the density difference between oil and water, the flow state and the viscosity of the fluid. The commonly used equipment is oil separator, including advection oil separator, inclined plate oil separator, and corrugated inclined plate oil separator. Hou et al. [105] used an oil-water separator and investigated its separation effect. The oil content of the effluent was less than $0.5 \%$, and the oil-water separation effect was good. The gravity separation method is mainly used to treat floated oil

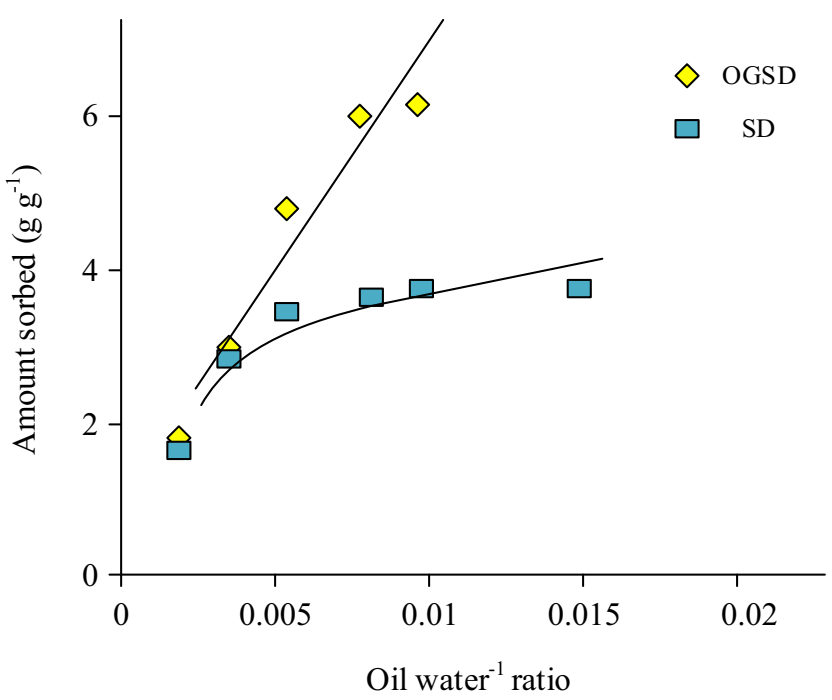

Fig. 14 Removal of oil as a function of oil/water ratio by SD and OGSD 
[106] and is not suitable for processing waste cutting fluid with serious emulsification.

\section{(b) Adsorption method}

The adsorption method is to passes the waste cutting fluid through a porous adsorbent or a filter bed composed of an adsorbent and the adsorbed pollutants on the adsorbent through chemical or physical action, thereby removing miscellaneous oil and pollutants in the waste fluid. The commonly used adsorbents include activated carbon, super oilabsorbing resin, fly ash, and bentonite, etc. Cao et al. [107] used cetyltrimethylammonium bromide to modify purified bentonite and prepared organically modified bentonite. The removal rate of COD in wastewater can reach $85.84 \%$. Li et al. [108] used activated carbon, diatomite, kaolin, clay and chitosan to adsorb trace oil in water. Among them, activated carbon had the best degreasing effect, with an adsorption rate of $95.74 \%$. Songsaeng et al. [109] added reduced graphene oxide to natural rubber latex to make a green adsorbent. The oil removal efficiency was higher than $70 \%$ after the material was reused 30 times.

In addition, natural wood chips have the advantages of low price, easy availability, good adsorption, and natural environmental protection, making it a key research object of green adsorption materials. However, natural wood chips must be modified to increase the oil absorption rate and reduce the water absorption rate because natural wood chips have an adsorption effect on oil and water. Banerjee et al. [110] used the method of grafting fatty acids to modify the surface of natural wood chips. Compared with sawdust (SD), oleic acid grafted sawdust (OGSD) has the best sorption capacity for oil. As shown in Fig. 14. Sang et al. [111] used pyrolysis to modify natural wood chips. The modified adsorbents oil absorption under the same oil concentration was increased by more than $100 \%$, and the water absorption was reduced by $20 \%$ to $30 \%$. The adsorption capacity of the adsorbent was limited,

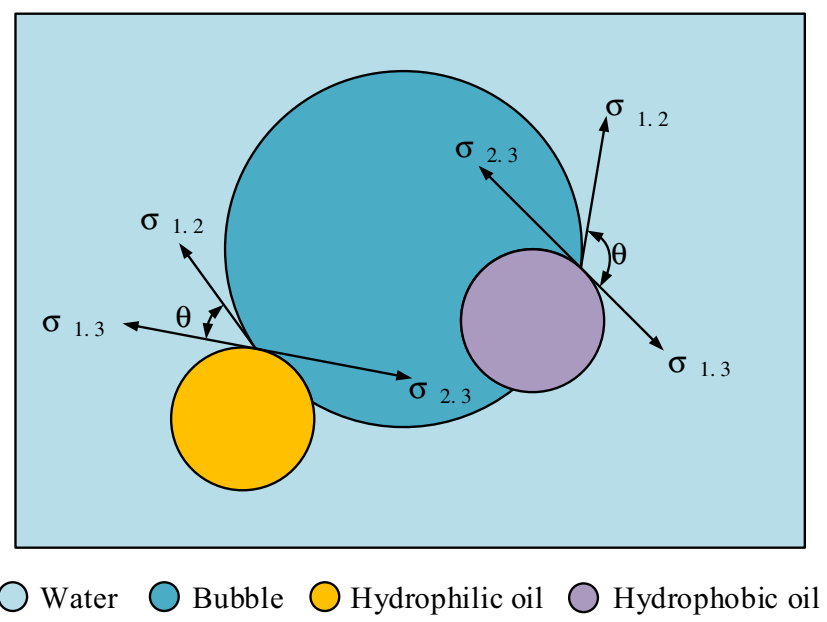

Fig. 15 Air floatation mechanism

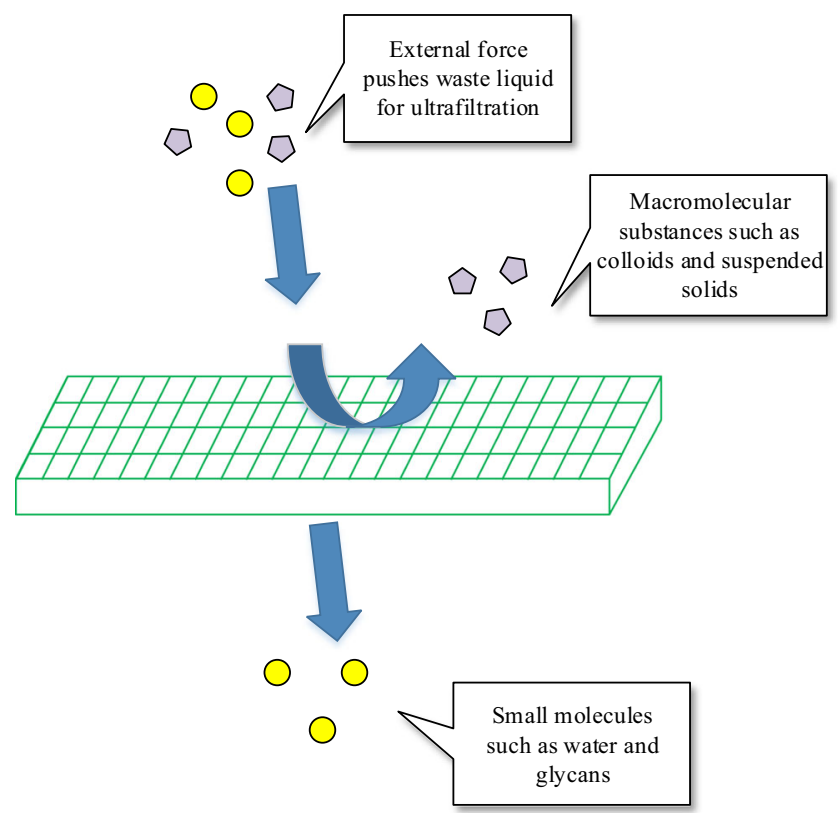

Fig. 16 Ultrafiltration mechanism

and regenerating the adsorbent material was difficult; thus, it is mostly used for waste cutting fluid with low oil content.

(c) Air floatation method

The air flotation method injects minute bubbles into the water, using the bubbles to adhere to the oil droplets in the water to form flocs with a density less than water, which float to the water surface under buoyancy to form a slick layer, and finally achieve oil-water separation by scraping off the slick layer [112]. The hydrophilicity and hydrophobicity of the oil droplets in the water determine whether they can adhere to the bubbles. The hydrophilicity and hydrophobicity of the oil droplets can be explained by the wetting contact angle $\theta$ between the interfacial tension lines of the air, water and oil. A wetting contact angle less than $90^{\circ}$ is hydrophilic, and adhering to bubbles is difficult; a wetting contact angle greater than $90^{\circ}$ is hydrophobic, and adhering to bubbles is easier. The mechanism of the air flotation method is shown in Fig. 15. The three phases of gas, water and oil are represented by 1,2 , and 3 respectively.

The commonly used air flotation processes include dissolved air flotation, electro flotation, dispersed (induced) air flotation, and centrifugal flotation [113]. Lei [114] used a twostage air flotation method to pretreat the emulsion wastewater. She found that air flotation had a unique effect on the emulsion wastewater. After the wastewater passed through the twostage air flotation method, the removal rate of COD and petroleum indicators was as high as $99 \%$. Air flotation is generally used for the separation of oil-water emulsions with small oil particle size and small density difference with water.

(d) Membrane separation method 
The membrane separation method uses the selective permeability of membranes to separate oil and other organic matter in wastewater. The technologies mainly include micro-filtration, ultrafiltration, nano-filtration, reverse-osmosis, and forward osmosis. The particle size of the emulsified oil in the waste cutting fluid is less than $10 \mu \mathrm{m}$, which can be effectively removed by ultrafiltration and micro-filtration; nano-filtration, reverse osmosis and forward osmosis have fewer applications. For micro-filtration and ultrafiltration, the pore size of the ultrafiltration membrane is smaller and the oil removal rate is higher. Therefore, to ensure a stable permeated water quality, ultrafiltration is the most widely used membrane separation method in the treatment of waste cutting fluid. The ultrafiltration mechanism is shown in Fig. 16. Yang et al. [115] obtained ultrafiltration scale filter membrane by Poly (ether sulfone) (PES) $/ \mathrm{TiO}_{2}$ hybrid treatment on the surface of polyethersulfone microporous membrane. The filter membrane can filter most of the oil stains in the waste cutting fluid. The COD removal rate was $89.7 \%$. Shi et al. [116] coated nano $\mathrm{TiO}_{2}$ on the surface of PVDF to obtain a hydrophilic membrane. The water flux of the modified super-hydrophilic membrane can reach up to $785 \mathrm{~L} \cdot\left(\mathrm{m}^{2}\right.$. h) ${ }^{-1}$, and the separation efficiency of the emulsion is $99 \%$.

The membrane separation technology has the advantages of high oil removal efficiency, stable effluent quality, low energy consumption, small footprint, and no secondary pollution. It is a green efficient waste cutting fluid treatment method. However, the separation membrane is easily contaminated and blocked, cleaning is troublesome, and the removal rate of COD may not be high. The selection and structure of membrane materials need to be further optimized.

\section{(2) Chemical treatment}

(a) Acid precipitation method

The surfactants charge the oil droplets in the wastewater. The emulsified oil particles cannot contact and aggregate due to the existence of $\zeta$ potential and electric double layer. By adding acid to increase the $\mathrm{H}^{+}$in the system, the negative

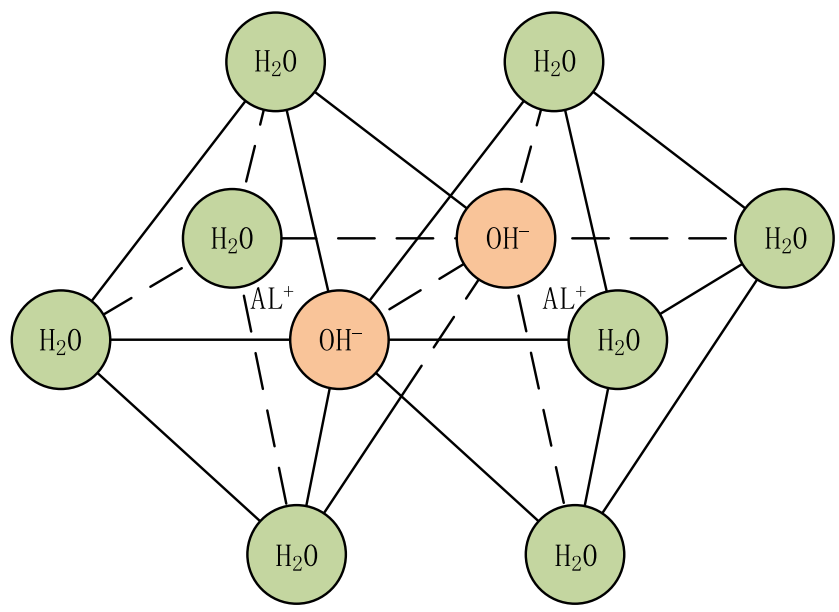

Fig. 17 Dimer structure diagram charge on the surface of the emulsified oil droplets can be neutralized, thereby reducing the $\zeta$ potential to achieve demulsification. Yin et al. [117] used acid precipitationcoagulation combined process to treat waste cutting fluid, and the COD removal rate could reach $61.2 \%$. Wu et al. [118] used sulfuric acid to treat a certain mechanical processing wastewater. When the acid precipitation-coagulation combined process was used, the COD removal rate can reach $71 \%$.

In the treatment of waste cutting fluid, the acid precipitation method is only used for simple oil-water separation. Generally, the acid precipitation method is combined with other technologies to remove impurities from the waste cutting fluid.

(b) Coagulation method

The coagulation method hydrolyzes the aluminum salt and iron salt in the coagulant to produce hydroxyl polymer products, and the hydroxyl polymer products have a flocculating effect on colloidal particles in water. The process is divided into three stages:

a) Hydrolysis stage. The metal ion and the hydroxyl group quickly undergo complexation reaction to form a mononuclear hydroxyl complex ion, and the $\mathrm{pH}$ increases.

b) Aggregation stage. The mononuclear hydroxyl complex ion undergoes hydrolysis and polymerization to form an octahedral structure. Every two octahedrons form a dimer by sharing a pair of hydroxyl groups. The dimer structure is shown in Fig. 17. After that, the hydroxyl and dimer are further hydrolyzed to generate polynuclear hydroxyl complex ions. As all hydroxyl are gradually combined, the polymerization form becomes larger rapidly.

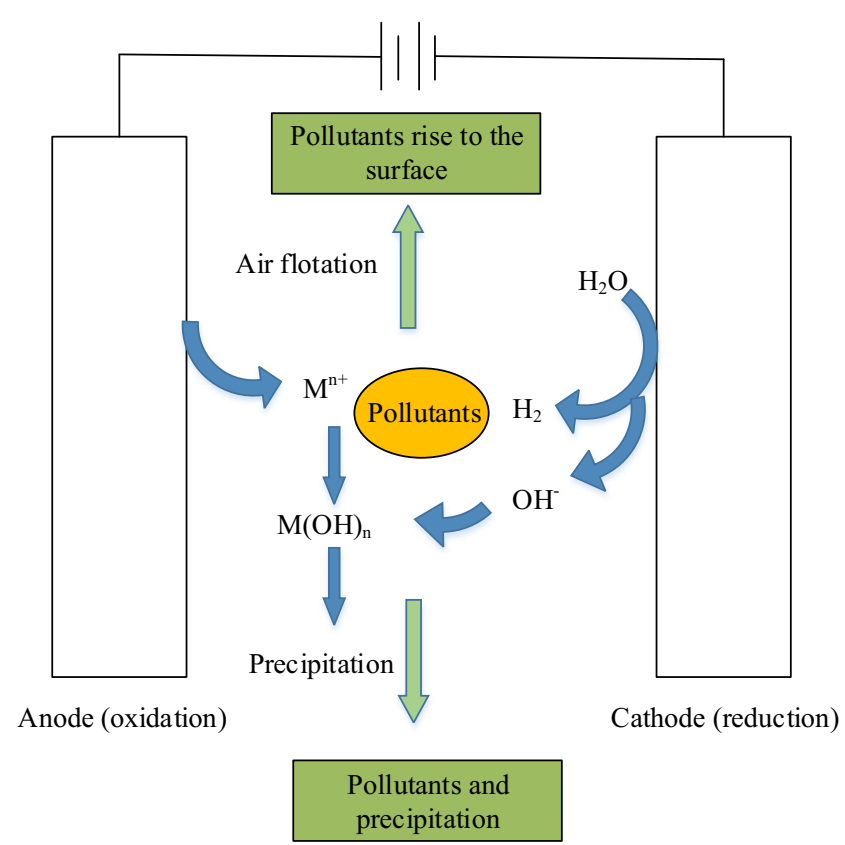

Fig. 18 Schematic diagram of EC reaction mechanism 
c) Gel-precipitation generation stage. The resulting polymer gradually reaches saturation for the absorption of hydroxyl groups and the form changes to the direction of gel precipitation. The $\mathrm{pH}$ increases due to local precipitation and finally converts into $\mathrm{Me}(\mathrm{OH})_{3}$ precipitation.

The formula of the hydrolysis polymerization reaction is

$\mathrm{x} M e^{3+}+\mathrm{yH}_{2} \mathrm{O}=\mathrm{Me}_{\mathrm{x}}(\mathrm{OH})_{\mathrm{y}}{ }^{(3 \mathrm{x}-\mathrm{y})+}+\mathrm{y} H^{+}$

In the formula, Me represents $\mathrm{Al}^{3+}$ and $\mathrm{Fe}^{3+}$ forms.

Cheng et al. [119] used demulsification-coagulationphotocatalytic chemical oxidation to treat waste cutting fluid, and the results showed that the COD removal rate was $99.5 \%$, and the decolorization rate was $100 \%$. Han et al. [120] used poly aluminum chloride (PAC) and poly ferric sulfate (PFS) to treat the waste cutting generated during the aluminum processing of a machinery manufacturing plant. They found that the optimal dosage of PAC and PFS were both $9 \mathrm{~g} \cdot \mathrm{L}^{-1}$, and the removal effect of PAC on macromolecular organics in cutting waste fluid was better than that of PFS.

The coagulant can quickly coagulate and remove impurities from the waste cutting fluid. However, more coagulant is needed to process excessive waste cutting fluid, which will increase the processing cost. With the continuous exploration of researchers, electrochemical coagulation (EC) which is a new type of green coagulation technology, has gradually developed. EC releases metal ions $\left(\mathrm{Al}^{3+}\right.$ and $\left.\mathrm{Fe}^{3+}\right)$ at the anode, causing an electrolytic reaction to generate gas at the cathode [121]. The reaction is

$A l(s)-3 e^{-} \rightarrow A l^{3+}(a q)$

$\mathrm{Fe}(\mathrm{s})-2 e^{-} \rightarrow \mathrm{Fe}^{2+}(a q)$

$\mathrm{Fe}^{2+}(\mathrm{s})-\mathrm{e}^{-} \rightarrow \mathrm{Fe}^{3+}(\mathrm{aq})$

$2 \mathrm{H}_{2} \mathrm{O}(\mathrm{aq})+2 e^{-} \rightarrow \mathrm{H}_{2}(\mathrm{~g})+2 \mathrm{OH}^{-}(a q)$
The mechanism of EC reaction [122] is shown in Fig. 18. The metal ions released by the anode act as a flocculant, and the cathode produces bubbles. The flocculant combines with pollutants in the water to form large flocs, which are then removed by precipitation or air flotation. Guvenc et al. [123] proved that $\mathrm{Fe}$ electrodes are more suitable for processing waste cutting fluid than Al electrodes. Kobya et al. [124] used continuous electrocoagulation to treat waste cutting fluid and found that the removal rates of COD, TOC, and turbidity of Fe electrodes were $98 \%, 95 \%$, and $99.9 \%$, respectively.

(c) Oxidation method

Oxidation methods generally include Fenton oxidation and electrochemical oxidation (EO). The Fenton oxidation method uses $\mathrm{Fe}^{2+}$ and hydrogen peroxide to generate hydroxyl radicals $\cdot \mathrm{OH}$. The $\cdot \mathrm{OH}$ is highly oxidizing and degrades organic pollutants through strong oxidizing.

The $\cdot \mathrm{OH}$ production:

$$
\begin{aligned}
& \mathrm{Fe}^{2+}+\mathrm{H}_{2} \mathrm{O}_{2} \rightarrow \mathrm{Fe}^{3+}+\cdot \mathrm{OH}+\mathrm{OH}^{-} \\
& \mathrm{Fe}^{3+}+\mathrm{H}_{2} \mathrm{O}_{2} \rightarrow \mathrm{Fe}^{2+}+\mathrm{HO}_{2} \cdot+\mathrm{H}^{+} \\
& \mathrm{Fe}^{2+}+\cdot \mathrm{OH} \rightarrow \mathrm{Fe}^{3+}+\mathrm{OH}^{-} \\
& \mathrm{Fe}^{3+}+\mathrm{HO}_{2} \cdot \rightarrow \mathrm{Fe}^{2+}+\mathrm{O}_{2}+\mathrm{H}^{+} \\
& \cdot \mathrm{OH}+\mathrm{H}_{2} \mathrm{O}_{2} \rightarrow \mathrm{H}_{2} \mathrm{O}+\mathrm{HO}_{2} \cdot \\
& \mathrm{Fe}^{2+}+\mathrm{HO}_{2} \cdot \rightarrow \mathrm{Fe}^{3+}+\mathrm{HO}_{2}^{-}
\end{aligned}
$$

The $\cdot \mathrm{OH}$ oxidation organic matter:

$$
\begin{aligned}
& \mathrm{RH}+\cdot \mathrm{OH} \rightarrow \mathrm{R} \cdot+\mathrm{H}_{2} \mathrm{O} \\
& \mathrm{R} \cdot+\mathrm{Fe}^{3+} \rightarrow \mathrm{R}^{+}+\mathrm{Fe}^{2+} \\
& \mathrm{R}^{+}+\mathrm{O}_{2} \rightarrow \mathrm{ROO}^{+} \rightarrow \mathrm{CO}_{2}+\mathrm{H}_{2} \mathrm{O} \\
& \mathrm{Fe}^{2+}+\mathrm{O}_{2}+2 \mathrm{H}^{+} \rightarrow \mathrm{Fe}(\mathrm{OH})_{2} \\
& 4 \mathrm{Fe}(\mathrm{OH})_{2}+\mathrm{O}_{2}+2 \mathrm{H}_{2} \mathrm{O} \rightarrow 4 \mathrm{Fe}(\mathrm{OH})_{3} \\
& \mathrm{Fe}^{3+}+3 \mathrm{HO}^{-} \rightarrow \mathrm{Fe}(\mathrm{OH})_{3}
\end{aligned}
$$

Amin et al. [125] used photo Fenton to treat waste cutting fluid after dissolved air flotation treatment. When $\mathrm{pH}$ was 3 , $\mathrm{FeSO}_{4}$ dosage was $35000 \mathrm{mg} \cdot \mathrm{L}^{-1}, \mathrm{H}_{2} \mathrm{O}_{2}(30 \%)$ dosage was 17 $\mathrm{g} \cdot \mathrm{L}^{-1}$, and COD and oil removal rate can reach about $99 \%$. Li et al. [126] used copper-clad iron powder as a Fenton-like
Fig. 19 Two oxidation mechanisms' schematic diagram of EO [127]: a Direct oxidation. b Indirect oxidation

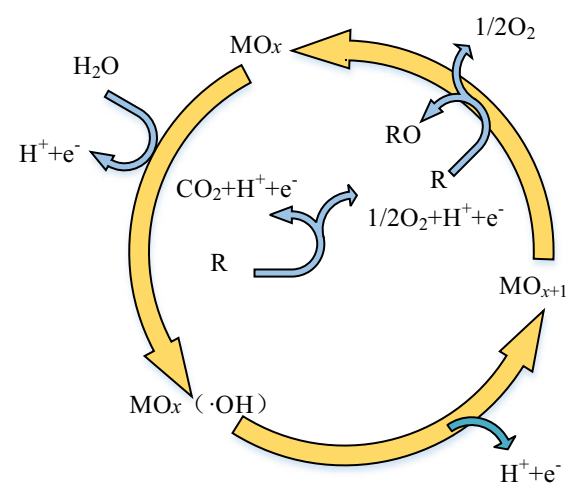

(a)

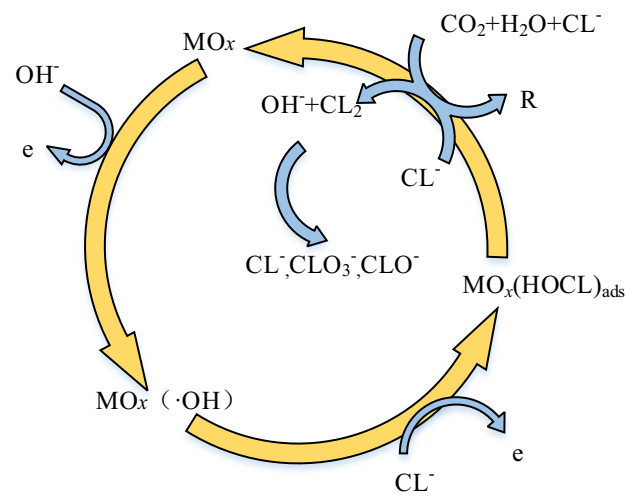

(b) 
catalyst to treat waste cutting fluid, and its COD removal rate could reach $96.7 \%$. However, the Fenton oxidation method produces a large amount of iron-containing sludge, which requires subsequent treatment of the sludge. In addition, the Fenton oxidation method can only occur smoothly when the $\mathrm{pH}$ is $2-5$, which will increase the cost and have a certain corrosive effect on the equipment.

EO refers to a method in which oxidants are generated electrochemically to oxidize pollutants in water. EO can degrade pollutants through two mechanisms: direct oxidation and indirect oxidation. The mechanism is shown in Fig. 19. Zhou et al. [128] studied the electrocatalytic oxidation of $\mathrm{PbO}_{2} / \mathrm{Ti}$ electrode to treat waste cutting fluid. After $5 \mathrm{~h}$ of electrolysis, the COD removal rate reached 95\%. Yang et al. [129] used Ti//rO electrodes to treat cutting and grinding cooling waste liquid in a certain factory. After $60 \mathrm{~min}$ of reaction, the COD removal rate of the cooling waste liquid was $78 \%$.

(3) Biological treatment method

The biological treatment method uses the metabolism of microorganisms to degrade the oil and other pollutants in the waste cutting fluid. According to the aerobic degree of microorganisms, the biological treatment method can be divided into aerobic biological treatment method and anaerobic biological treatment method. Shi et al. [130] used the biological contact oxidation method to treat oily wastewater and found that it had a good removal effect on COD and oil. Zhang et al. [131] studied the combined use of membrane bioreactor (MBR) and Fenton reaction to treat waste cutting fluid. Under the best conditions, the COD removal rate can reach 97\%. Compared with physical methods and chemical methods, biological treatment methods have the advantages of low cost, environmental friendliness, and high efficiency. However, microorganisms have harsh environmental conditions; thus, biological methods have difficulty directly treating special organic wastewater with low biodegradability.

(4) Combined treatment method
The composition of several waste cutting fluids is complex, and a single treatment cannot purify them. To this end, the researchers considered the combination of multiple technologies to treat this type of waste cutting fluid. Wang et al. [132] used coagulation demulsification-Fenton oxidation to treat emulsion wastewater deeply, and the COD removal rate of emulsion wastewater was close to $70 \%$. The treated wastewater met the discharge requirements. Zhao et al. [133] used coagulation heat-activated persulfate oxidation to treat waste cutting fluid, and the COD removal rate was $76 \%$. Jiang et al. [134] used the ultrafiltration-up-flow anaerobic sludge bed (UASB)-contact oxidation process to treat the emulsion wastewater, and the treated wastewater met the discharge standards.

The characteristics of waste cutting fluid impurity removal technology are shown in Table 11. From the perspective of COD removal efficiency and environmental protection, coagulation, oxidation, biological and combined treatment methods are all excellent in treating waste cutting fluid. However, for waste cutting fluid with complex impurities, the combined treatment method is an efficient waste cutting fluid treatment method.

\subsection{Microbial removal mechanisms and methods}

The base oil and various additives in the cutting fluid will provide the necessary carbon, sulfur, phosphorus and other elements for the survival and reproduction of microorganisms, which will cause the growth of microorganisms. The growth of microorganisms will degrade the cutting fluid, causing the cutting fluid to be replaced and produce peculiar smells. The microbial degradation of water-soluble cutting fluid is shown in Fig. 20. In addition, the microorganisms in the cutting fluid can cause severe respiratory diseases for the operators and endanger their health. After the cutting fluid was contaminated by microorganisms, Perkins et al. [136] isolated pathogens such as Legionella, Klebsiella pneumoniae, and Escherichia coli, and detected microorganisms such as Staphylococcus,

Table 11 Characteristics of waste cutting fluid impurity removal technology

\begin{tabular}{lllll}
\hline Methods & & COD removal performance & Environmental performance & Economic performance \\
\hline Physical method & Gravity separation method & Marginal & Excellent & Excellent \\
& Adsorption method & Good & Good & Marginal \\
& Air floatation method & Excellent & Good & Good \\
& Membrane separation method & Good & Good & Marginal \\
Chemical treatment & Acid precipitation method & Marginal & Good & Good \\
& Coagulation method & Excellent & Good & Good \\
Biological treatment method & Excellent & Excellent & Good \\
Combined treatment method & Good & Good & Good \\
\hline
\end{tabular}




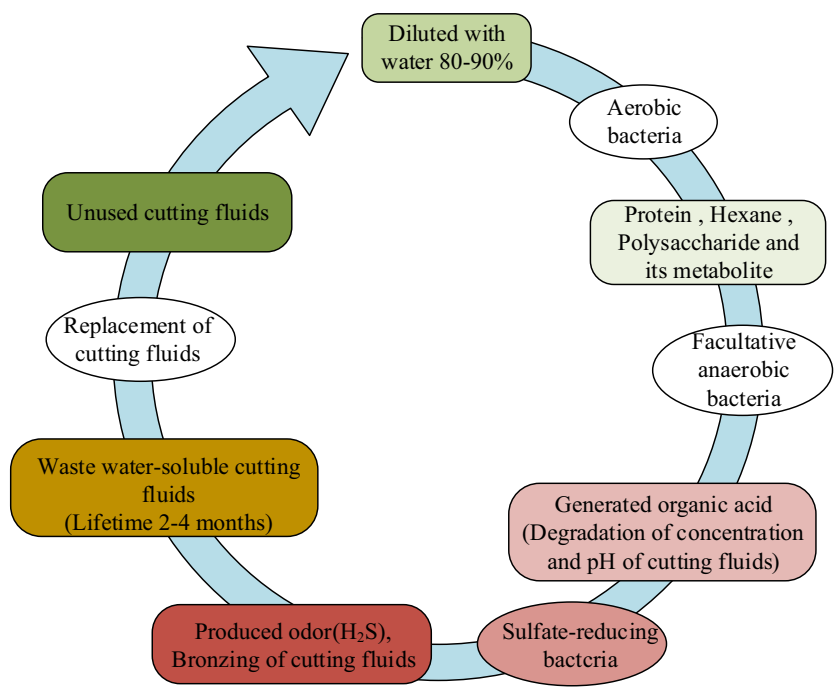

Fig. 20 Microbial degradation of water-soluble cutting fluid [135]

Streptococcus, and sulfate-reducing bacteria. Rhodes et al. [137] isolated Anaphylactic pseudomonas pneumoniae in cutting fluid. Many fungi such as Penicillium and Aspergillus were observed in cutting fluids [138]. For this reason, the removal of microorganisms in cutting fluids is the focus of reducing the replacement of cutting fluids, reducing production costs, and restraining the biological hazards of cutting fluids. Thus far, many ways for sterilizing cutting fluids are available, such as Fenton oxidation method, biological method, and bactericide injection. However, the Fenton oxidation method has a low utilization rate of medicines and will produce a large amount of iron sludge, and the biological treatment method is relatively harsh on condition control. When the cutting fluid is injected with a bactericide, the bacterial concentration will decrease once, but it will return to its original value after a few weeks. Therefore, these methods cannot be used as eco-friendly cutting fluid sterilization methods.
According to the concept of green environmental protection, at the start of removing metal chips and other contaminants, green efficient methods for removing bacteria must also be considered. According to the existing green efficient sterilization technology, it can be roughly divided into nanocomposite sterilization technology, ultraviolet (UV) ray sterilization technology, $\mathrm{O}_{3}$ sterilization technology, $\mathrm{UV} / \mathrm{O}_{3}$ synergistic sterilization technology, and $\mathrm{UV} / \mathrm{O}_{2}$ synergistic sterilization technology.

\subsubsection{Nanocomposite sterilization technology}

Nanocomposite sterilization technology is a type of antibacterial and sterilization technology developed in recent years, and the focus of nanotechnology and antibacterial technology research. Ramos et al. [139] used thymol and silver nanoparticles to prepare a polylactic acid base film with antioxidant and antibacterial performances. Ebrahimi et al. [140] developed a nanostructured lipid carrier containing hydrophilic ceftriaxone sodium and studied its inhibitory effect on the gramnegative bacteria $E$. coli. At present, nanocomposite sterilization materials mainly include metal nanocomposite materials and photocatalytic nanocomposite materials. Metal nanocomposites mainly use the antibacterial properties of $\mathrm{Ag}^{+}, \mathrm{Cu}^{2+}$, $\mathrm{Zn}^{2+}$, and other metal ions themselves, and through physical adsorption, ion exchange or mixed sintering methods, $\mathrm{Ag}^{+}$, $\mathrm{Cu}^{2+}, \mathrm{Zn}^{2+}$ or oxides of such metal ions are fixed in porous materials to make metal nanocomposites. Among them, silver-based nanocomposites have become a research hotspot of metal nanocomposites due to their strong antibacterial properties and low harm to humans. Photocatalytic nanocomposite materials mainly rely on a series of chemical reactions based on the optical reaction of semiconductor oxides such as $\mathrm{TiO}_{2}, \mathrm{ZnO}$, and $\mathrm{ZrO}_{2}$ for sterilization. $\mathrm{TiO}_{2}$ has the advantages of good chemical stability, strong bactericidal ability, and nontoxicity to the human body [141], making the $\mathrm{TiO}_{2}$
Fig. 21 Method of silver nanoparticles inactivating bacteria [142]

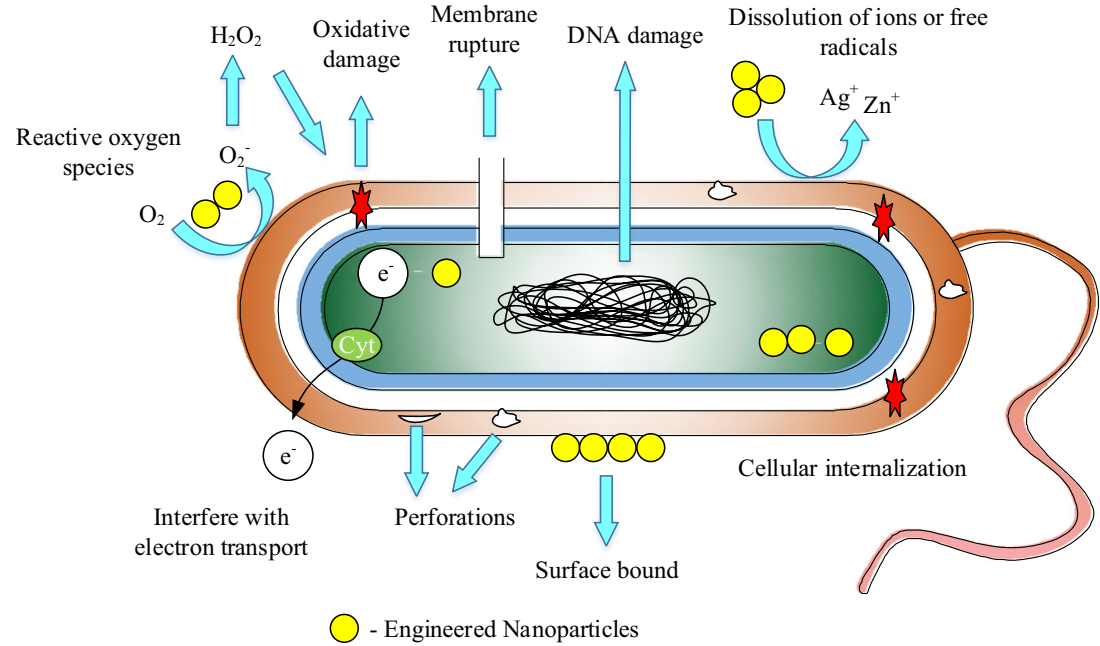


Fig. 22 Preparation of antibacterial cotton fiber

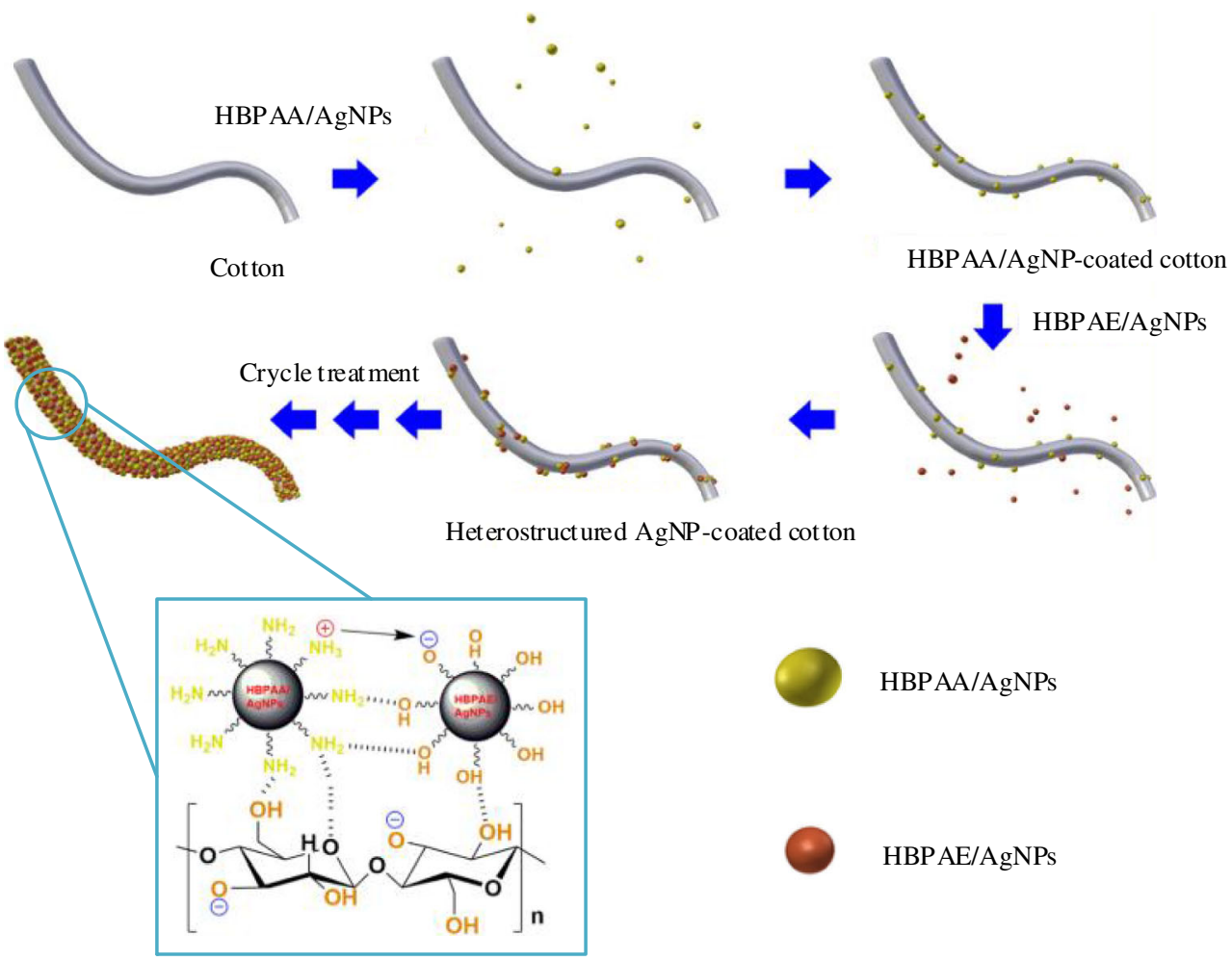

photocatalytic nanocomposite material a focus of research on sterilization materials.

\section{(1) Silver-based materials}

The method of silver nanoparticles inactivating bacteria is shown in Fig. 21, including

a) Release $\mathrm{Ag}^{+}$. Silver ions directly act on cell enzymes and proteins, affect cell respiration and ion transmembrane movement, and ultimately lead to cell death [143]

b) Produce reactive oxygen species (ROS). Abnormal accumulation of ROS induces oxidative stress; ROS attack cell membranes, react with fats, proteins and nucleic acids, and hinder cell transmission systems, leading to DNA damage and cell death [144]

c) Direct contact with cell membrane and destroy its cell integrity

d) Change the permeability of the cell membrane. Silver nanoparticles can accumulate on the cell membrane, combine with the cell membrane, attack the phospholipid bilayer of the cell membrane, and form bumps and holes on the cell membrane, leading to the loss of material in the cell [145]

e) Bind to proteins and interfere with their normal functions. Silver nanoparticles change the expression of envelope and heat shock protein, affect cell membrane function, and ultimately lead to cell death [146].
Zhang et al. [147] used gelatin as a stabilizer to synthesize graphene oxide-nanosilver antibacterial material at room temperature. When the concentration of this material was $10 \mathrm{ppm}$, the inhibition rate for E. coli reached 99.9\%. Xu et al. [148] used hyperbranched poly(amidoamine) (HBPAA) and hyperbranched poly(amine-ester)(HBPAE)-functionalized silver nanoparticles (AgNPs) to self-assemble synergistically and prepare antibacterial cotton fibers. The preparation is shown in Fig. 22. Bilal et al. [149] used biogenic AgNPs from Convolvulus arvensis extract and chitosan to develop ecofriendly novel conjugates with antimicrobial, antibiofilm, and anticancer potentialities. They used Staphylococcus aureus and E. coli as experimental subjects, and the number of colonies added with the conjugate was remarkably lower than that without the conjugate.

(2) $\mathrm{TiO}_{2}$ photocatalytic nanocomposite materials

$\mathrm{TiO}_{2}$ photocatalytic nanocomposite materials are not widely used in cutting fluid sterilization, but they are mainly used in equipment for purifying air and water. $\mathrm{TiO}_{2}$ has three crystal types, namely, anatase, rutile, and brookite, among which anatase $\mathrm{TiO}_{2}$ has a better photocatalytic effect. $\mathrm{TiO}_{2}$ is an $\mathrm{n}$ type semiconductor with band energy of $3.2 \mathrm{eV}$, which is equivalent to the energy of a $387.5 \mathrm{~nm}$ photon. Therefore, under light greater than its band energy, the valence electrons of the $\mathrm{TiO}_{2}$ semiconductor will be excited to the conduction band, thereby generating photoelectrons $\left(\mathrm{e}^{-}\right)$in the valence band and holes $\left(\mathrm{h}^{+}\right)$in the conduction band: 


$$
\mathrm{TiO}_{2} \rightarrow e^{-}+h^{+}
$$

Holes have a strong ability to obtain electrons, which can deprive the organic matter on the surface of the particles or electrons in the system to activate and oxidize substances that do not originally absorb light. In the system of water and air, $\mathrm{TiO}_{2}$ can undergo the following series of chemical reactions under the irradiation of sunlight, especially UV:

$$
\begin{aligned}
& \mathrm{OH}^{-}+h^{+} \rightarrow \cdot \mathrm{OH} \\
& \mathrm{H}_{2} \mathrm{O}+h^{+} \rightarrow \cdot \mathrm{OH}+\mathrm{H}^{+} \\
& \mathrm{O}_{2}+e^{-} \rightarrow \cdot \mathrm{O}_{2}^{-} \\
& \cdot \mathrm{O}_{2}^{-}+\mathrm{H}_{2} \mathrm{O} \rightarrow \cdot \mathrm{OOH}+\mathrm{OH}^{-} \\
& 2 \cdot \mathrm{OOH} \rightarrow \mathrm{H}_{2} \mathrm{O}_{2}+\mathrm{O}_{2} \\
& \cdot \mathrm{OOH}+\mathrm{H}_{2} \mathrm{O}+e^{-} \rightarrow \mathrm{H}_{2} \mathrm{O}_{2}+\mathrm{OH}^{-} \\
& \mathrm{H}_{2} \mathrm{O}_{2}+e^{-} \rightarrow \cdot \mathrm{OH}+\mathrm{OH}^{-} \\
& \cdot \mathrm{OH}+\cdot \mathrm{OH} \rightarrow \mathrm{H}_{2} \mathrm{O}_{2}
\end{aligned}
$$

The generated active hydroxyl $(\cdot \mathrm{OH})$, superoxide ion $\left(\cdot \mathrm{O}^{2-}\right)$, perhydroxyl $(\cdot \mathrm{OOH})$ and hydrogen peroxide $\left(\mathrm{H}_{2} \mathrm{O}_{2}\right)$ can interact with biological macromolecules (such as lipids, proteins, enzymes, and nucleic acid macromolecules). They directly destroy the structure of biological cells through a series of chain oxidation reactions, thereby playing a role of sterilization, mildew prevention, and deodorization. Its bactericidal efficacy is much higher than that of traditional bactericides such as chlorine, hypochlorite and hydrogen peroxide [150]. For example $\cdot \mathrm{OH}$ can attack the unsaturated bonds of organic matter or extract its $\mathrm{H}$ atoms:

$\mathrm{R}_{3} \mathrm{CH}+\cdot \mathrm{OH} \rightarrow \mathrm{R}_{3} \mathrm{C} \cdot+\mathrm{H}_{2} \mathrm{O}$

The reaction will generate new free radicals $\left(\mathrm{R}_{3} \mathrm{C} \cdot\right)$, trigger a chain reaction, and cause bacterial protein mutation and lipid decomposition, thereby killing bacteria and decomposing them into nontoxic small molecules. Selma et al. [151] prepared iron-doped $\mathrm{TiO}_{2}$ films. Studies have shown that as the amount of iron doped increases, the antibacterial activity against E. coli and S. aureus gradually increases. Rizzo et al. [152] synthesized an optimized nitrogen-doped $\mathrm{TiO}_{2}$. They conducted experiments on gram-negative bacteria, and the results showed that the sterilization rate reached almost $100 \%$ after optimal irradiation for $60 \mathrm{~min}$.

Nanocomposite materials have the advantages of aging resistance, high temperature resistance, excellent comprehensive performance, stable antibacterial properties, and longevity. They represent a new type of sterilization composite material. Nanocomposite materials are sterilized by active oxygen, active hydroxyl, and superoxide ion. This method has no pollution and is a green sterilization method. At present, nanocomposite sterilization technology is not widely used in cutting fluid sterilization, but it is expected to become an important research content in the field of cutting fluid sterilization with the advancement of science and technology.

\subsection{2 $\mathrm{O}_{3}$ sterilization technology}

$\mathrm{O}_{3}$ is a strong oxidant and can effectively inactivate microorganisms. The principle of $\mathrm{O}_{3}$ sterilization is to use the extremely unstable characteristics of the three oxygen atoms that make up $\mathrm{O}_{3}$ and release new ecological oxygen when decomposed. The new ecological oxygen has a strong oxidizing ability. It will oxidize the enzymes needed to decompose glucose inside bacteria, which will inactivate the bacteria and die. The reaction formula is

$\mathrm{O}_{3} \rightarrow \mathrm{O}_{2}+\mathrm{O}$

$\mathrm{O}_{3}$ sterilization technology has the advantages of thorough sterilization. The application of $\mathrm{O}_{3}$ sterilization technology in cutting fluid is becoming mature. Liu et al. [153] adopted the electro flocculation $/ \mathrm{O}_{3}$ sterilization process as the treatment method for cutting fluid repair. The $\mathrm{O}_{3}$ aeration time was 10 min, and the sterilization rate reached $99.96 \%$. Ma et al. [142] developed an $\mathrm{O}_{3}$ treatment technology using an air dielectric barrier discharge plasma system. The researchers added K. pneumoniae, Pseudomonas aeruginosa, E. coli, and Proteus vulgaris to the water-soluble cutting fluid for sterilization experiments. The results showed that more than $99.9 \%$ of the bacteria were eliminated. However, $\mathrm{O}_{3}$ sterilization technology also has problems that need to be solved urgently, such as the immature detection and control technology of $\mathrm{O}_{3}$ and the corrosive effect of residual $\mathrm{O}_{3}$ on transportation pipelines.

\subsubsection{UV sterilization technology}

UV sterilization technology means that UV rays with a wavelength in the range of $240-280 \mathrm{~nm}$ destroy the molecular structure of DNA or RNA in bacteria and viruses, causing growth cell death or regenerative cell

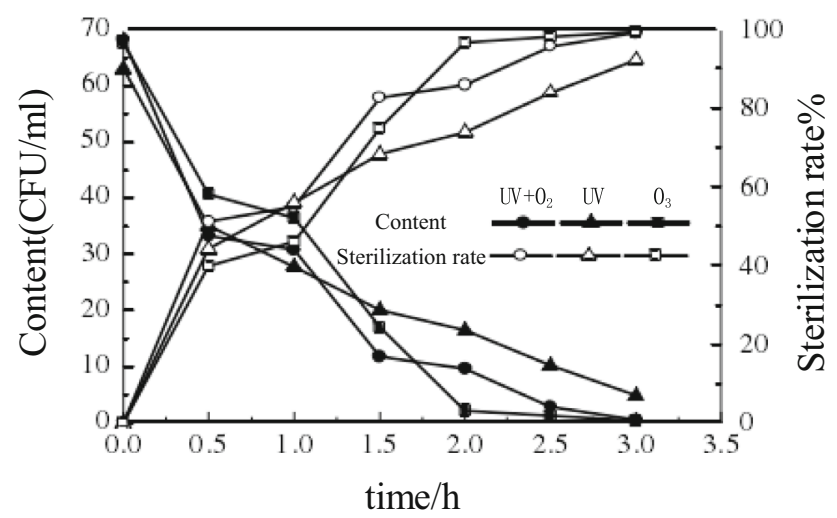

Fig. 23 Sterilization rate of different methods of processing waste cutting fluid 
Table 12 Characteristics of microbial removal technology

\begin{tabular}{llll}
\hline Methods & Sterilization performance & Environmental performance & Economic performance \\
\hline Nanocomposite & Good & Marginal & Marginal \\
$\mathrm{O}_{3}$ & Good & Marginal & Good \\
$\mathrm{UV}$ & Marginal & Marginal & Good \\
$\mathrm{UV} / \mathrm{O}_{3}$ & Good & Marginal & Good \\
$\mathrm{UV} \mathrm{O}_{2}$ & Good & Good & Good \\
\hline
\end{tabular}

death, and achieving sterilization and disinfection. The application of UV sterilization technology in cutting fluids was proposed by Rober et al. [154] as early as 1983, and many researchers have conducted related studies since then. Johnson et al. [155] implanted Pseudomonas fluorescens into metal cutting fluids irradiated them with a $6 \mathrm{~W}$ glass UV lamp and found that P. fluorescens in the cutting fluid was reduced by $99 \%$ within $60 \mathrm{~min}$. Saha et al. [156] added different concentrations of $P$. fluorescens, Pseudomonas oleophila subsp. oleophila, and Mycobacterium chelonae to the semisynthetic unused 5\% diluted metal cutting fluid sample. Under static and mixed agitation conditions, irradiation with a high-radiation-intensity $(192 \mu \mathrm{W} /$ $\left.\mathrm{cm}^{2}, 55 \mathrm{~W}\right) \mathrm{UV}$ lamp followed. Under static conditions, when exposed for $10 \mathrm{~min}$, only a $56 \%$ reduction for Pseudomonas and a $74 \%$ reduction for $M$. chelonae were observed. Under mixed agitation conditions, after 3 min of exposure, P. fluorescens, P. oleophila subsp. oleophila, and M. chelonae decreased by $98.8 \%, 98.9 \%$, and $82 \%$, respectively. There results showed that the combination of high-intensity UV rays and mixing can successfully eliminate bacteria and microorganisms in a short exposure time.

Compared with $\mathrm{O}_{3}$ sterilization technology, UV sterilization technology does not have any side effects on cutting fluid and equipment, and UV does not require storage and subsequent treatment. However, the degree of UV sterilization depends on the intensity and exposure time of UV rays and the resistance of microorganisms to UV rays. Sometimes when the UV light source is small or the cutting fluid needs to be processed more, problems such as insufficient light will occur, resulting in the incomplete elimination of microorganisms, which will cause secondary pollution of the cutting fluid. In addition, several researchers have found that microorganisms can repair radiation damage caused by UV rays, and the surviving microorganisms are more resistant to UV radiation [157].

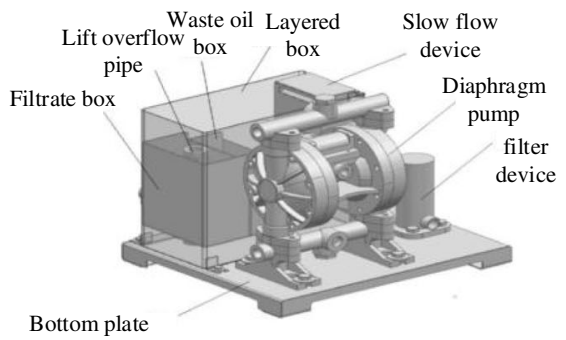

(a)

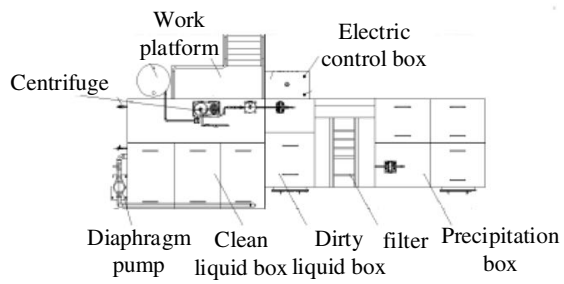

(b)

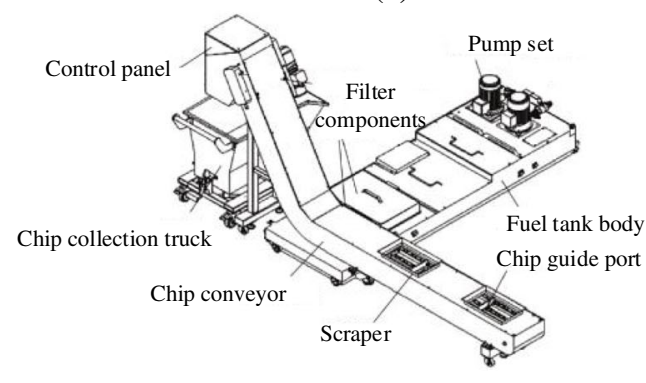

(c)

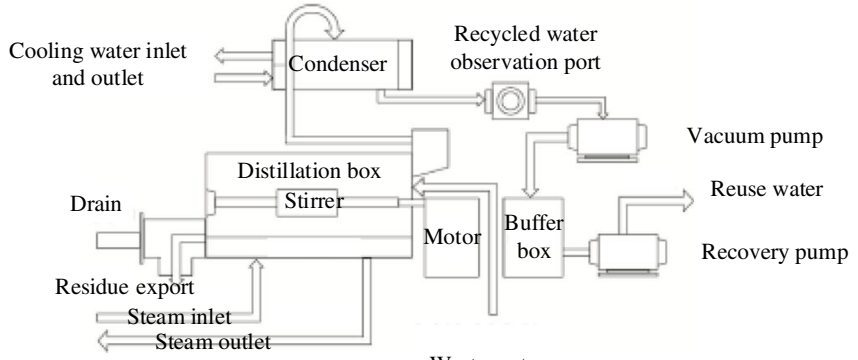

Waste water

(d)

Fig. 24 Equipment sketches: a Gravity separation waste cutting fluid recovery and treatment equipment. b Cutting fluid regeneration treatment system. c Decompression dehydration drying device. $\mathbf{d}$ Automatic chip removal filter system 
Table 13 Patented equipment composition and effects

\begin{tabular}{|c|c|}
\hline Patent numbers & Equipment composition and effects \\
\hline $\begin{array}{l}\text { CN201910216940.7 } \\
\quad[165]\end{array}$ & $\begin{array}{l}\text { Composition: The cutting fluid proportioning box is equipped with an oil-water separator, a deodorizer, a cutting fluid recovery } \\
\text { proportioning box, a cloth bag filter, a telecentric separator, a paper belt filter assembly, and a cloth bag filter. } \\
\text { Effect: Compact structure, simple and convenient operation, wide range of uses, high filtration efficiency and long service life. }\end{array}$ \\
\hline $\begin{array}{l}\mathrm{CN} 201821474755.5 \\
\quad[166]\end{array}$ & $\begin{array}{l}\text { Composition: Cutting fluid recovery tank, cutting fluid recovery pipe. One end of the liquid return pipe is connected with a } \\
\text { liquid return cover, the inside of the liquid return cover is clamped with a filter plate, and the side of the liquid return cover } \\
\text { close to the filter plate is clamped with a sealing ring. } \\
\text { Effect: Improve the stability of the filter plate installed inside the liquid return cover, and avoid the deflection of the filter plate } \\
\text { inside the liquid return cover. }\end{array}$ \\
\hline $\begin{array}{l}\text { CN201721868604.3 } \\
\quad[167]\end{array}$ & $\begin{array}{l}\text { Composition: Sedimentation tank, centrifuge, screw conveyor, waste adsorption device and oil slick filter device. The upper end } \\
\text { of the centrifuge has a feeding hopper, and the lower end has a solid discharge port and a liquid discharge port. A lifting pump } \\
\text { is provided in the sedimentation tank. } \\
\text { Effect: The waste adsorption device can effectively remove the waste contained in the cutting liquid. The oil slick filter device } \\
\text { can remove the slick contained in the cutting liquid. This avoids the deterioration of the liquid, and the performance of the } \\
\text { recovered liquid is relatively good. }\end{array}$ \\
\hline $\begin{array}{l}\mathrm{CN} 201420162367.9 \\
\quad[168]\end{array}$ & $\begin{array}{l}\text { Composition: Shell, magnetic roller and soft roller, curved pallet, iron chip cutting fluid separation device, cutting fluid filter } \\
\text { device. } \\
\text { Effect: The cutting fluid recovery device has better cutting fluid recovery quality and higher recovery rate. }\end{array}$ \\
\hline $\begin{array}{l}\mathrm{CN} 201720047919.5 \\
\quad[169]\end{array}$ & $\begin{array}{l}\text { Composition: Cutting fluid release device, cutting table, cutting fluid first collecting device, collector, cutting fluid second } \\
\text { collecting device. } \\
\text { Effect: The cutting fluid recovery mechanism can effectively and timely collect and recover the used cutting fluid, and can } \\
\text { reduce the number of cleanings and improve the efficiency of metal processing. }\end{array}$ \\
\hline
\end{tabular}

\subsection{4 $\mathrm{UV} / \mathrm{O}_{3}$ and $\mathrm{UV} / \mathrm{O}_{2}$ synergistic sterilization technology}

The use of $\mathrm{O}_{3}$ and UV sterilization technology can only have a strong elimination effect on the unstable microbes in the cutting fluid. However, some highly stable microorganisms, which cannot be removed by using $\mathrm{O}_{3}$ or UV irradiation alone, remain in the cutting fluid. For this reason, the $\mathrm{UV} / \mathrm{O}_{3}$ synergistic sterilization technology came into being. Wu et al. [158] studied the performance of $\mathrm{UV} / \mathrm{O}_{3}$ combined sterilization and found that $\mathrm{UV} / \mathrm{O}_{3}$ is more effective than $\mathrm{UV}$ or $\mathrm{O}_{3}$ sterilization alone, and the combined sterilization's efficiency can reach $99.99 \%$ with the increase of UV radiation intensity and $\mathrm{O}_{3}$ dosage.

However, the $\mathrm{UV} / \mathrm{O}_{3}$ synergistic sterilization technology still has several unresolved problems such as the risk of corrosion to pipelines and other equipment, and insufficient UV radiation. Researchers have also made relevant explorations on these issues. Shen et al. [159] used $\mathrm{UV} / \mathrm{O}_{2}$ synergistic sterilization technology to treat aluminum alloy waste cutting fluid and compared the sterilization effects of $\mathrm{UV}, \mathrm{UV}+\mathrm{O}_{2}$, and $\mathrm{O}_{3}$ on cutting fluid. The experiment found that after $3 \mathrm{~h}$ of treatment, the UV sterilization rate was $92.4 \%$, the $\mathrm{UV}+\mathrm{O}_{2}$ sterilization rate was $99.27 \%$, and the $\mathrm{O}_{3}$ sterilization rate was 99.5\%. The experimental results are shown in Fig. 23. According to the problems of $\mathrm{O}_{3}$ and considering the concept of green environmental protection, $\mathrm{UV} / \mathrm{O}_{2}$ synergistic sterilization technology to process aluminum alloy cutting fluid can quickly and effectively kill bacteria while ensuring the health of operators.
The microorganisms in the cutting fluid are harmful to organisms and the environment, and the main reason for the replacement of the cutting fluid. While we are starting to remove contaminants such as metal chips and miscellaneous oils, we must also focus on sterilization methods. The characteristics of microbial removal technology are shown in Table 12. According to the concept of environmental protection, the $\mathrm{UV} / \mathrm{O}_{2}$ synergistic sterilization is an efficient, lowhazard green sterilization technology.

\subsection{Existing integrated circulating purification and regeneration equipment}

In addition to discharging the waste cutting fluid into the natural environment, removing impurities and recycling the waste cutting fluid that has a simple composition can be considered. Wang et al. [160] designed and developed a set of waste cutting fluid recovery and treatment equipment using the gravity separation treatment method, as shown in Fig. 24(a). The waste liquid treatment efficiency of this equipment was about $17 \mathrm{~L} / \mathrm{min}$. The processed cutting waste fluid met the national waste fluid discharge standards. $\mathrm{Wu}$ [161] designed a cutting fluid regeneration treatment system, as shown in Fig. 24(b). The oil content of the cutting fluid processed by the system was less than $0.5 \%$, the solid particle accuracy was less than 5 microns, and the $\mathrm{pH}$ range was 5 to 14 , which can be directly recycled. Fan et al. [162] designed and improved the decompression dehydration drying device, as shown in Fig. 24(c). The average removal rate of the total suspended solids in the wastewater was over $99.38 \%$, and the operating cost 
was 2.14 hundred/ton. Wang et al. [163] developed an integrated, low-cost, and high-control precision automatic chip removal filter system for computer numerical control machine tools through multistage filtration, oil-water separation, and intelligent control. It can be used in various processing environments, as shown in Fig. 24(d). The system avoids waste chips splashing, reduces air pollution caused by cutting fluid volatilization, and realizes recycling of cutting waste fluid. $\mathrm{Li}$ et al. [164] used alcohol amine to neutralize the acidic substances produced by microorganisms in the cutting fluid, combined with the use of a bactericide, and then concentrated the waste cutting fluid with a vacuum decompression distillation equipment to realize the regeneration of the waste cutting fluid. According to the need to treat $10 \mathrm{t}$ of waste liquid per month, the scheme can save 454000 per a year.

In addition, researchers have many invented devices that remove impurities and recycle the cutting fluid. These inventive devices avoid the discharge of cutting waste fluid, reduce the pollution of cutting fluid to organisms and the environment, and reduce the waste of resources. Patented equipment composition and effects are shown in the Table 13. The existing integrated circulating purification and regeneration equipment purifies the waste cutting fluid based on the impurity removal technology; thus, the cutting fluid is recycled, which avoids the waste of resources to a certain extent and saves the production cost of the enterprise.

\section{Conclusions}

Aiming at the pollution problem of cutting fluid in metal processing, this study carries out a systematic review. Below are key research findings:

(1) Organic additives and biodegradable vegetable base oils are the main components of eco-friendly cutting fluids. First, the polar groups of amide and boric acid organic rust inhibitors have a greater affinity for metals, and can be firmly adsorbed on the metal surface to form a directional adsorption layer; through chemical modification of diethanolamine and dodecenyl succinic acid, the antirust performance of organic additives is further improved. Then, the esterification reaction of ethylene glycol and formic acid, and the condensation reaction of guanidine hydrochloride, diethylenetriamine and other amine group-containing monomers can obtain additives with excellent bactericidal properties. Second, the dodecanoic acid diethanolamide borate obtained by the esterification condensation reaction of fatty acid and methanol, and the azeotropic principle synthetic alcohol amine borate all have good extreme pressure performance. Finally, due to the excellent physical and chemical properties of saturated fatty acids, vegetable oils have become the primary choice for cutting fluid base oils. Among them, the high fatty acid content of soybean oil has become the focus of research. In addition, nanoparticles can further improve the lubricating properties of vegetable oils.

(2) The process characteristics of cutting fluid reduction technology (dry cutting, solid lubrication, cryogenic cooling, MQL, and NMQL) are complex and different. Compared with dry cutting and solid lubrication, MQL and NMQL can effectively reduce the cutting temperature. Moreover, it can increase the viscosity of lubricating oil, and the thickness of oil film can keep tool/workpiece interface completely separated. The carrying capacity is improved. Compared with lowtemperature cooling, MQL and NMQL have excellent lubrication performance and economy. Compared with MQL nano particles can remarkably improve the thermal conductivity, permeability, and antiwear properties of the lubricating fluid, and the thermal-mechanical level of NMQL decreases faster, which can not only slow down the wear of the tool but also help the workpiece obtain the desired surface quality.

(3) Cutting fluid is facing the severe challenge of heavy pollution and difficult circulation. For the treatment of oil mist, the best method is the chemical mist reduction method. Among them, the organic antimisting additive has the advantages of environmental protection and quick response, which has become the best choice. From the perspective of COD removal efficiency and environmental protection, coagulation, oxidation, biological and combined treatment methods are all excellent in treating waste cutting fluid. However, for waste cutting fluid with complex impurities, the combined treatment method is an efficient waste cutting fluid treatment method. Then, for the removal of microorganisms, considering factors such as sterilization and environmental protection, the $\mathrm{UV} / \mathrm{O}_{2}$ synergistic sterilization is an efficient, low-hazard technique. Finally, the existing recycling purification and regeneration equipment, based on the lightweight, integrated design principle, combined with impurity removal technique, has achieved initial results in cutting fluid recovery and capital reduction.

To promote the engineering application and development of eco-friendly cutting fluids and its circulating purification requires the joint efforts of researchers. This review is expected to provide theoretical basis and technical support for researchers to study the green clean processing of metal processing.

\section{Prospects}

According to the previous systematic review, future research directions may focus on the following topics: 


\section{(1) Amino acid additives}

Amino acids can be obtained through protein hydrolysis and completely decomposed in the natural environment, which makes them have the advantages of eco-friendly, low price, and wide sources. In recent years, studies have found lone pairs of electrons on $\mathrm{S}$ and $\mathrm{N}$ in amino acid molecules that form surface complexes with empty orbitals such as $\mathrm{Fe}$ and $\mathrm{Al}$ and adsorb to the metal surface, forming a dense adsorption film to prevent metal corrosion effectively. In addition, the surface activity of amino acids enables adsorbing on the more active places on the metal/solution interface, resulting in an increase in the activation energy of the interface reaction and a change in the electrical double layer structure of the interface, which strongly blocks the cathode or anode in the conjugation reaction of the corrosion battery. These characteristics will sharply reduce the rate of metal corrosion. Therefore, amino acid can be used as a eco-friendly antirust additive. In addition, with the development of quantum chemistry, molecular design, computer simulation and quantum chemistry calculations for amino acid additives can be carried out, which can further explore the antirust mechanism of amino acids and modify the molecules of amino acids to enhance their antirust performance.

\section{(2) Self-adapting jet parameter supply system}

During machining, the airflow field generated by the rotation of the tool will hinder the cutting fluid entering the machining area, the frictional heat generated by machining will accumulate over time, and the constant supply of cutting fluid cannot appropriately match the corresponding cooling requirements. Aiming at the above problems, a self-adapting supply system for jet parameters is proposed. This kind of supply system uses information collection equipment such as sensors and vision systems to collect data on the movement state of the tool, the temperature of the processing area, and the depth of processing. The data are transmitted to the machine tool control center by Bluetooth and other communication equipment, and the machine tool control center analyzes and processes the received data and feeds them back to the supply system, which realizes the interconnection between the machine tool and supply system. First, this kind of supply system controls the movement of the nozzle to synchronize with the movement of the tool according to the movement state of the tool. Second, this kind of supply system adjusts the jet parameters such as target distance and supply angle according to the airflow field generated by the rotation of the tool and the cavity of the workpiece. Finally, this kind of supply system adjusts jet parameters such as liquid supply flow rate and gasliquid ratio according to the force and heat generated by the processing.
(3) Complete database system of the processing conditionscutting fluid

In the field of metal processing, multiple processing methods such as grinding, milling, and drilling are available. The cooling and lubrication requirements of different processing methods are related to factors such as the mechanical properties of the workpiece, the material of the tool, and the amount of cutting, which requires the selection of appropriate cutting fluid and cutting fluid supply volume under different processing conditions. If the selected cutting fluid and supply volume do not meet the requirements of cooling and lubrication, it will cause waste of cutting fluid or damage the surface integrity of the workpiece. The processing conditions (processing methods, mechanical properties of the workpiece, material of the tool, and cutting amount) can be matched with the type of cutting fluid and the amount of cutting fluid supply volume, that is, each processing condition has a cutting fluid and cutting fluid supply volume corresponding to it, and the processing condition-cutting fluid database is established. For each processing condition, the intelligent management system can extract and mine the corresponding data configuration from the database, which makes the processing more efficient and the resource allocation more accurate.

Abbreviations BOD, Biochemical oxygen demand; COD, Chemical oxygen demand; MQL, Minimum quantity lubrication; ZDDP, Zinc dialkyl dithiophosphates; BTA, Benzotriazole; NMQL, Nano fluid minimum quantity lubrication; TOC, Total organic carbon; SD, Sawdust; OGSD, Oleic acid grafted sawdust; PES, Poly (ether sulfone); PAC, Poly aluminum chloride; PFS, Poly ferric sulfate; EC, Electrochemical coagulation; EO, Electrochemical oxidation; MBR, Membrane bioreactor; UASB, Up-flow anaerobic sludge bed; UV, Ultraviolet; ROS, Reactive oxygen species; HBPAA, Hyperbranched poly(amidoamine); HBPAE, Hyperbranched poly(amine-ester); AgNPs, Functionalized silver nanoparticles

Acknowledgements This study was financially supported by: the National Key Research and Development Program of China (Grant No. 2020YFB2010500), the National Natural Science Foundation of China (Grant Nos. 51975305 and 51905289), the Major Science and Technology Innovation Engineering Projects of Shandong Province (Grant No. 2019JZZY020111), the Natural Science Foundation of Shandong Province (Grant Nos. ZR2020KE027, ZR2020ME158 and ZR2019PEE008) and the Applied Basic Research Youth Project of Qingdao science and technology plan (Grant No. 19-6-2-63-cg).

Author contribution Xifeng Wu: investigation, writing (originaldraft), and writing (review and editing);

Changhe Li: conceptualization, formal analysis, validation, and writing (review and editinh);

Zongming Zhou: formal analysis, validation;

Xiaolin Nie: conceptualization, validation;

Yun Chen: formal analysis, conceptualization;

Yanbin Zhang: formal analysis, validation, and writing (review and editing):

Huajun Cao: conceptualization, formal analysis;

Bo Liu: conceptualization, validation;

Naiqing Zhang: conceptualization, validation; 
Zafar Said: formal analysis, validation;

Sujan Debnath: formal analysis, conceptualization;

Muhammad Jamil: formal analysis, validation;

Hafiz Muhammad Ali: conceptualization, validation ;

Shubham Sharma: formal analysis, validation.

Data availability Data sharing is not applicable to this article.

\section{Declarations}

The authors declare that this manuscript was not submitted to more than one journal for simultaneous consideration. Also, the submitted work is original and has not been published elsewhere in any form or language.

Consent to participate and for publication The authors declare that they participated in this paper willingly and the authors declare to consent to the publication of this paper.

Conflict of interest The authors declare no competing interests.

\section{References}

1. Majumdar S, Das P, Kumar S, Roy D, Chakraborty S (2020) Evaluation of cutting fluid application in surface grinding. Measurement 169:108464. https://doi.org/10.1016/j. measurement.2020.108464

2. Singh R (2020) Progress of environment friendly cutting fluids/ solid lubricants in turning-A review. Mater Today: Proc 37(P2): 3577-3580

3. Yuliia Z, Maryna B, Valeriy K, Antonina M (2021) Technological and Ecological Aspects of Disposal of Spent Cutting Fluids. J Ecol Eng 22(4):207-212

4. Shokrani A, Dhokia V, Newman ST (2012) Environmentally conscious machining of difficult-to-machine materials with regard to cutting fluids. Int J Mach Tools Manuf 57:83-101

5. Yuan SM, Hou XB, Wang L, Chen BC (2018) Experimental Investigation on the Compatibility of Nanoparticles with Vegetable Oils for Nanofluid Minimum Quantity Lubrication Machining. Tribol Lett 66(3):106

6. Canter N (2019) Metalworking fluids: The quest for bioresistance. Tribol Lubr Technol 75(3)

7. Alimardanov KM, Sadygov OA, Babaev NR, Ismailova SI, Sultanova SA (2018) N-Substituted Aminomethoxybicyclo [2.2.1] heptanols and Their Antimicrobial Activity in Lubricating Fluids and Oils. Russ J Org Chem 54(3):382-392

8. Wang XM, Li CH, Zhang YB, Ding WF, Yang M, Gao T, Cao HJ, Xu XF, Wang DZ, Said Z, Debnath S, Jamil M, Ali HM (2020) Vegetable oil-based nanofluid minimum quantity lubrication turning: Academic review and perspectives. J Manuf Process 59:76-97

9. Yin QG, Li CH, Dong L, Bai XF, Zhang YB, Yang M, Jia DZ, Li RZ, Liu ZQ (2021) Effects of Physicochemical Properties of Different Base Oils on Friction Coefficient and Surface Roughness in MQL Milling AISI 1045. Int J Pr Eng Man-GT. https://doi.org/10.1007/s40684-021-00318-7

10. Zhang YB, Li CH, Jia DZ, Zhang DK, Zhang XW (2015) Experimental evaluation of $\mathrm{MoS}_{2}$ nanoparticles in jet MQL grinding with different types of vegetable oil as base oil. J Clean Prod 87:930-940

11. Chen Q, Wang X, Wang Z, Liu Y, You T (2013) Preparation of water-soluble nanographite and its application in water-based cutting fluid. Nanoscale Res Lett 8(1):52
12. Wang W, Han DY, Jin Y, Li DD, Cao ZB, Song MH (2017) Research Progress and Development Trend of Cutting Oil. Contemp Chem Ind 46(2):336-338+346. https://doi.org/10. 3969/j.issn.1671-0460.2017.02.042

13. Wang YG, Li CH, Zhang YB, Yang M, Li BK, Dong L, Wang J (2018) Processing Characteristics of Vegetable Oil-based Nanofluid MQL for Grinding Different Workpiece Materials. Int J Pr Eng Man-GT 5(2):327-339. https://doi.org/10.1007/s40684018-0035-4

14. Li BK, Li CH, Zhang YB, Wang YG, Jia DZ, Yang M, Zhang NQ, Wu QD, Han ZG, Sun K (2017) Heat transfer performance of MQL grinding with different nanofluids for Ni-based alloys using vegetable oil. J Clean Prod 154:1-11. https://doi.org/10.1016/j. jclepro.2017.03.213

15. Elinski MB, Lamascus P, Zheng L, Jackson A, Carpick RW (2020) Cooperativity Between Zirconium Dioxide Nanoparticles and Extreme Pressure Additives in Forming Protective Tribofilms: Toward Enabling Low Viscosity Lubricants. Tribol Lett 68(4). https://doi.org/10.1007/s11249-020-01346-1

16. Saini V, Bijwe J, Seth S, Ramakumar SSV (2020) Interfacial interaction of PTFE sub-micron particles in oil with steel surfaces as excellent extreme-pressure additive. J Mol Liq 325:115238. https://doi.org/10.1016/J.MOLLIQ.2020.115238

17. Somashekaraiah R, Suvin PS, Gnanadhas DP, Kailas SV, Chakravortty D (2016) Eco-Friendly, Non-Toxic Cutting Fluid for Sustainable Manufacturing and Machining Processes. Tribol Online 11(5):556-567

18. Laopaiboon L, Phukoetphim N, Vichitphan K, Laopaiboon P (2008) Biodegradation of an aldehyde biocide in rotating biological contactors. World J Microbiol Biotechnol 24(9):1633-1641

19. Groot AD, Geier J, Flyvholm MA, Lensen G, Coenraads PJ (2010) Formaldehyde-releasers: relationship to formaldehyde contact allergy. Metalworking fluids and remainder. Part 1. Contact Dermat 63(3):129-139. https://doi.org/10.1111/j.16000536.2010.01714.x

20. Zhang HJ, Gao Y, Ma XD, Geng NB, Zhang YC, Chen JP (2013) Research advances in analytical methods, environmental behaviors and toxic effects of short chain chlorinated paraffins (SCCPs). Sci Sin(Chimica) 43(03):255-264

21. Spikes H (2004) The History and Mechanisms of ZDDP. Tribol Lett 17(3):469-489

22. Bukowski JA (2003) Review of respiratory morbidity from occupational exposure to oil mists. Appl Occup Environ Hyg 18(11): 828-837

23. Picciotto S, Peters A, Eisen EA (2015) Hypothetical Exposure Limits for Oil-Based Metalworking Fluids and Cardiovascular Mortality in a Cohort of Autoworkers: Structural Accelerated Failure Time Models in a Public Health Framework. Am J Epidemiol 181(8):563-570

24. Stear MA (2003) Controlling Health Risks from Workplace Exposure to Metalworking Fluids in the United Kingdom Engineering Industry. Appl Occup Environ Hyg 18(11):877-882

25. Bhaumik S, Paleu V, Sharma S, Dwivedi S, Borkar S, Kamaraj M (2020) Nano and micro additivated glycerol as a promising alternative to existing non-biodegradable and skin unfriendly synthetic cutting fluids. J Clean Prod 263:121383. https://doi.org/10.1016/j. jclepro.2020.121383

26. Sultan AZ, Sharif S, Kurniawan D (2014) Examining the Effect of Various Vegetable Oil-Based Cutting Fluids on Surface Integrity in Drilling Steel - A Review. Adv Mater Res 845:809-813

27. Zhou H, Chen YX, Chen WN, Zhou XW, Rong Z (2008) Synthesis and Antirust Performance Study on Dodecencylsuccinic Acid Diethanolamide. Technol Dev Chem Ind 37(02):12-14. https://doi.org/10.3969/j.issn.1671-9905. 2008.02.005 
28. Gan WL, Chen YM, Li X, Yi SZ, Zhang Y, Yang J (2019) Application of Modified Dodecenyl Succinic Acid in Semisynthetic Cutting Fluid. Lubr Eng 44(6):132-137

29. Liu J, Liu W, Zhou HY (2014) Preparation and Application of Environmental Friendly Water Soluble Corrosion Inhibitor. Lubr Eng 39(1):119-124

30. Wang YJ, Zhong JC, Wang HZ (2013) Synthesis of Triethanolamine Borate and Evaluation of Its Antirust Performance. Mater Protect 46(11):29-31

31. Yang HG, Zhang J, Ye M (2011) Research on the Performance of an Eco-Friendly Nitrogen Organic Boric Acid Ester Antirust Additive. Adv Mater Res 399-401:1348-1351

32. Sonogi K, Nabeshima A (2008) Antirust composition. EP05710526A.

33. Karol TJ, Donnelly SG, Stunkel BW (1997) Synergistic Rust Inhibitors and Lubricating Composition. US08619054.

34. Zhang XY, Ma L, Hao J, Wang HL (2008) Study on the synthesis and bactericidal performance of water-based cutting fluid bactericide. Fine Special Chem 16(5):15-16

35. Ezzat H, Nagy S, Shawky ES, Tarek F, Yasser A (2018) Synthesis of antibacterial additive for metal working fluids application. MATEC Web Conf 162. https://doi.org/10.1051/matecconf/ 201816205011

36. Wang XF (2017) Synthesis and Performance Evaluation of Waterbased Cutting Fluid Bactericide. Technol Dev Chem Ind 46(06): 26-28

37. Curtis MA (2010) Antimicrobial Composition. US11426825.

38. Pohlman J (2010) Cold Temperature Stable Biocide Composition. US12731403.

39. Xia E, Dobie AK, Denick J (2009) Antimicrobial Composition and Uses There of. US10852460.

40. Yuan B, Yi SZ, Du TY (2015) Development of Twelve Acid Diethanolamide Boric Acid Ester and Its Application in Semisynthetic Cutting Fluid. Lubr Eng 40(12):99-102. https://doi. org/10.3969/j.issn.0254-0150.2015.12.019

41. Meng XT, Huang W, Cong YF, Liu ZJ (2015) Preparation of Alcohol Amine Borate Antiwear Additive. Contemp Chem Ind 44(09):2113-2115. https://doi.org/10.3969/j.issn.1671-0460. 2015.09.019

42. Teramoto K, Hirata I, Maruyama T (2009) WaterSolubleWorkingfluid. JP2009059085W.

43. Gao T, Li CH, Zhang YB, Yang M, Jia DZ, Jin T, Hou YL, Li RZ (2019) Dispersing mechanism and tribological performance of vegetable oil-based CNT nanofluids with different surfactants. Tribol Int 131:51-63

44. Nguyen DN (2003) Water-Dispersible Lubricating Blend for Metal Working Processing. US10219919.

45. Li BK, Li CH, Zhang YB, Wang YG, Yang M, Jia DZ, Zhang NQ, Wu QD, Ding WF (2017) Numerical and experimental research on the grinding temperature of minimum quantity lubrication cooling of different workpiece materials using vegetable oilbased nanofluids. Int J Adv Manuf Technol 93(12-13):1971-1988

46. Liu GT, Li CH, Zhang YB, Yang M, Jia DZ, Zhang XP, Guo SM, Li RZ, Zhai H (2017) Process parameter optimization and experimental evaluation for nanofluid MQL in grinding Ti-6Al-4V based on grey relational analysis. Mater Manuf Process 33(09): 950-963

47. Abdalla HS, Patel S (2006) The performance and oxidation stability of sustainable metalworking fluid derived from vegetable extracts. J Eng Manuf 220(12):2027-2040

48. Lodhi APS, Kumar D (2020) Natural ingredients based environmental friendly metalworking fluid with superior lubricity. Colloids Surf A Physicochem Eng Asp A 613:126071. https:// doi.org/10.1016/j.colsurfa.2020.126071

49. Guo SM, Li CH, Zhang YB, Wang YG, Li BK, Yang M, Zhang XP, Liu GT (2017) Experimental evaluation of the lubrication performance of mixtures of castor oil with other vegetable oils in MQL grinding of nickel-based alloy. J Clean Prod 140:1060 1076. https://doi.org/10.1016/j.jclepro.2016.10.073

50. Bai XF, Li CH, Dong L, Yin QA (2019) Experimental evaluation of the lubrication performances of different nanofluids for minimum quantity lubrication (MQL) in milling Ti-6Al-4V. Int J Adv Manuf Technol 101(9-12):2621-2632

51. Li M, Yu TB, Zhang RC, Wang WS (2020) Study on the Milling Surface Quality of GH4169 Alloy Based on Graphene-Enhanced MQL Method. J Northeast Univ, Nat Sci 41(03):387-392

52. Zhang YB, Li CH (2020) Vegetable oil-based Nano-fluid Minimum Quantity Lubrication grinding mechanism and grinding force prediction model and experimental verification. J Mech Eng 56(09):44

53. Yang M, Li CH, Zhang YB, Jia DZ, Li RZ, Hou YL, Cao HJ (2019) Effect of friction coefficient on chip thickness models in ductile-regime grinding of zirconia ceramics. Int J Adv Manuf Technol 102(5-8):2617-2632

54. Yang M, Li CH, Zhang YB, Jia DZ, Li RZ, Hou YL, Cao HJ, Wang J (2019) Predictive model for minimum chip thickness and size effect in single diamond grain grinding of zirconia ceramics under different lubricating conditions. Ceram Int 45(12):1490814920

55. Yang M, Li CH, Zhang YB, Jia DZ, Zhang XP, Hou YL, Shen B, Li RZ (2018) Microscale bone grinding temperature by dynamic heat flux in nanoparticle jet mist cooling with different particle sizes. Mater Manuf Process 33(1-4):58-68

56. Mao C, Cai P, Yongle HU, Zhong Y, Zhang M (2020) Effect of laser-discrete-quenching on bonding properties of electroplated grinding wheel with AISI 1045 steel substrate and nickel bond. Chin J Aeronaut 34:79-89. https://doi.org/10.1016/j.cja.2020.09. 010

57. Li HN, Zhao YJ, Cao S, Chen H, Qi X, Sun X, Li C, Liu G (2021) Controllable generation of 3D textured abrasive tools via multiplepass laser ablation. J Mater Process Technol 295:117149. https:// doi.org/10.1016/J.JMATPROTEC.2021.117149

58. Yang YY, Gong YD, Li CH, Wen XL, Sun JY (2021) Mechanical performance of $316 \mathrm{~L}$ stainless steel by hybrid directed energy deposition and thermal milling process. J Mater Process Technol 291:117023. https://doi.org/10.1016/j.jmatprotec.2020.117023

59. Li HN, Wang JP, Wu CQ, Zhao YJ, Xu J, Liu XL, Zhu WQ (2020) Damage behaviors of unidirectional CERP in orthogonal cutting: A comparison between single-and multiple-pass strategies. Compos Part B 185:107774. https://doi.org/10.1016/j. compositesb.2020.107774

60. Klocke F, Eisenblätter G (1997) Dry Cutting. CIRP Ann-Manuf Technol 46:519-526. https://doi.org/10.1016/j.jmatprotec.2020. 117023

61. Jia DZ, Li CH, Zhang DK, Zhang YB, Zhang XW (2014) Experimental verification of nanoparticle jet minimum quantity lubrication effectiveness in grinding. J Nanopart Res 16(12):1-15

62. Wang CY, Xie YX, Qin Z, Lin HS, Yuan YH, Wang QM (2015) Wear and breakage of TiAlN- and TiSiN-coated carbide tools during high-speed milling of hardened steel. Wear 336-337:29-42

63. Wang W, Yao P, Wang J, Huang CZ, Zhu HT, Zou B, Liu HL, Yan JW (2016) Crack-free ductile mode grinding of fused silica under controllable dry grinding conditions - ScienceDirect. Int J Mach Tools Manuf 109:126-136

64. Tawakoli T, Azarhoushang B (2008) Influence of ultrasonic vibrations on dry grinding of soft steel. Int $J$ Mach Tools Manuf 48(14):1585-1591

65. Paul S, Chattopadhyay AB (1996) Determination and control of grinding zone temperature under cryogenic cooling. Int J Mach Tools Manuf 36(4):491-501 
66. Hu TC, Hu LT, Zhang YS (2012) Preparation of Composite Lubrication Structure and its Tribological Properties on 45\# Steel Surface. Tribology 32(01):14-20

67. Agarwal S, Rao PV (2007) Performance improvement of sic grinding using solid lubricants. Mach Sci Technol 11(1):61-79

68. Yildiz Y, Nalbant M (2008) A review of cryogenic cooling in machining processes. Int J Mach Tools Manuf 48(9):947-964

69. Yuan SM, Han WL, Zhu GY, Hou XB, Wang L (2019) Recent Progress on the efficiency increasing methods of minimum quantity lubrication technology in green cutting. J Mech Eng 55(05): 175-185

70. Zhao W, He N, Li L (2006) Friction and Wear Properties of WCCo Cemented Carbide Sliding Against Ti6Al4V Alloy in Nitrogen Gas. Tribology 26(05):439-442

71. Zhao YJ, Xu WH, Xi CZ, Liang DT, Li HN (2021) Automatic and accurate measurement of microhardness profile based on image processing. IEEE Trans Instrum Meas 70:1-9. https://doi.org/10. 1109/TIM.2021.3067191

72. Dong L, Li CH, Zhou FM, Bai XF, Gao W, Duan ZJ, Li XP, Lv XJ, Zhang FB (2021) Temperature of the 45 steel in the minimum quantity lubricant milling with different Judges. Int J Adv Manuf Technol 113(9-10):2779-2790

73. Kaynak Y, Tobe H, Noebe RD, Karaca HE, Jawahir IS (2014) The effects of machining on the microstructure and transformation behavior of NiTi Alloy. Scr Mater 74:60-63. https://doi.org/10. 1016/j.scriptamat.2013.10.023

74. Liu JY, Han RD, Zhang L, Guo HB (2007) Study on lubricating characteristic and tool wear with water vapor as coolant and lubricant in green cutting. Wear 262(3-4):442-452

75. Sadeghi MH, Haddad MJ, Tawakoli T, Emami M (2009) Minimal quantity lubrication-MQL in grinding of Ti-6Al-4V titanium alloy. Int J Adv Manuf Technol 44(5-6):487-500

76. Davim JP, Sreejith PS, Gomes R, Peixoto C (2006) Experimental studies on drilling of aluminium (AA1050) under dry, minimum quantity of lubricant, and flood-lubricated conditions. Proc Inst Mech Eng Part B 220(10):1605-1611

77. Wang YG, Li CH, Zhang YB, Yang M, Li BK, Jia DZ, Hou YL, Mao C (2016) Experimental evaluation of the lubrication properties of the wheel/workpiece interface in minimum quantity lubrication (MQL) grinding using different types of vegetable oils. $\mathrm{J}$ Clean Prod 127:487-499

78. Duan ZJ, Li CH, Ding WF, Zhang YB, Yang M, Gao T, Cao HJ, Xu XF, Wang DZ, Mao C, Li HN, Kumar GM, Said Z, Debnath S, Jamil M, Ali HM (2021) Milling Force Model for Aviation Aluminum Alloy: Academic Insight and Perspective Analysis. Chin J Mech Eng 34(1):18. https://doi.org/10.1186/s10033-02100536-9

79. Zhang YB, Li CH, Yang M, Jia DZ, Wang YG, Li BK, Hou YL, Zhang NQ, Wu QD (2016) Experimental evaluation of cooling performance by friction coefficient and specific friction energy in nanofluid minimum quantity lubrication grinding with different types of vegetable oil. J Clean Prod 139(DEC.15):685-705

80. Zhang YB, Li HN, Li CH, Huang CZ, Ali HM, Xu XF, Mao C, Ding WF, Cui X, Yang M, Yu TB, Jamil M, Gupta MK, Jia DZ, Said Z (2021) Nano-enhanced biolubricant in sustainable manufacturing: from process ability to mechanisms. Friction. https://doi.org/10.1007/s40544-021-0536-y

81. Cui X, Li CH, Ding WF, Chen Y, Mao C, Xu XF, Liu B, Wang DZ, Li HN, Zhang YB (2021) Minimum quantity lubrication machining of aeronautical materials using carbon group nanolubricant: from mechanisms to application. Chin J Aeronaut

82. Yang M, Li CH, Luo L, Li RZ, Long YZ (2021) Predictive model of convective heat transfer coefficient in bone micro-grinding using nanofluid aerosol cooling. Int Commun Heat Mass Transfer 125:105317. https://doi.org/10.1016/j. icheatmasstransfer.2021.105317
83. Cui X, Li CH, Zhang YB, Jia DZ, Zhao YJ, Li RZ, Cao HJ (2019) Tribological properties under the grinding wheel and workpiece interface by using graphene nanofluid lubricant. Int J Adv Manuf Technol 104(9-12):3943-3958

84. Duan ZJ, Yin QG, Li CH, Dong L, Bai XF, Zhang YB, Yang M, Jia DZ, Li RZ, Liu ZQ (2020) Milling force and surface morphology of 45 steel under different $\mathrm{Al}_{2} \mathrm{O}_{3}$ nanofluid concentrations. Int J Adv Manuf Technol 107(3-4):1277-1296

85. Gao T, Li CH, Yang M, Zhang YB, Jia DZ, Ding WF, Debnath S, Yu TB, Said Z, Wang J (2021) Mechanics analysis and predictive force models for the single-diamond grain grinding of carbon fiber reinforced polymers using CNT nano-lubricant. J Mater Process Technol 290:116976. https://doi.org/10.1016/j.jmatprotec.2020. 116976

86. Behera BC, Alemayehu H, Ghosh S, Rao PV (2017) A comparative study of recent lubri-coolant strategies for turning of Ni-based superalloy. J Manuf Process 30:541-552. https://doi.org/10.1016/ j.jmapro.2017.10.027

87. Li CH, Wang S, Zhang Q, Jia DZ (2013) Evaluation of Minimum Quantity Lubrication Grinding with Nano-particles and Recent Related Patents. Recent Pat Nanotechnol 7(2):167-181

88. Zhang YB, Li CH, Jia DZ, Li BK, Wang YG, Yang M, Hou YL, Zhang XW (2016) Experimental study on the effect of nanoparticle concentration on the lubricating property of nanofluids for MQL grinding of Ni-based alloy. J Mater Process Technol 232: 100-115

89. Park KH, Suhaimi MA, Yang GD, Lee DY, Lee SW, Kwon P (2017) Milling of titanium alloy with cryogenic cooling and minimum quantity lubrication (MQL). Int J Precis Eng Manuf Technol Mach Tool 18(1):5-14

90. Zhang DK, Li CH, Jia DZ, Ma HL (2014) The experimental investigation of mql grinding performance with nanoparticles jet of spheroidal graphite cast iron. Manuf Technol Mach Tool 11:98103. https://doi.org/10.3969/j.issn.1005-2402.2014.11.031

91. Jia DZ, Li CH, Zhang YB, Yang M, Zhang XP, Li RZ, Ji HJ (2019) Experimental evaluation of surface topographies of NMQL grinding $\mathrm{ZrO}_{2}$ ceramics combining multiangle ultrasonic vibration. Int J Adv Manuf Technol 100(1-4):457-473

92. Zhang JC, Wu WT, Li CH, Yang M, Zhang YB, Jia DZ, Hou YL, Li RZ, Cao HJ, Ali HM (2020) Convective Heat Transfer Coefficient Model Under Nanofluid Minimum Quantity Lubrication Coupled with Cryogenic Air Grinding Ti-6Al-4V. Int J Pr Eng Man-GT 8:1113-1135. https://doi.org/10.1007/ s40684-020-00268-6

93. Gao T, Zhang XP, Li CH, Zhang YB, Yang M, Jia DZ, Ji HJ, Zhao YJ, Li RZ, Yao P, Zhu LD (2020) Surface morphology evaluation of multi-angle $2 \mathrm{D}$ ultrasonic vibration integrated with nanofluid minimum quantity lubrication grinding. J Manuf Process 51:44-61

94. Wu WT, Li CH, Yang M, Zhang YB, Jia DZ, Hou YL, Li RZ, Cao HJ, Han ZG (2019) Specific Energy and G ratio of Grinding Cemented Carbide under Different Cooling and Lubrication Conditions. Int J Adv Manuf Technol 105(1-4):67-82

95. Zhang XP, Li CH, Jia DZ, Gao T, Zhang YB, Yang M, Li RZ, Han ZG, Ji HJ (2019) Spraying parameter optimization and microtopography evaluation in nanofluid minimum quantity lubrication grinding. Int J Adv Manuf Technol 103(5-8):2523-2539

96. Gao T, Li CH, Jia DZ, Zhang YB, Yang M, Wang XM, Cao HJ, Li RZ, Ali HM, Xu XF (2020) Surface morphology assessment of CFRP transverse grinding using CNT nanofluid minimum quantity lubrication. J Clean Prod 277:123328. https://doi.org/10.1016/ j.jclepro.2020.123328

97. Jiang LY, Qin HL, Zhang XP, Zeng GL (2015) Application of Oil Mist Collection and Treatment System in the Machining Shop. Saf Environ Eng 22(04):88-93. https://doi.org/10.13578/j.cnki.issn. 1671-1556.2015.04.015 
98. Zhao JW, Yin DB, Wang LM (2018) Oil mist filter for production of loudspeakers. CN201711400817.

99. Huang JY, Zhu XF (2018) Oil mist filter. CN201720285550.1.

100. Ma CH, Sun GX, Wang JY, Yang JC (2018) Air compressor machine oil mist filter revolves and divides device. CN201721027059.5

101. Duan ZJ, Li CH, Cao HJ, Xu XF, Zhang N, Dong L, Zhang YB, Bai XF, Wu WT, Gao T, Yang M, Jia DZ, Li RZ, Hou YL (2019) Device for recycling, separating and purifying oil mist during MQL (Minimum Quantity Lubricant) grinding and machining process. CN201910100369.2.

102. Dasch JM, D'arcy JB, Kinare SS, Yaming Y, Kopple RG, Salmon SC (2008) Mist Generation from High-Speed Grinding with Straight Oils. Tribol Trans 51(3):381-388

103. Greeley M, Rajagopalan N (2004) Impact of Environmental Contaminants on Maching Properties of Metalworking Fluids. Tribol Int 37(4):327-332

104. Yalcinkaya F, Boyraz E, Maryska J, Kucerova K (2020) A Review on Membrane Technology and Chemical Surface Modification for the Oily Wastewater Treatment. Materials 13(2):493

105. Hou J, Yu JC, Su MD (2015) Experimental research on seperating effect of gravity oil-water separator. Chem Eng Mach 42(01):24 27+67. https://doi.org/10.3969/j.issn.0254-6094.2015.01.006

106. Zhang T, Ruan JK, Cheng W (2020) Research Progress of Cutting Fluid Wastewater Treatment Technology. Chin J Environ Eng 14(09):2362-2377

107. Cao CY, Yu B, Zhao YY (2012) Study on Disposal of Oily Wastewater by Organo-bentonite. Bull Chin Ceram Soc 31(06): 1382-1387

108. Li H, Li GZ, Qian XB, Zhang JF, Liao SQ, Yu P (2014) Experimental study on the removal of trace oil from water by adsorption. Ind Water Treatment 34(05):69-72. https://doi.org/ 10.3969/j.issn.1005-829X.2014.05.021

109. Songsaeng S, Thamyongkit P, Poompradub S (2019) Natural rubber/reduced-graphene oxide composite materials: Morphological and oil adsorption properties for treatment of oil spills. J Adv Res 20:79-89

110. Banerjee SS, Joshi MV, Jayaram RV (2006) Treatment of oil spill by sorption technique using fatty acid grafted sawdust. Chemosphere 64(6):1026-1031

111. Sang HJ, Ding WM, Xu JN (2013) Adsorption of oil from water solution by modified sawdust. J Beijing Univ Chem Technol(Natural Science Edition) 40(01):98-102

112. Moosai R, Dawe RA (2003) Gas attachment of oil droplets for gas flotation for oily wastewater cleanup. Sep Purif Technol 33(3): 303-314

113. Rubio J, Souza ML, Smith RW (2002) Overview of flotation as a wastewater treatment technique. Miner Eng 15(3):139-155

114. Lei QR (2016) Two-Stage Air Floatation \& Iron Carbon Oxidation for Emulsion Wastewater Treatment. Guangdong Chem Ind 43(07):127-128+143

115. Yang ZS, Feng LJ, Zhao G (2019) Treatment and reuse of waste cutting fluid based on tight ultrafiltration method. Modern Chem Ind 39(11):158-162. https://doi.org/10.16606/j.cnki.issn02534320.2019.11.034

116. Shi H, He Y, Pan Y, Di HH, Zeng GY, Zhang L, Zhang CL (2016) A modified mussel-inspired method to fabricate $\mathrm{TiO}_{2}$ decorated superhydrophilic PVDF membrane for oil/water separation. J Membr Sci 506:60-70. https://doi.org/10.1016/j.memsci.2016. 01.053

117. Yin JX, Yu JJ, Chen ZB, Wang SP, Bai ZD, Sun LP (2017) Study on the treatment of highly concentrated wastewater containing cutting fluid by acid eduction-coagulation. Ind Water Treatment 37(01):68-72
118. Wu WZ, Jing YH (2013) Study on the treatment of cutting wastewater by acid precipitation and coagulation. Energy Environ 2:7880. https://doi.org/10.3969/j.issn.1672-9064.2013.02.034

119. Cheng G, Lu XB, Li Y (2006) A new process of emulsive wastewater treatment using demulsification-coagulation-photoanalytical chemical oxidation. Basic Sci J Text Univ 19(04): 376-379

120. Han ZR, Yu JJ, Wang SP, Chen ZB, Sun LP (2018) Characteristics of organic substances removal from wastewater containing cutting fluid by aluminium salt and ferric salt coagulation. Ind Water Treatment 38(3):81-85

121. Song PP, Yang ZH, Xu HY, Huang J, Yang X, Wang L (2014) Investigation of Influencing Factors and Mechanism of Antimony and Arsenic Removal by Electrocoagulation Using Fe-AI Electrodes. Ind Eng Chem Res 53(33):12911-12919

122. Chaudhari PK (2014) Treatment of wastewater by electrocoagulation: a review. Environ Sci Pollut Res Int 21(4): 2397-2413

123. Guvenc SY, Okut Y, Ozak M, Haktanir B, Bilgili MS (2017) Process optimization via response surface methodology in the treatment of metal working industry wastewater with electrocoagulation. Water Sci Technol 75(4):833-846

124. Kobya M, Omwene PI, Ukundimana Z (2019) Treatment and Operating Cost Analysis of Metalworking Wastewaters by a Continuous Electrocoagulation Reactor. J Environ Chem Eng 8(2):103526. https://doi.org/10.1016/j.jece.2019.103526

125. Amin MM, Mofrad GMM, Pourzamani H, Sebaradar MS, Ebrahim K (2017) Treatment of industrial wastewater contaminated with recalcitrant metal working fluids by the photo-Fenton process as post-treatment for DAF - ScienceDirect. J Ind Eng Chem 45:412-420

126. Li XW, Zhang CT, Liang WD, Wang HR, Mao L (2018) Preparation of Fenton-like reaction catalyst and its application in treatment of waste cutting fluid. Modern Chem Ind 38(08):94-98

127. Bonfatti F, Ferro S, Lavezzo F, Malacarne M, Battisti AD (2000) Electrochemical Incineration of Glucose as a Model Organic Substrate. II. Role of Active Chlorine Mediation. J Electrochem Soc 147(2):592-596

128. Zhou NL, Wang ZQ, Xiang YH (2009) Electro-catalytic oxidation of titanium-based $\mathrm{PbO}_{2}$ electrode to the treatment of water-based cutting fluid wastewater. Ind Water Treatment 29(4):66-69

129. Yang SB, Jang SH, Hong SC, Suh JM, Lee WK (2017) Treatment of COD from Wasted Soluble Cutting Fluids using Ti-IrO Electrode. J Korea Soc Waste Manag 34(7):744-750

130. Shi C, Yang Q, Li N (2012) Study on the treatment of oil-bearing wastewater from the locomotive depot by biological contact oxidation process. Ind Water Treatment 32(12):42-44+92. https:// doi.org/10.3969/j.issn.1005-829X.2012.12.010

131. Zhang Q, Yu CJ, Fang J, Xu HY, Jiang QL, Yang SK, Wang WK (2017) Using the Combined Fenton-MBR Process to Treat Cutting Fluid Wastewater. Pol J Environ Stud 26(3):1375-1383. https://doi.org/10.15244/pjoes/68229

132. Wang KP, Lu C, He Q, Zhang K (2015) Chemical demulsification-Fenton oxidation of emulsion wastewater. Chin J Environ Eng 9(06):2880-2886

133. Zhao LX, Zhang LH, Wang W, Zhang YB (2017) Treatment of metal cutting liquid wastewater by thermal activated persulfate combined with coagulation. J Xi'an Polytech Univ 31(2):192-196

134. Jiang X, Huang TY, Li XF, Li YP, Cui XC (2018) Treatment of Emulsion Liquid Wastewater by a Combined Process of Ultrafiltration/UASB/Contact Oxidation. China Water Wastewater 34(22):100-103

135. Ma S, Kim K, Huh J, Kim DE, Lee S, Hong Y (2018) Regeneration and purification of water-soluble cutting fluid through ozone treatment using an air dielectric barrier discharge. Sep Purif Technol 199:289-297 
136. Perkins SD, Angenent LT (2010) Potential pathogenic bacteria in metalworking fluids and aerosols from a machining facility. FEMS Microbiol Ecol 74(3):643-654

137. Rhodes G, Fluri A, Ruefenacht A, Gerber M, Pickup R (2011) Implementation of a Quantitative Real-Time PCR Assay for the Detection of Mycobacterium immunogenum in Metalworking Fluids. J Occup Environ Hyg 8(8):478-483

138. Rao SN (2011) Experimental investigation of microbial contamination of nano cutting fluids with CNT inclusion. Global J Res Eng 11(4):2249-4596

139. Ramos M, Fortunati E, Peltzer MA, Cristofaro F, Visai L, Valente AJM (2020) Controlled Release of Thymol from Poly(Lactic Acid)-Based Silver Nanocomposite Films with Antibacterial and Antioxidant Activity. Antioxidants 9(5). https://doi.org/10.3390/ antiox 9050395

140. Ebrahimi S, Farhadian N, Karimi M, Ebrahimi M (2020) Enhanced bactericidal effect of ceftriaxone drug encapsulated in nanostructured lipid carrier against gram-negative Escherichia coli bacteria: drug formulation, optimization, and cell culture study. Antimicrob Resist Infect Control 9(1):126-132

141. Chen SG, Guo YJ, Zhong HQ, Chen SJ, Li JN, Ge ZC, Tang JN (2014) Synergistic antibacterial mechanism and coating application of copper/titanium dioxide nanoparticles. Chem Eng J 256: 238-246

142. Ratte HT (2010) Bioaccumulation and toxicity of silver compounds: A review. Environ Toxicol Chem 18(1):89-108

143. Bottero JY, Auffan M, Rose J, Mouneyrac C, Botta C, Labille J, Masion A, Thill A, Chaneac C (2011) Manufactured metal and metal-oxide nanoparticles:Properties and perturbing mechanisms of their biological activity in ecosystems. Compt Rendus Geosci 343(2):168-176

144. Kim S, Ryu D (2013) Silver nanoparticle-induced oxidative stress, genotoxicity and apoptosis in cultured cells and animal tissues. J Appl Toxicol 33:78-89. https://doi.org/10.1002/jat.2792

145. Xu XHN, Brownlow WJ, Kyriacou SV, Wan Q, Viola JJ (2004) Real-Time Probing of Membrane Transport in Living Microbial Cells Using Single Nanoparticle Optics and Living Cell Imaging. Biochemistry 43(32):10400-10413

146. Hwang ET, Jin HL, Yun JC, Kim YS, Kim BC, Sang BI, Man BG (2010) Analysis of the toxic mode of action of silver nanoparticles using stress-specific bioluminescent bacteria. Small 4(6):746-750

147. Zhang DH, Liu XH, Xin W (2011) Green synthesis of graphene oxide sheets decorated by silver nanoprisms and their antibacterial properties. J Inorg Biochem 105(9):1181-1186

148. Xu SJ, Zhang F, Yao LR, Zhu CH, Morikawa H, Chen YY (2017) Eco-friendly fabrication of antibacterial cotton fibers by the cooperative self-assembly of hyperbranched poly(amidoamine)- and hyperbranched poly(amine-ester)-functionalized silver nanoparticles. Cellulose 24(3):1493-1509

149. Bilal M, Zhao Y, Rasheed T, Ahmed I, Hassan S, Nawaz M, Iqbal H (2019) Biogenic Nanoparticle-Chitosan Conjugates with Antimicrobial, Antibiofilm, and Anticancer Potentialities: Development and Characterization. Int J Environ Res Public Health 16(4):598. https://doi.org/10.3390/ijerph16040598

150. Liu AL, Li ZQ, Wu ZQ, Xia XH (2018) Study on the photocatalytic reaction kinetics in $\mathrm{TiO}_{2}$ nanoparticles coated microreactor integrated microfluidics device. Talanta 182:544-548

151. Selma MH, AL-Jawad Taha AA, Salim MM (2017) Synthesis and characterization of pure and $\mathrm{Fe}$ doped $\mathrm{TiO}_{2}$ thin films for antimicrobial activity. Optik-Int J Light Electron Optics 142:42-53
152. Rizzo L, Sannino D, Vaiano V, Sacco O, Scarpa A, Pietrogiacomi $\mathrm{D}$ (2014) Effect of solar simulated $\mathrm{N}$-doped $\mathrm{TiO}_{2}$ photocatalysis on the inactivation and antibiotic resistance of an E. coli strain in biologically treated urban wastewater. Appl. Catal. B 144:369378

153. Liu WF, Fei QZ, Xu Z, Fei HJ, Zhang XW (2018) Investigation on Restoring Experiment for Cutting Fluid by Process of ElectroFlocculaction and Ozone Sterilization. J Dalian Jiaotong Univ 39(01):105-109. https://doi.org/10.13291/j.cnki.djdxac.2018.01. 021

154. Robert G, Li X (1983) Ultraviolet anti-corrosion treatment and device for cutting fluid. Manuf Technol Mach Tool 10:15-16

155. Johnson DL, Phillips ML (2002) UV Disinfection of Soluble Oil Metalworking Fluids. AIHA J 63(2):178-183

156. Saha R, Donofrio RS, Bagley ST (2014) Determination of the effectiveness of UV radiation as a means of disinfection of metalworking fluids. Ann Microbiol 64(2):831-838

157. Madanchi N, Thiede S, Herrmann C (2017) Functional and Environmental Evaluation of Alternative Disinfection Methods for Cutting Fluids. Proc CIRP 61:558-563

158. Wu DH, You H, Sun LX, Liu WW (2010) Effect of UV radiation and ozone combined on water sterilization. J Harbin Inst Technol 42(11):1793-1797

159. Shen YY, Shen YH, Dong LH, Li QH (2018) Research on the Regeneration Treatment of Aluminum Alloy Cutting Liquid Waste Based on $\mathrm{UV} / \mathrm{O}_{2}$ Advanced Oxidation. Technol Water Treatment 44(12):96-100. https://doi.org/10.16796/j.cnki.10003770.2018.12.020

160. Wang S, Luo J, Zhang T, Xue Z, Wang H (2020) Study on Cutting Fluid Purification Processor Equipment. Guangzhou Chem Ind 48(03):115-117+154

161. Wu MX (2015) Cutting fluid (emulsion) regeneration treatment system. "GAC Trumpchi Cup" Proceedings of the Eighth Academic Conference of Guangdong Automobile Industry. 7983.

162. Fan Y, Zhou ZD, Li RL, Wu XF, Qiu GY, Kazuhiko N, Gao J (2018) Treatment and Reuse of Highly Concentrated Cutting Fluid Wastewater by Decompression-Dehydration-Drying System. Acta Sci Nat Univ Pekin 54(06):1267-1275

163. Wang YP, Liu YC, Zhao JP (2020) Research on technology of automatic chip removal and filtration system based on CNC machine tool. Manuf Technol Mach Tool 05:136-139

164. Li Z, Liang XW, Feng WQ (2021) Regeneration and reuse of spent metal working fluid. Electroplating Finish 40(01):80-82. https://doi.org/10.19289/j.1004-227x.2021.01.015

165. Shen JY, Lei S, Dong LQ (2019) Cutting fluid deodorization and filtering system and control method thereof. CN201910216940.7.

166. Huang SF (2019) Numerically-controlled machine tool cutting fluid recycling device. CN201821474755.5.

167. Wu JC (2018) Cutting liquid recovery system. CN201721868604.3.

168. Weng GC, Xu W (2014) Grinding machine cutting fluid recovery device. CN201420162367.9.

169. Liu RP (2017) Mechanism is retrieved to metal cutting machine's cutting fluid. CN201720047919.5.

Publisher's note Springer Nature remains neutral with regard to jurisdictional claims in published maps and institutional affiliations. 


\section{Affiliations}

Xifeng $\mathrm{Wu}^{1} \cdot$ Changhe $\mathrm{Li}^{1}{ }^{1}$ (1) Z Zongming Zhou ${ }^{2} \cdot{\text { Xiaolin } \mathrm{Nie}^{3} \cdot \text { Yun Chen }^{4} \cdot \text { Yanbin Zhang }^{1} \cdot \text { Huajun Cao }}^{5} \cdot$ Bo Liu $^{6}$. Naiqing Zhang ${ }^{7} \cdot$ Zafar Said $^{8} \cdot$ Sujan Debnath ${ }^{9} \cdot$ Muhammad Jamil $^{10} \cdot$ Hafiz Muhammad Ali $^{11} \cdot$ Shubham Sharma $^{12}$

1 School of Mechanical and Automotive Engineering, Qingdao University of Technology, Qingdao 266520, China

2 Hanergy (Qingdao) Lubrication Technology Co., Ltd., Qingdao 266200, China

3 Nanjing Kerun Lubricants Co., Ltd., Nanjing 211106, China

4 Chengdu Tool Research Institute Co., Ltd., Chengdu 610500, China

5 School of Mechanical Engineering, Chongqing University, Chongqing 400044, China

6 Sichuan Future Aerospace Industry LLC., Shifang 618400, China

7 Shanghai Jinzhao Energy Saving Technology Co., Ltd., Shanghai 200436, China
8 Department of Sustainable and Renewable Energy Engineering, University of Sharjah, Sharjah 27272, United Arab Emirates

9 Mechanical Engineering Department, Curtin University, 98009 Miri, Malaysia

10 College of Mechanical and Electrical Engineering, Nanjing University of Aeronautics and Astronautics, Nanjing 210016, China

11 Mechanical Engineering Department, King Fahd University of Petroleum and Minerals, Dhahran 31261, Saudi Arabia

12 Department of Mechanical Engineering and Advanced Materials Science, Council of Scientific and Industrial Research (CSIR) Central Leather Research Institute (CLRI), Regional Center for Extension and Development, Jalandhar ,144021, India 